AUTARQUIA ASSOCIADA À UNIVERSIDADE DE SÃO PAULO

DESENVOLVIMENTO DE UM SISTEMA DE IRRADIAÇÃO PARA PRODUÇÃO DE RADIOISÓTOPOS GASOSOS APLICADOS EM PROCESSOS INDUSTRIAIS

Nelson Xavier Cardozo

Dissertação apresentada como parte dos requisitos para obtenção do Grau de Mestre em Ciências na Área de Tecnologia Nuclear - Aplicações

Orientador:

Prof. Dr. Wilson Aparecido Parejo Calvo 
INSTITUTO DE PESQUISAS ENERGÉTICAS E NUCLEARES

Autarquia associada à Universidade de São Paulo

DESENVOLVIMENTO DE UM SISTEMA DE IRRADIAÇÃO PARA PRODUÇÃO DE RADIOISÓTOPOS GASOSOS APLICADOS EM PROCESSOS INDUSTRIAIS

Nelson Xavier Cardozo

Dissertação apresentada como parte dos
requisitos para obtenção do Grau de
Mestre em Ciências na Área
de Tecnologia Nuclear-Aplicações
Orientador:

Prof. Dr. Wilson Aparecido Parejo Calvo

Versão Corrigida

São Paulo

2016 
Dedico essa dissertação à minha mãe Maria Luiza, responsável pelo meu caráter e conquistas, à minha futura esposa Letícia pelo apoio e dedicação em toda jornada, aos meus familiares e amigos que ajudaram de alguma forma e a todos meus professores e alunos. 


\section{AGRADECIMENTOS}

Ao Dr. Wilson Aparecido Parejo Calvo, meu orientador, pela oportunidade fornecida, auxílios e exemplo que levarei para o resto da vida de dedicação a área de Tecnologia Nuclear.

À Dra. Margarida Mizue Hamada, Gerente do Centro de Tecnologia das Radiações, ao M.Sc. Samir Luiz Somessari, Gerente Adjunto de Produtos e Serviços, e aos funcionários do CTR pela valiosa colaboração na execução desse trabalho: Sra. Claudia Regina Nolla, Sr. Paulo De Souza Santos, Dr. Pablo Antonio Vasquez Salvador, Dr. Osvaldo Luiz da Costa, Dr. Nelson Minoru Omi, Sr. Jose Jorge Ambiel, Eng. José Mauro Vieira, Sr. Marcos Cardoso Da Silva, Dr. Anselmo Feher, M.Sc. Celia Marina Napolitano, Eng. Francisco Edmundo Sprenger e Sr. Vagner Fernandes

Ao Dr. Frederico Antonio Genezini, Gerente do Centro do Reator de Pesquisa e aos funcionários do CRPq pelas irradiações no Reator Nuclear de Pesquisa IEA-R1: Dr. Guilherme Soares Zahn, Sr. Paulo Sergio Santiago, M.Sc. José Roberto Berretta e M.Sc. Adolfo Marra Neto.

Ao Instituto de Pesquisas Energéticas e Nucleares (IPEN/CNEN-SP), por toda estrutura fornecida para execução deste trabalho e à TRACERCO do Brasil, pelo fornecimento de parte do sistema de irradiação para produção de radioisótopos gasosos. 


\title{
DESENVOLVIMENTO DE UM SISTEMA DE IRRADIAÇÃO PARA PRODUÇÃO DE RADIOISÓTOPOS GASOSOS APLICADOS EM PROCESSOS INDUSTRIAIS \\ Nelson Xavier Cardozo
}

\begin{abstract}
RESUMO
Dentre as diversas aplicações dos radioisótopos, a utilização dos radiotraçadores é considerada uma das mais importantes, no diagnóstico de funcionamento dos equipamentos de processos, em plantas de indústrias químicas e petroquímicas. Os radiotraçadores são utilizados em procedimentos analíticos para obtenção de dados qualitativos e quantitativos de sistemas, em estudos de transferências físicas e físico-químicas. Na produção de radioisótopos gasosos utilizados como traçadores em processos industriais, destacam-se $0{ }^{41} \mathrm{Ar}$ e ${ }^{79} \mathrm{Kr}$, gases nobres (inertes) que possuem baixa reatividade com os demais elementos químicos. O ${ }^{41} \mathrm{Ar}$ é um emissor gama de alta energia $(1,29 \mathrm{MeV})$ e apresenta elevada porcentagem de transformações com essa energia, o que resulta em quantidades relativamente pequenas necessárias em relação a outras para uma detecção eficaz, mesmo em componentes com grandes espessuras. Atualmente, a produção de radioisótopos gasosos em reatores nucleares de pesquisa é realizada em pequenas quantidades (bateladas), por meio de ampolas de quartzo contendo o gás natural ${ }^{40} \mathrm{Ar}$ ou ${ }^{78} \mathrm{Kr}$. Nesse sentido, o objetivo desse estudo é desenvolver um sistema de irradiação capaz de produzir em escala contínua, o radioisótopo gasoso ${ }^{41} \mathrm{Ar}$, dentre outros, com atividade de $7,4 \times 10^{11} \mathrm{~Bq}(20 \mathrm{Ci})$ por ciclo de irradiação, por meio do Reator IEA-R1 de 4,5 MW, fluxo de nêutrons térmicos médio de $4,71 \times 10^{13} \mathrm{ncm}^{-2} \mathrm{~s}^{-1}$, para suprir uma demanda existente em empresas de END e inspeções, e pelo próprio Centro de Tecnologia das Radiações, no IPEN/CNEN-SP. O sistema de irradiação (SI) é constituído por uma cápsula de irradiação em alumínio, linhas de transferência, válvulas agulhas, conexões anilhadas, conectores rápidos, manovacuômetro, sistema de vácuo, dewar de liquefação, blindagem em chumbo, cilindros de armazenamento e transporte (CAT), dentre outros. O SI foi aprovado nos testes de estanqueidade e estabilidade (testes de formação de bolhas, pressurização, evacuação e com equipamento leak detector SPECTRON $600 \mathrm{~T}$ ). Na produção experimental para obtenção de $1,07 \times 10^{11} \mathrm{~Bq}(2,9 \mathrm{Ci}) \mathrm{de}{ }^{41} \mathrm{Ar}$, distribuíram-se dosímetros de alanina em diversos componentes e dispositivos do Sl. Além disso, determinaram-se as taxas de exposição na parede da blindagem em chumbo, ao concentrar o gás radioativo liquefeito e no CAT, após a transferência do ${ }^{41} \mathrm{Ar}$, pelo medidor de radiação portátil Teletector ${ }^{\circledR}$ Probe $6150 \mathrm{AD}-\mathrm{t} / \mathrm{H}$.
\end{abstract}




\title{
DEVELOPMENT OF A IRRADIATION SYSTEM FOR PRODUCTION OF GASEOUS RADIOISOTOPES APPLIED IN INDUSTRIAL PROCESSES
}

\author{
Nelson Xavier Cardozo
}

\begin{abstract}
Among the various applications of radioisotopes, the use of radiotracers is considered the most important in diagnosing operation and troubleshooting of industrial process plants in chemical and petrochemical companies. The radiotracers are used in analytical procedures to obtain qualitative and quantitative data systems, in physical and physicochemical studies transfers. In the production of gaseous radioisotopes used as tracers in industrial process measurements, argon-41 $\left({ }^{41} \mathrm{Ar}\right)$ and krypton-79 $\left({ }^{79} \mathrm{Kr}\right)$ have low reactivity with other chemical elements. ${ }^{41} \mathrm{Ar}$ is a transmitter range with high-energy $(1.29 \mathrm{MeV})$ and a high percentage of this energy transformation $(99.1 \%)$, resulting in relatively small quantities required in relation to the other, for an efficient detection, even in large thicknesses components. Nowadays, the production of gaseous radioisotopes in nuclear research reactors is performed in small quantities (batches), through quartz ampoules containing natural gas ${ }^{40} \mathrm{Ar}$ or ${ }^{78} \mathrm{Kr}$. In this sense, the aim of this study is to develop an irradiation system for gaseous radioisotope production in continuous scale, applied in industrial applications of emission tomography and flow measurement. The irradiation system may produce ${ }^{41} \mathrm{Ar}$ with activity of $7.4 \times 10^{11} \mathrm{~Bq}(20 \mathrm{Ci})$ per irradiation cycle, through the Reactor IEA-R1 with $4.5 \mathrm{MW}$ and average thermal neutron flux of $4.71 \times 10^{13} \mathrm{ncm}^{-2} \mathrm{~s}^{-1}$ to meet an existing demand in NDT and inspections companies, and even needed by the Radiation Technology Centre, at IPEN/CNEN-SP. The irradiation system consists of an aluminium irradiation capsule, transfer lines, needle valves, stripy connections, quick connectors, manometer, vacuum system, dewar, lead shielding, storage and transport cylinders, among other components. The irradiation system was approved in the leakage and stability tests (bubble test, pressurization, evacuation and with leak detector equipment SPECTRON $600 \mathrm{~T}$ ). In the experimental production, alanine dosimeters were distributed into various components of the irradiation system, obtaining $1.07 \times 10^{11} \mathrm{~Bq}(2.9 \mathrm{Ci})$ of ${ }^{41} \mathrm{Ar}$. In addition, exposure rates were determined in the lead shielding wall, in which the liquefied radioactive gas was concentrated, and in the storage and transport cylinders after ${ }^{41} \mathrm{Ar}$ was transferred, by the portable radiation meter Teletector ${ }^{\circledR}$ Probe 6150 AD-t/H.
\end{abstract}




\section{SUMÁRIO}

Página

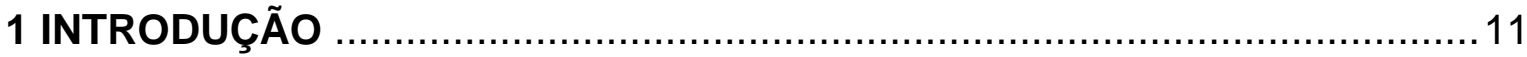

1.1 Histórico e justificativa................................................................. 12

2 OBJETIVOS

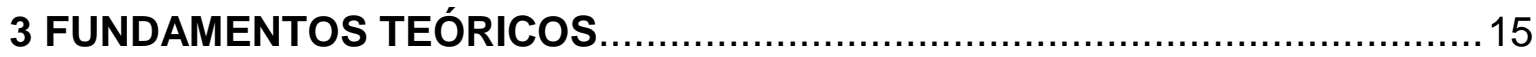

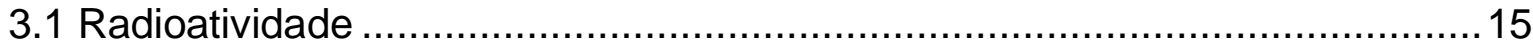

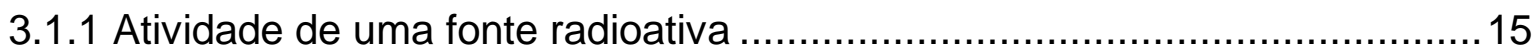

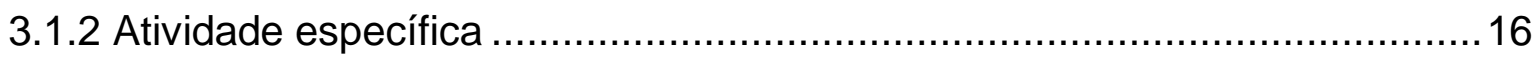

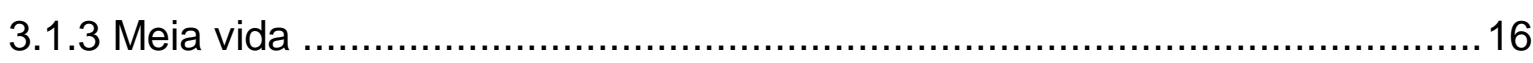

3.2 Produção de fontes radioativas artificiais com nêutrons ................................ 17

3.2.1 Seção de choque para reações nucleares ................................................. 17

3.2.2 Reatores nucleares de pesquisa e a produção de radioisótopos .................18

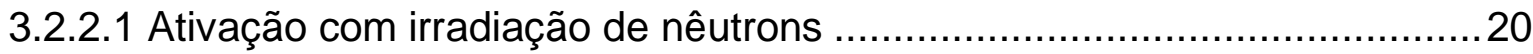

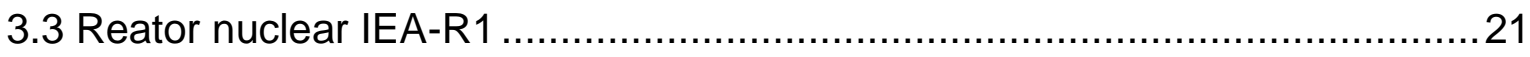

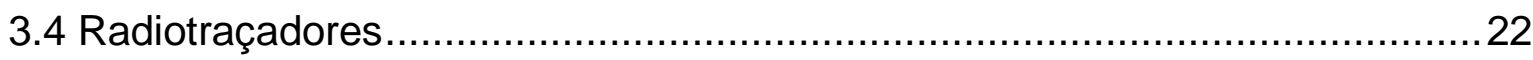

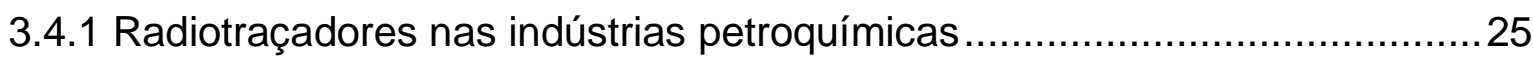

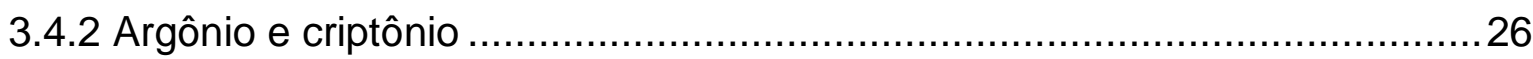

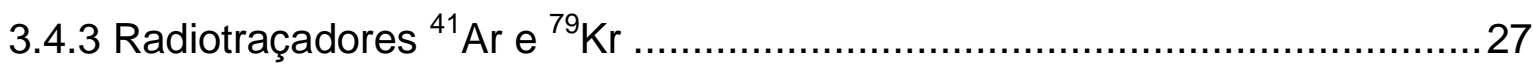

4 MATERIAL E MÉTODOS

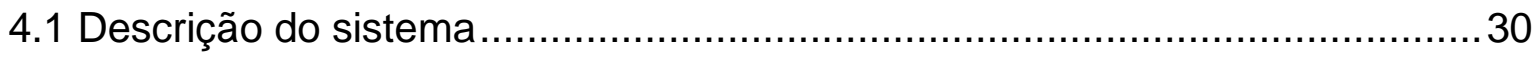

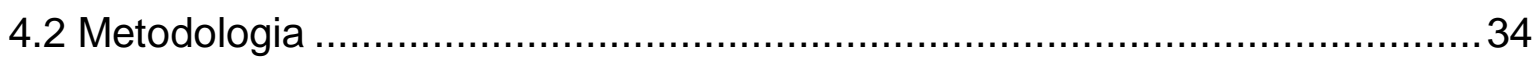

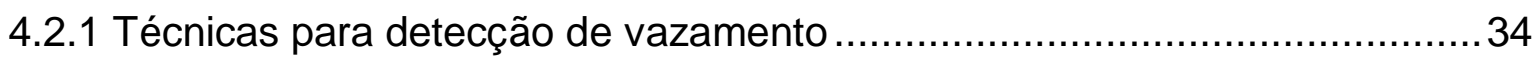

4.2.1.1 Verificação de bolhas com solução formadora de espuma.......................34

4.2.1.2 Acompanhamento da variação de pressão ………………………........35

4.2.1.3 Detecção de vazamento com gás hélio (leak detector). ...........................35

4.2.2 Método para produção do radioisótopo gasoso..........................................38 


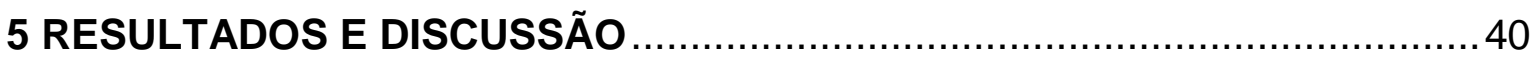

5.1 Projeto e construção do sistema de irradiação ....................................... 40

5.1 .1 Cápsula de irradiação ................................................................ 43

5.1.2 Sistema de liquefação (dewar) e blindagem no sistema de irradiação ........ 44

5.1.3 Cilindros de armazenamento e transporte (CATs) ............................... 45

5.1.4 Plataforma com a linha de transferência do gás...................................46

5.2 Procedimento operacional do sistema de irradiação ................................. 47

5.2.1 Etapa 1 - Injeção do argônio natural $\left({ }^{40} \mathrm{Ar}\right)$ na $\mathrm{Cl}$ e irradiação da cápsula no

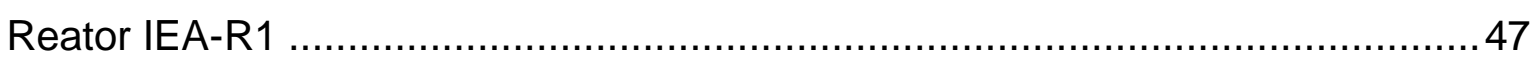

5.2.2 Etapa 2 - Preparação do SI e dos CATs para receberem o gás radioativo.. 48 5.2.3 Etapa 3 - Transferência do gás radioativo $\left({ }^{41} \mathrm{Ar}\right)$ da $\mathrm{Cl}$ para o SI e liquefação

5.2.4 Etapa 4 - Transferência do gás radioativo para os CATs .........................50

5.3 Testes de estanqueidade e estabilidade ............................................ 50

5.3.1 Verificação de bolhas com solução formadora de espuma ........................50

5.3.2 Pressurização e evacuação do sistema ........................................... 51

5.3.3 Ensaio com detector de vazamento de hélio (leak detector) .....................53

5.4 Teste do sistema sem material radioativo ............................................ 54

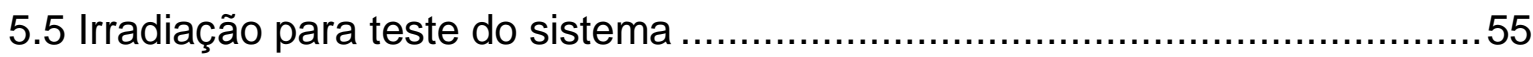

5.6 Estimativa para obtenção de atividades superiores .................................58

6 CONCLUSÃO

6.1 Sugestões para melhoria do Sistema de Irradiação ...............................60

ANEXO A - Trabalho completo publicado no WCIPT8 - 8th World Congress

On Industrial Process Tomography.

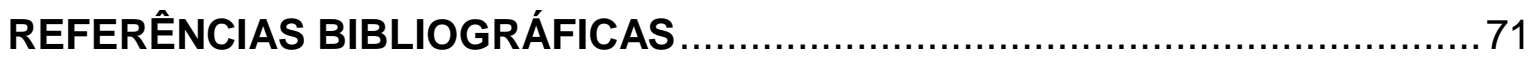




\section{LISTA DE FIGURAS}

Página

FIGURA 1 - Produção de radioisótopos gasosos em ampolas de quartzo ............12 FIGURA 2 - Sistema de irradiação, transferência e transporte de argônio (SITTAr)

FIGURA 3 - Reator nuclear de pesquisa IEA-R1 (5 MW), do IPEN-CNEN/SP [13].

FIGURA 4 - Reator nuclear de pesquisa TRIGA Mark II, em Marrocos.

FIGURA 5 - Injeção e deteç̧ão de radiotraçador para determinação da

distribuição do tempo de residência (DTR)

FIGURA 6 - Cápsula de irradiação para imersão na piscina do Reator IEA-R1 ...30

FIGURA 7 - Linha de transferência em aço inoxidável AISI 304 com diâmetro

interno de 6,35 $\mathrm{mm}(1 / 4 ")$ na parte superior

FIGURA 8 - Linha de transferência em aço inoxidável AISI 304 com diâmetro

interno de 3,175 mm (1/8") na parte inferior

FIGURA 9 - Válvula agulha, conexão anilhada, manovacuômetro e engates rápidos presentes na linha de transferência do gás radioativo

FIGURA 10 - Sistema de resfriamento para liquefação via nitrogênio líquido .......32

FIGURA 11 - Blindagem em chumbo ao redor do dewar de liquefação 32

FIGURA 12 - Caixa em acrílico com saída para o sistema de exaustão do Reator IEA-R1 .33

FIGURA 13 - Cilindro de armazenamento e transporte de gás radioativo. 33

FIGURA 14 - Método da bolha com solução formadora de espuma .34

FIGURA 15 - Método de acompanhamento da variação de pressão .35

FIGURA 16 - Técnica utilizada para detecção de vazamento com equipamento leak detector

FIGURA 17 - Esquema de funcionamento de um espectrômetro de massa em um equipamento leak detector com gás hélio

FIGURA 18 - Imersão da cápsula de irradiação na piscina do Reator IEA-R1 .....38

FIGURA 19 - Fluxograma do procedimento experimental 
FIGURA 20 - Projeto do sistema de irradiação para produção de radioisótopos gasosos aplicados em processos industriais

FIGURA 21 - Esquema geral do sistema de irradiação de radioisótopos gasosos aplicados em processos industriais

FIGURA 22 - Sistema de irradiação para produção de radioisótopos gasosos

aplicados em processos industriais

FIGURA 23 - Extremidades inferior (a) e superior (b) da cápsula de irradiação ... 44

FIGURA 24 - Dewar de liquefação do gás ${ }^{41} \mathrm{Ar}$ ou ${ }^{79} \mathrm{Kr}$.

FIGURA 25 - Blindagem em chumbo na qual está instalado o dewar de liquefação do gás radioativo $\left({ }^{41} \mathrm{Ar}\right.$ ou ${ }^{79} \mathrm{Kr}$ )

FIGURA 26 - Cilindro de armazenamento e transporte fornecido pela TRACERCO do Brasil

FIGURA 27 - Plataforma do sistema de Irradiação com as válvulas,

manovacuômetro, e blindagem em chumbo 46

Figura 28 - Etapas do procedimento operacional para produção do ${ }^{41} \mathrm{Ar}$

FIGURA 29 - Fluxograma da etapa 1 - Injeção do ${ }^{40} \mathrm{Ar}$ na $\mathrm{Cl}$ e irradiação da cápsula no Reator IEA-R1

FIGURA 30 - Fluxograma da etapa 2 - Preparação do SI e dos CATs para receberem o gás radioativo

FIGURA 31 - Fluxograma da etapa 3 - Transferência do radioisótopo gasoso ao dewar

FIGURA 32 - Fluxograma da etapa 4 - Transferência do gás radioativo aos CATs

FIGURA 33 - Fotografias a) e b) do manovacuômetro instalado no sistema de irradiação (-1bar), obtidas às 10h00min dos dias 18 e 19/02/2016, respectivamente

FIGURA 34 - Fotografias a) e b) do manovacuômetro instalado no sistema de irradiação (10 bar), obtidas nos dias 22 às 16h47min e 24/02/2016 às 14h41min, respectivamente

FIGURA 35 - Fotografias a) e b) do manômetro instalado na cápsula de irradiação (16 bar), obtidas às 13h00min dos dias 04 e 07/03/2016, respectivamente .52

FIGURA 36 - Teste com leak detector e gás hélio injetado na válvula do SI. .53

FIGURA 37 - Taxa de vazamento detectada no ensaio com equipamento leak detector SPECTRON $600 \mathrm{~T}\left(10^{-9} \mathrm{mbar} . \mathrm{L} / \mathrm{s}\right)$ 
FIGURA 38 - Revestimento do dewar em PTFE, no interior da blindagem ...........55

FIGURA 39 - Dosímetros de alanina utilizados na primeira obtenção do ${ }^{41} \mathrm{Ar}$......57

FIGURA 40 - Dosímetros distribuídos ao longo da linha de transferência do SI ..57

FIGURA 41 - Dosímetro de alanina na linha de transferência ao CAT, no qual se registrou a maior dose absorvida (5 Gy), na obtenção do ${ }^{41} \mathrm{Ar}$ no SI 58 


\section{INTRODUÇÃO}

Dentre as diversas aplicações industriais dos radioisótopos, como no uso de fontes fixas e móveis de radiação ionizante em gamagrafia, indicadores de nível para líquidos e para medidas de densidade e espessura, a utilização dos radioisótopos como traçadores (radiotraçadores) é considerada uma das mais importantes. Um traçador consiste em um material injetado em um sistema, para obter informações sobre as reais condições desse sistema em relação à passagem e localização de fluidos, por meio da detecção desse material em diferentes pontos. Existem traçadores químicos não isotópicos, corantes fluorescentes e os radioativos que são amplamente utilizados por indústrias petroquímicas, por terem propriedades associadas à emissão da radiação que facilitam a análise de sistemas complexos e de difícil acesso, comuns em tais indústrias $[1,2,3]$.

Radiotraçadores podem ser utilizados em procedimentos analíticos para obtenção de dados qualitativos e quantitativos de sistemas, em estudos de transferências físicas e físico-químicas para compreensão de características como detergência, flotação e reações metalúrgicas, em estudos de mecanismos de reações, tais como oxidação, isomerização de hidrocarbonetos, polimerização e vulcanização de borracha, aromatização de petróleo e em diferentes técnicas nucleares, tais como, na detecção de vazamentos, medida de vazão e distribuição do tempo de residência em instalações petroquímicas e gasodutos $[1,3]$.

Na produção de radioisótopos gasosos utilizados como traçadores em processos industriais, destacam-se o Argônio-41 ( $\left.{ }^{41} \mathrm{Ar}\right)$ e Criptônio-79 $\left({ }^{79} \mathrm{Kr}\right)$, gases nobres (inertes) que possuem baixa reatividade com os demais elementos químicos, produzidos por meio da reação nuclear $(\mathrm{n}, \boldsymbol{\gamma})$, sendo $0{ }^{41} \mathrm{Ar}$ um emissor gama de alta energia (1,29 MeV), meia-vida de 110 minutos e elevada porcentagem de transformações nesta energia $(99,1 \%)$, que proporciona sua utilização em quantidades relativamente pequenas, em relação a outros 
radioisótopos para uma detecção eficiente em componentes com grandes espessuras de parede (5 a $6 \mathrm{~cm}$ ) e $0{ }^{79} \mathrm{Kr}$, um emissor gama de baixa energia $(0,51 \mathrm{MeV})$ mas com meia-vida de 35 horas, que proporciona sua utilização em locais mais distantes do centro de produção $[3,4,5]$.

\subsection{Histórico e justificativa}

A produção de radioisótopos gasosos em reatores nucleares de pesquisa em pequenas quantidades ocorre por meio de ampolas de quartzo contendo o gás, conforme FIG. 1, na qual são mostradas as etapas seguidas para a primeira produção na Índia, em 2006, dos radiotraçadores gasosos ${ }^{41} \mathrm{Ar}$ e ${ }^{79} \mathrm{Kr}$ utilizando o método de ativação com nêutrons dos isótopos naturais ${ }^{40} \mathrm{Ar} e{ }^{78} \mathrm{Kr}$, visando uma padronização da produção e o fornecimento dos radioisótopos para utilização em indústrias [6,7].

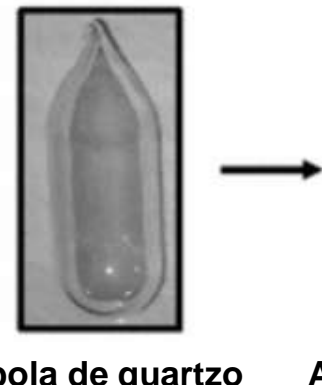

Ampola de quartzo preenchida com gás

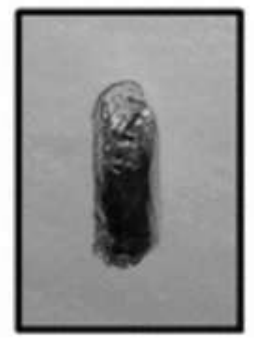

Ampola envolvida com papel alumínio

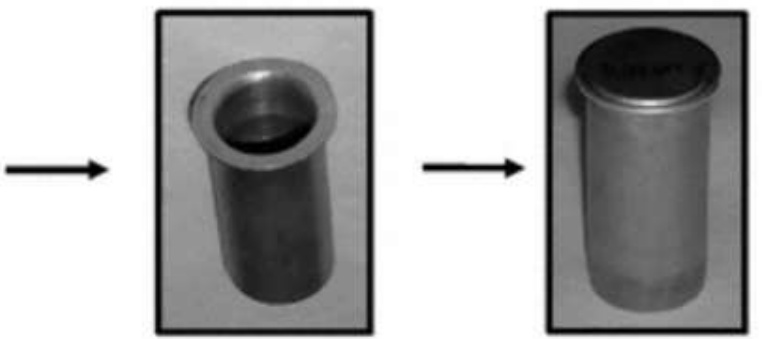

Cápsula em alumínio utilizada para irradiação
Cápsula soldada e pronta para irradiação

FIGURA 1 - Produção de radioisótopos gasosos em ampolas de quartzo [6]

Para produção de quantidades superiores utilizam-se cápsulas de irradiação constituídas por cilindros de amostragem, válvulas e uma linha de transferência para cilindros de armazenamento revestidos com chumbo (blindagem) que, após receberem o gás radioativo, são transportados até o local de utilização do radiotraçador.

Esta segunda forma de produção foi empregada algumas vezes no reator nuclear de pesquisas IEA-R1, localizado no IPEN/CNEN-SP por meio de um sistema de irradiação, transferência e transporte de argônio (SITTAr), conforme FIG. 2. O sistema era montado no saguão da piscina toda vez que a 
operação era realizada e o radiotraçador gasoso ${ }^{41} \mathrm{Ar}$ produzido para atender uma demanda de empresas de ensaios não destrutivos e inspeções. Mas, por apresentar problemas de vazamentos e elevadas taxas de dose nos operadores, a produção foi interrompida por meio desse sistema. Assim, originou-se o desenvolvimento do sistema de irradiação para produção de radioisótopos gasosos, objeto deste estudo [8].

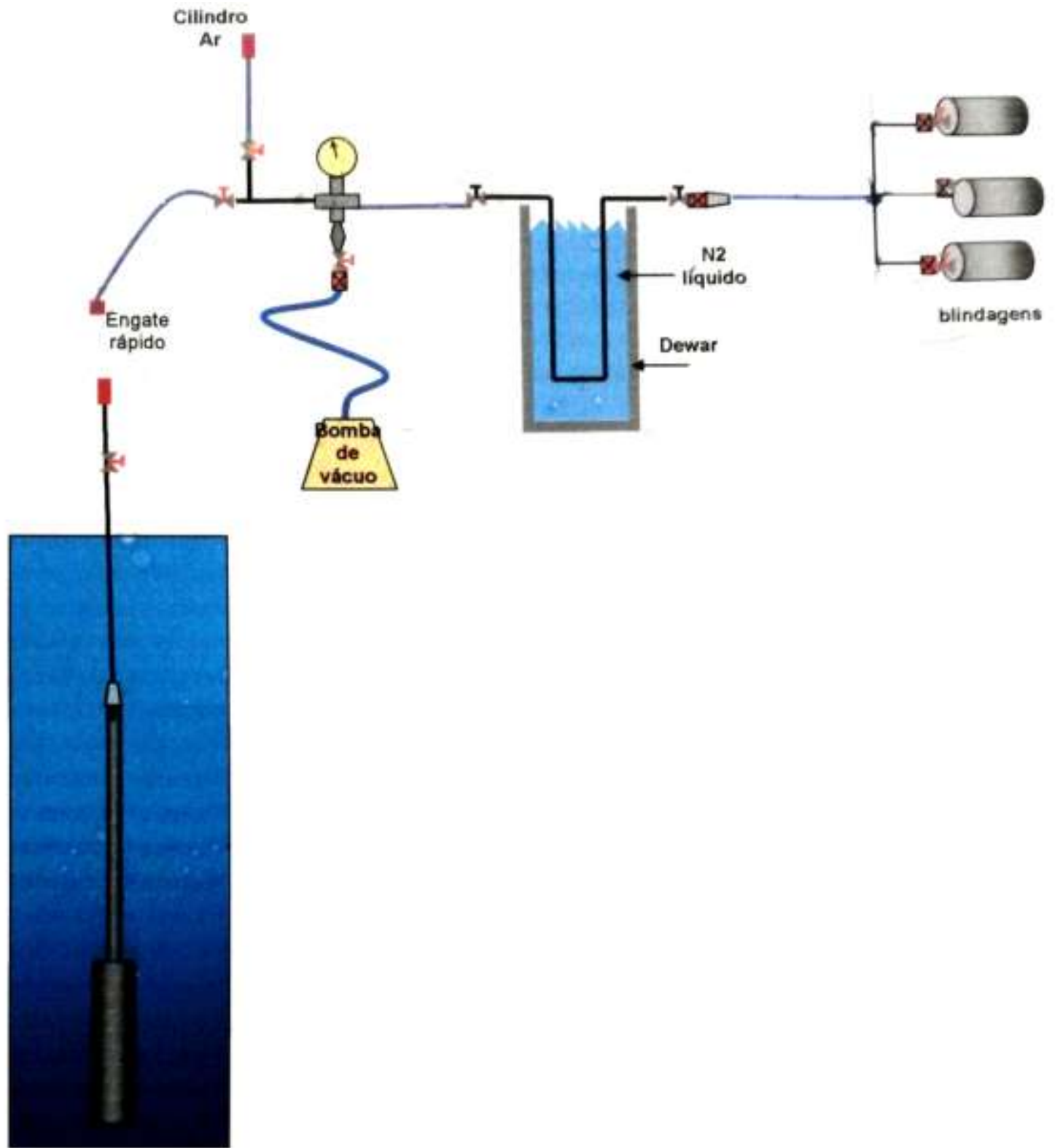

FIGURA 2 - Sistema de irradiação, transferência e transporte de argônio (SITTAr)[8] 


\section{OBJETIVOS}

Desenvolver um sistema de irradiação capaz de produzir, em escala contínua, radioisótopos gasosos utilizados como radiotraçadores, com atividade máxima de $7,4 \times 10^{11} \mathrm{~Bq}(20 \mathrm{Ci})$, por meio de um reator nuclear de pesquisa tipo piscina (Material Testing Reactor - MTR), tal como o Reator IEA-R1, para suprir uma demanda existente em empresas de ensaios não destrutivos (END) e inspeções ou pelo próprio grupo de Aplicação da Tecnologia de Radioisótopos do Centro de Tecnologia das Radiações (CTR), no IPEN/CNEN-SP.

Produzir o radiotraçador argônio-41 $\left({ }^{41} \mathrm{Ar}\right)$ ou Criptônio-79 $\left({ }^{79} \mathrm{Kr}\right)$ por meio da reação nuclear $(\mathrm{n}, \boldsymbol{\gamma})$ com uma atividade inferior (2,9 Ci), para avaliar aspectos de radioproteção e operação do sistema de irradiação desenvolvido.

Disponibilizar a produção de radiotraçadores gasosos com o sistema de irradiação às empresas parceiras, na realização de END e inspeções, além de acompanhar a utilização e o diagnóstico de funcionamento dos equipamentos em indústrias químicas e petroquímicas. 


\section{FUNDAMENTOS TEÓRICOS}

\subsection{Radioatividade}

As desintegrações espontâneas (decaimentos) que ocorrem por meio da emissão de radiações por núcleos atômicos de determinados elementos (radioatividade) natural ou artificialmente gerados, estão relacionadas a diversas técnicas da física nuclear e, tanto o estudo, quanto o uso de fontes de radioisótopos são de grande importância [9].

As radiações originárias de processos atômicos e nucleares são convenientemente classificadas em quatro tipos gerais [10]:

- Elétrons emitidos em decaimentos nucleares (partículas beta);

- Partículas pesadas carregadas (partículas alfa, prótons, produtos de fissão, ou produtos de diversas reações nucleares);

- Radiações eletromagnéticas (raios $X$ emitidos em reordenações das camadas eletrônicas dos átomos e raios gama $(\gamma)$ originados em transições dentro do próprio núcleo);

- Nêutrons (térmicos, epitérmicos e rápidos) gerados em diversos processos nucleares.

\subsubsection{Atividade de uma fonte radioativa}

A atividade de uma fonte radioativa é definida como a taxa de decaimento ( $\mathrm{dN} / \mathrm{dt}$ ), dada pela lei fundamental do decaimento radioativo, expressa na Equação 1, na qual " $N$ " corresponde ao número de átomos radioativos e " $\lambda$ " a constante de desintegração (probabilidade de decaimento por unidade de tempo característica de cada radioisótopo) [10].

$$
A=\left.\frac{d N}{d t}\right|_{\text {decaimento }}=-\lambda \cdot N
$$


De acordo com Kaplan (1963), Rutherford e Soddy, ao estudarem a taxa de decaimento da atividade do tório (Th), obtiveram curvas exponenciais, o que demonstra que a atividade " $A$ " de certa fonte de radioisótopos pode ser expressa como uma função do tempo de decaimento $\left(t_{d}\right)$, conforme Equação 2, na qual " $\mathrm{A}_{0}$ " corresponde a Atividade inicial do radioisótopo [9].

$$
A=A_{0} \cdot e^{\left(-\lambda \cdot t_{d}\right)}
$$

No Sistema Internacional de Unidades (SI), adota-se o bequerel (Bq) como unidade padrão de atividade que corresponde a uma desintegração por segundo. Porém, existe a unidade curie ( $\mathrm{Ci}$ ) que também é muito utilizada para quantificar a atividade, sendo $1 \mathrm{~Bq}$ equivalente a $2,703 \times 10^{-11} \mathrm{Ci}[10]$.

\subsubsection{Atividade específica}

A atividade específica $(A)$ de uma fonte radioativa é definida como a atividade por unidade de massa da amostra do radioisótopo e pode ser obtida por meio da Equação 3, na qual "m" representa a massa da amostra, "M" a massa molar e "NA" ao número de Avogadro $\left(6,02 \times 10^{23}\right.$ núcleos/mol) [10].

$$
A=\frac{\lambda N}{m}=\frac{\lambda N}{N M / N_{A}} \therefore A=\frac{\lambda N_{A}}{M}
$$

\subsubsection{Meia vida}

A meia vida $\left(t_{1 / 2}\right)$ é uma grandeza física que também caracteriza um radioisótopo, pois corresponde ao tempo necessário para a desintegração da metade dos átomos radioativos e está relacionada com a taxa de decaimento, de acordo com a Equação 4 [9].

$$
t_{1 / 2}=\frac{0,693}{\lambda}
$$




\subsection{Produção de fontes radioativas artificiais com nêutrons}

Uma das formas de produzir artificialmente radioisótopos é por meio de reações com nêutrons, uma vez que estes são efetivos na produção de transformações nucleares por não possuírem carga elétrica e, consequentemente, não estarem sujeitos à força eletrostática, favorecendo a penetração no núcleo (captura do nêutron) que desestabiliza e se torna radioativo. A reação entre nêutron e núcleo origina na maioria dos casos partículas alfa, prótons, fótons de radiação gama ou dois outros nêutrons, porém neste trabalho será abordada apenas a reação que produz radiação gama (reação $n, \gamma$ ), representada na Equação 5, na qual o isótopo "X", ao capturar o nêutron se torna um núcleo composto (elevando sua massa atômica "A" em uma unidade) ocorrendo a liberação de um raio gama " $\gamma_{\text {pronto }}$ e a formação do radioisótopo [9].

$$
{ }_{Z} X^{A}+{ }_{0} n^{1} \longrightarrow\left[{ }_{Z} X^{A+1}\right] \longrightarrow\left({ }_{Z} X^{A+1}\right) *+\gamma_{\text {pronto }}
$$

\subsubsection{Seção de choque para reações nucleares}

No estudo de reações nucleares é necessário quantificar a probabilidade de ocorrência destas reações e para este propósito utiliza-se a seção de choque, particular de cada tipo de reação, representada pela letra grega sigma $(\sigma)$ e que pode ser considerada um coeficiente de absorção de partículas incidentes [9].

A seção de choque para reações nucleares pode ser expressa em termos da unidade $10^{-24} \mathrm{~cm}^{2}$ (denominada barn) e no caso das reações de captura de nêutrons variam de acordo com a energia do nêutron. Por conveniência, agrupam-se os nêutrons em três faixas de energia: nêutrons térmicos (energia menor que $1 \mathrm{eV}$ ), nêutrons epitérmicos e intermediários (entre 1 eV e $100 \mathrm{keV}$ ) e nêutrons rápidos: (Energia maior que $100 \mathrm{keV}$ ) [9]. 


\subsubsection{Reatores nucleares de pesquisa e a produção de radioisótopos}

Um reator nuclear de pesquisa tem por finalidade principal o fornecimento de uma fonte de nêutrons para pesquisa e aplicações diversas e a maioria deles é utilizada para pesquisa e desenvolvimento (P\&D), treinamento, testes de materiais e produção de radioisótopos para medicina nuclear e indústria. Os reatores de pesquisa possuem potência menor (até $200 \mathrm{MWt}$ ), quando comparados aos reatores de potência (3.000 MWt ou $1.000 \mathrm{MWe})$, voltados à geração de energia elétrica [11].

Tais reatores são mais simples que os reatores nucleares de potência, operam a temperaturas mais baixas e necessitam de muito menos combustível. Por outro lado, o seu combustível requer urânio com maior enriquecimento, tipicamente até $20 \%$ em urânio-235 $\left({ }^{235} \mathrm{U}\right)$, do que a dos reatores nucleares de potência (3\% a $5 \%)$. Mas, alguns reatores de pesquisa ainda utilizam urânio altamente enriquecido, contendo um nível de $93 \%$ em ${ }^{235} \mathrm{U}$ [11].

Os reatores de pesquisa também têm uma elevada densidade de potência no núcleo, exigindo construções especiais. Tal como acontece com reatores nucleares, o núcleo requer resfriamento e, geralmente, um moderador é necessário para desacelerar os nêutrons de fissão. Muitos reatores de pesquisa também usam um refletor para reduzir a perda de nêutrons do núcleo e para sustentar a reação em cadeia [11].

Existe uma variedade de projetos em uso para reatores de pesquisa, quando comparados aos reatores nucleares de potência, com diferentes modos de operação [11].

Um dos tipos de reatores de pesquisa é o reator de piscina tipo Material Testing Reactor (MTR), tal como o Reator IEA-R1 localizado no IPEN/CNEN-SP, mostrado na FIG. 3, no qual o núcleo tem um conjunto de elementos combustíveis em uma piscina contendo água deionizada. Entre os elementos combustíveis estão as barras de controle e espaços vazios na placa matriz, para irradiação de amostras. A água controla e resfria o núcleo do reator, ao passo que grafite, berílio ou outro material é utilizado como refletor. Tubos circulares ou elipsoidais penetram na blindagem do reator para acessar os nêutrons e raios gama, a partir do núcleo, para a realização de experimentos de irradiação [11]. 


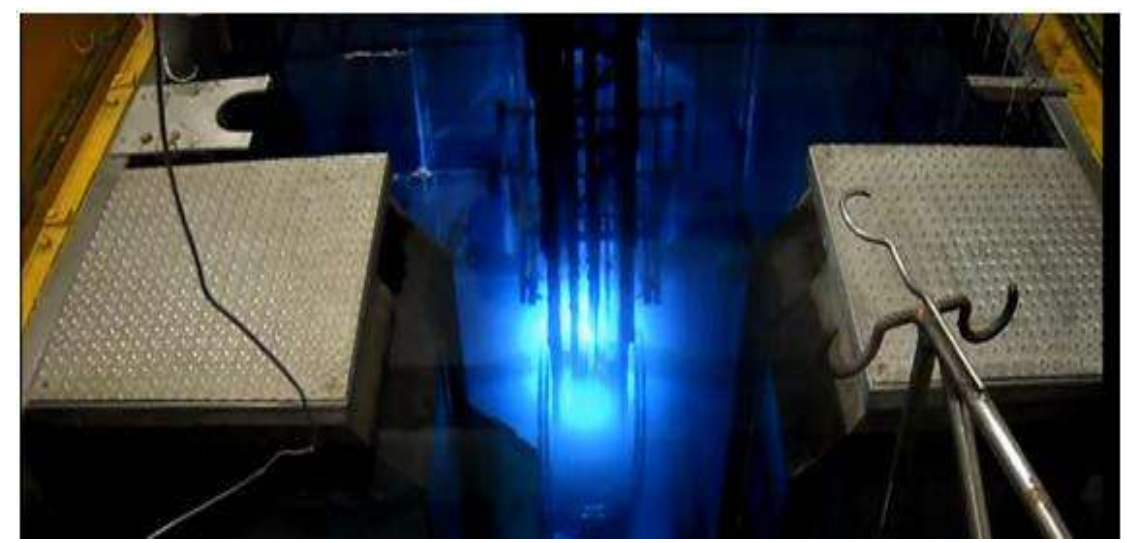

FIGURA 3 - Reator nuclear de pesquisa IEA-R1 (5 MW), do IPEN-CNEN/SP [13].

Outro tipo de reator é o Training, Research, Isotopes, General Atomics (TRIGA), mostrado na FIG. 4. Este tipo de reator foi desenvolvido com características de segurança intrínseca, principalmente, para serem utilizados em formação de pessoal e realização de pesquisas em tecnologia nuclear. Por ser versátil, pode operar tanto no estado contínuo ou, com segurança, na forma pulsada em níveis de potência muito elevados (25.000 MWt), em frações de segundo. Outros tipos de núcleos são refrigerados e moderados com água pesada $[11,12]$.

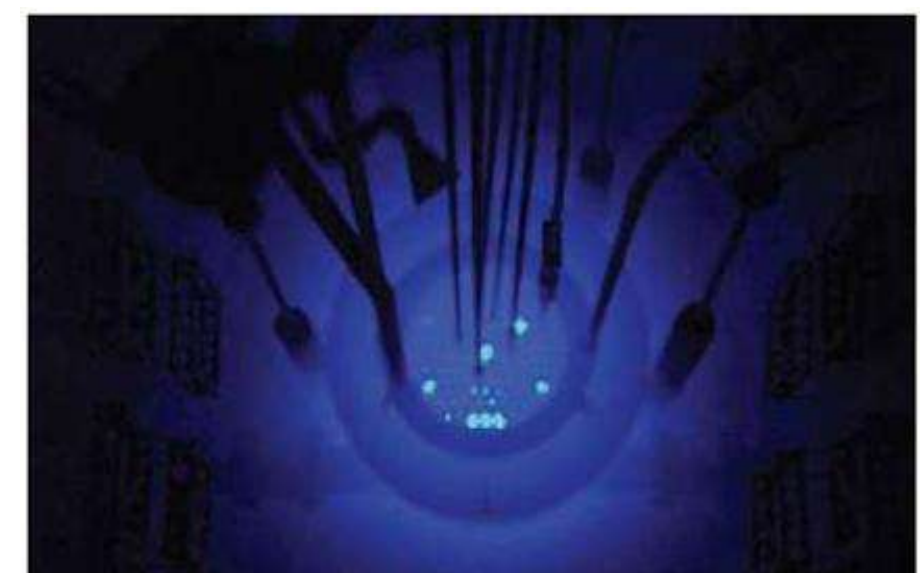

FIGURA 4 - Reator nuclear de pesquisa TRIGA Mark II, no Marrocos [11].

Reatores do tipo homogêneo têm um núcleo que funciona como um reservatório, que contém uma solução líquida de sais de urânio, isto é, seu combustível se encontra na forma líquida. Outros tipos, não tão comuns, são os reatores rápidos que não requerem moderadores e usam uma mistura de urânio e plutônio como combustível [11]. 


\subsubsection{Ativação com irradiação de nêutrons}

Uma das principais funções de um reator nuclear de pesquisa é a produção de radioisótopos que ocorre quando se irradia com nêutrons um núcleo alvo, no qual um determinado nuclídeo forma um radioisótopo por meio de uma reação de captura $(n, \gamma)$ que decai posteriormente para um isótopo estável ao emitir determinada radiação [9].

O crescimento do radioisótopo (2) depende da seção de choque da reação " $\sigma$ ", do fluxo de partículas ativadoras " $\phi$ ", no caso nêutrons, e do número de átomos " $\mathrm{N}_{1}$ " do nuclídeo alvo. Porém, considerando que o radioisótopo, ao ser formado, decai conforme sua taxa de decaimento " $\lambda_{2}$ " e que o consumo do nuclídeo alvo durante a irradiação é desprezível, a taxa de decaimento do radioisótopo é dada conforme Equação 6 [9].

$$
\frac{d N_{2}}{d t}=\phi \sigma N_{1}-\lambda_{2} N_{2}
$$

Considerando que no início da irradiação $(\mathrm{t}=0)$ não há átomos radioativos " $\mathrm{N}_{2}$ " e integrando a Equação 6 , desde o início até o instante final da irradiação " $t_{i}$ ", obtém-se a Equação 7 que proporciona uma estimativa da atividade induzida "A" durante a irradiação com nêutrons [9].

$$
\lambda_{2} N_{2}=N_{1} \sigma \phi\left(1-e^{-\lambda t_{i}}\right)=A
$$

Durante a formação do radioisótopo, há o decaimento do mesmo, ocorre o fenômeno de saturação, ou seja, só é possível atingir uma atividade máxima durante uma irradiação, denominada atividade de saturação " $A_{\infty}$ ", que pode ser determinada conforme a Equação 8. Por este motivo adota-se um tempo de irradiação máximo de aproximadamente quatro vezes o tempo de meia vida do 
radioisótopo (tempo necessário para atingir aproximadamente $93,7 \%$ da atividade de saturação) [9].

$$
A_{\infty}=N_{1} \sigma \phi
$$

\subsection{Reator nuclear IEA-R1}

O reator IEA-R1, instalado no Centro do Reator de Pesquisa (CRPq), do IPEN/CNEN-SP é um reator controlado e refrigerado a água leve (deionizada) e que utiliza elementos de berílio e grafite como refletores. Foi projetado para operar a uma potência máxima de $5 \mathrm{MW}$. Porém, operou inicialmente a potência de 2 MW e a partir de 1993 passou a operar em ciclos de 64 horas contínuas semanais a 3,5 MW de potência num arranjo de 24 elementos combustíveis padrões, todos fabricados no próprio Instituto [13].

O reator dispõe de 144 posições de irradiação no núcleo, distribuídas em 15 elementos de irradiação para irradiações longas e um sistema pneumático para irradiações curtas (até 5 minutos), com nove tubos de irradiação horizontais (beam holes) que fornecem feixes de nêutrons, utilizados em experimentos de física nuclear, física de estado sólido, pesquisas em terapia de câncer por captura de nêutrons em boro ou Boron Neutron Capture Therapy (BNCT) e neutrongrafia [13].

Atualmente, o reator é utilizado para as seguintes finalidades [13]:

- Produção de radioisótopos para uso em medicina nuclear, tais como: o samário-153 $\left({ }^{153} \mathrm{Sm}\right)$, utilizado como paliativo da dor em metástases óssea e no tratamento de artrite reumatoide; o iodo-131 ( $\left.{ }^{131} \mathrm{I}\right)$, utilizado na terapia de câncer de tireoide e hipertiroidismo, na terapia de hepatomas, na localização e terapia de feocromocitomas, neuroblastomas e outros tumores, no estudo da função renal, na determinação do volume plasmático e volume sanguíneo total; e o irídio-192 ( ${ }^{192} \mathrm{Ir}$ ), produzido na forma de fios metálicos, utilizados na técnica de Braquiterapia para o tratamento de câncer. Pesquisas estão 
sendo realizadas para a produção de geradores de tecnécio-99m, lutécio-177 e rênio-188;

- Produção de fontes radioativas para radiografia industrial e medidores nucleares $\left({ }^{60} \mathrm{Co}\right.$ e $\left.{ }^{192} \mathrm{Ir}\right)$, e de radiotraçadores em diagnóstico de processos industriais, tais como, bromo-82 (na forma de sal $\mathrm{KBr}$ é utilizado para medição de vazão em rios e em efluentes líquidos industriais), mercúrio-203 (determinação da massa imobilizada de mercúrio em células eletrolíticas), criptônio-79, argônio-41 e lantânio 140 (inspeção de tubulações em refinarias de petróleo);

- Irradiação de amostras para a realização de análises multielementares, utilizando a técnica de Análise por Ativação Neutrônica (AAN), em materiais geológicos, produtos industriais (plásticos e resinas, catalisadores, petróleo, metais e ligas metálicas), amostras arqueológicas, tecidos animais e humanos, vegetais, alimentos e amostras ambientais;

- Pesquisas em Física Nuclear;

- Serviços de neutrongrafia; e

- Treinamento de pessoal licenciado para operação de reatores nucleares.

Diversos pesquisadores, de diferentes instituições públicas e privadas utilizam o reator de pesquisa IEA-R1, incluindo: Centro de Engenharia Nuclear (CEN) e Centro de Tecnologia das Radiações (CTR), ambos do IPEN/CNEN-SP; Centro de Energia Nuclear na Agricultura (CENA/USP); Universidade Estadual de Campinas (UNICAMP); Companhia de Tecnologia de Saneamento Ambiental (CETESB); dentre outras, além da TRACERCO do Brasil e da TRICOM Tecnologia, empresas privadas que realizam inspeções e diagnósticos em refinarias de petróleo [13].

\subsection{Radiotraçadores}

Radiações emitidas por radioisótopos em pequenas quantidades podem atravessar a matéria e serem detectadas por onde passam, dependendo 
da energia que possuem, por meio de detectores de radiação. Portanto, o deslocamento de um radioisótopo pode ser acompanhado e seu percurso ser "traçado" num mapa do local. Por esse motivo, esses isótopos recebem o nome de traçadores radioativos [14].

Na seleção de um traçador radioativo, os fatores mais importantes que se levam em consideração são [2,15]:

- Atividade específica;

- Meia vida;

- Tipo de radiação;

- Energia da radiação; e

- Tipo de traçador (físico ou químico).

Existem outros tipos de traçadores, tais como, os traçadores químicos não isotópicos e os corantes fluorescentes. Porém, os traçadores radioativos são mais utilizados por possuírem diversas vantagens $[2,15]$ :

- A diversidade de isótopos que podem ser utilizados;

- A meia-vida (tempo necessário para que o número de núcleos radioativos se reduza à metade do número original) variando de minutos até anos, possibilitando a escolha do traçador de acordo com a duração prevista para o experimento. Essa vantagem tem um valor decisivo, quando se trata de águas de renovação lenta (águas subterrâneas), que ficariam contaminadas durante um longo tempo, se fosse empregado um traçador não radioativo;

- A medida da radiação sem a interferência de outros materiais contidos no meio. Mediante técnicas de espectrometria por raios gama, pode-se identificar o traçador de forma inequívoca, detectando-se sua energia característica. Essa técnica permite o emprego simultâneo de dois ou mais traçadores com garantia de identificação e a medida de cada um deles; 
- O limite de detecção é extremamente baixo, o que resulta pequeno volume de injeção e, por consequência, em facilidade de execução e pouca interferência no processo; e

- O mesmo traçador pode ser empregado sob diversas formas químicas. Isso é muito importante, pois dessa forma garante-se que o traçador tenha um comportamento semelhante ao do meio estudado.

$\mathrm{E}$, entre as desvantagens, destacam-se $[2,15]$ :

- Os isótopos de meia vida curta tem que ser produzidos e utilizados em datas fixas;

- A autorização para produção, manipulação, transporte e utilização de materiais radioativos; e

- A necessidade de proteção radiológica, de forma a se manter os níveis de radiação seguros aos trabalhadores e indivíduos do público, evitando-se a contaminação ambiental de acordo com a legislação adequada e as normas da Comissão Nacional de Energia Nuclear (CNEN): CNEN-NN-3.01 - Diretrizes básicas de proteção radiológica; CNEN-NN-3.02 - Serviços de radioproteção; CNEN-NN-5.01 Transporte de materiais radioativos; e CNEN-NN-6.05 - Gerência de rejeitos radioativos em instalações radiativas.

Em relação à norma CNEN-NN-3.01 (Res. 164/2014), cujo objetivo é estabelecer os requisitos básicos de proteção radiológica das pessoas em relação à exposição à radiação ionizante, são estipulados limites de dose anuais para indivíduo ocupacionalmente exposto e indivíduo do público, apresentados na TAB. 1[16]. 
TABELA 1 - Limites de dose anuais estabelecidos pela CNEN

\section{Limites de dose anuais}

\begin{tabular}{|c|c|c|c|}
\hline Grandeza & Órgão & $\begin{array}{c}\text { Indivíduo } \\
\text { ocupacionalmente } \\
\text { exposto (mSv/ano) }\end{array}$ & $\begin{array}{l}\text { Indivíduo } \\
\text { do público } \\
\text { (mSv/ano) }\end{array}$ \\
\hline Dose efetiva $(E)^{[a]}$ & Corpo inteiro & $20^{[c]}$ & $1^{[\mathrm{d}]}$ \\
\hline \multirow{3}{*}{ Dose equivalente $\left(\mathrm{H}_{\mathrm{T}}\right)^{[\mathrm{b}]}$} & Cristalino & $20^{[c]}$ & 15 \\
\hline & Pele ${ }^{[e]}$ & 500 & 50 \\
\hline & Mãos e pés & 500 & - \\
\hline
\end{tabular}

Fonte: CNEN, 2014 [16].

Notas:

${ }^{[a]}$ Dose efetiva (E) é a soma das doses equivalentes ponderadas nos diversos órgãos e tecidos, $E=\sum_{T} w_{T} \cdot H_{T}$, onde $\mathrm{H}_{\mathrm{T}}$ é a dose equivalente no tecido ou órgão e $\mathrm{W}_{\mathrm{T}}$ é um fator de ponderação de órgão ou tecido. A unidade no sistema internacional é o joule por quilograma $(\mathrm{J} / \mathrm{kg})$, denominada sievert (Sv).

${ }^{[b]}$ Dose equivalente - $\mathrm{H}_{\mathrm{T}}$ - grandeza expressa por $H_{T}=D_{T} \cdot W_{R}$, onde $D_{T}$ é dose absorvida média no órgão ou tecido e $w_{R}$ é o fator de ponderação da radiação.

[c] Média aritmética em 5 anos consecutivos, desde que não exceda 50 mSv em qualquer ano.

[d] Em circunstâncias especiais, a CNEN pode autorizar um valor de dose efetiva de até $5 \mathrm{mSv}$ em um ano, desde que a dose efetiva média em um período de 5 anos consecutivos, não exceda a $1 \mathrm{mSv}$ por ano.

${ }^{[e]}$ Valor médio em $1 \mathrm{~cm}^{2}$ de área, na região mais irradiada.

\subsubsection{Radiotraçadores nas indústrias petroquímicas}

Em indústrias petroquímicas, nas quais 0 acesso a dutos e outros equipamentos é difícil, os radiotraçadores são os mais utilizados, em virtude das propriedades de emissão da radiação. Eles são injetados no meio a ser estudado, e após certa distância, é registrada a passagem da nuvem radioativa, utilizandose detectores de radiação, proporcionando informações a respeito do sistema em análise [2,15].

Neste tipo de ensaio um traçador radioativo (na fase líquida, sólida ou gasosa) é injetado em um ponto do sistema e detectado em dois ou mais pontos a jusante. Conforme o pulso de traçador radioativo passa pelos detectores de 
radiação, o tempo de percurso e a intensidade do pulso são medidos, conforme FIG. 5. Da análise destes dados é possível mensurar variáveis de processo como velocidade, vazão, tempo de residência, dispersão, vazamento e arraste $[2,15,17]$.
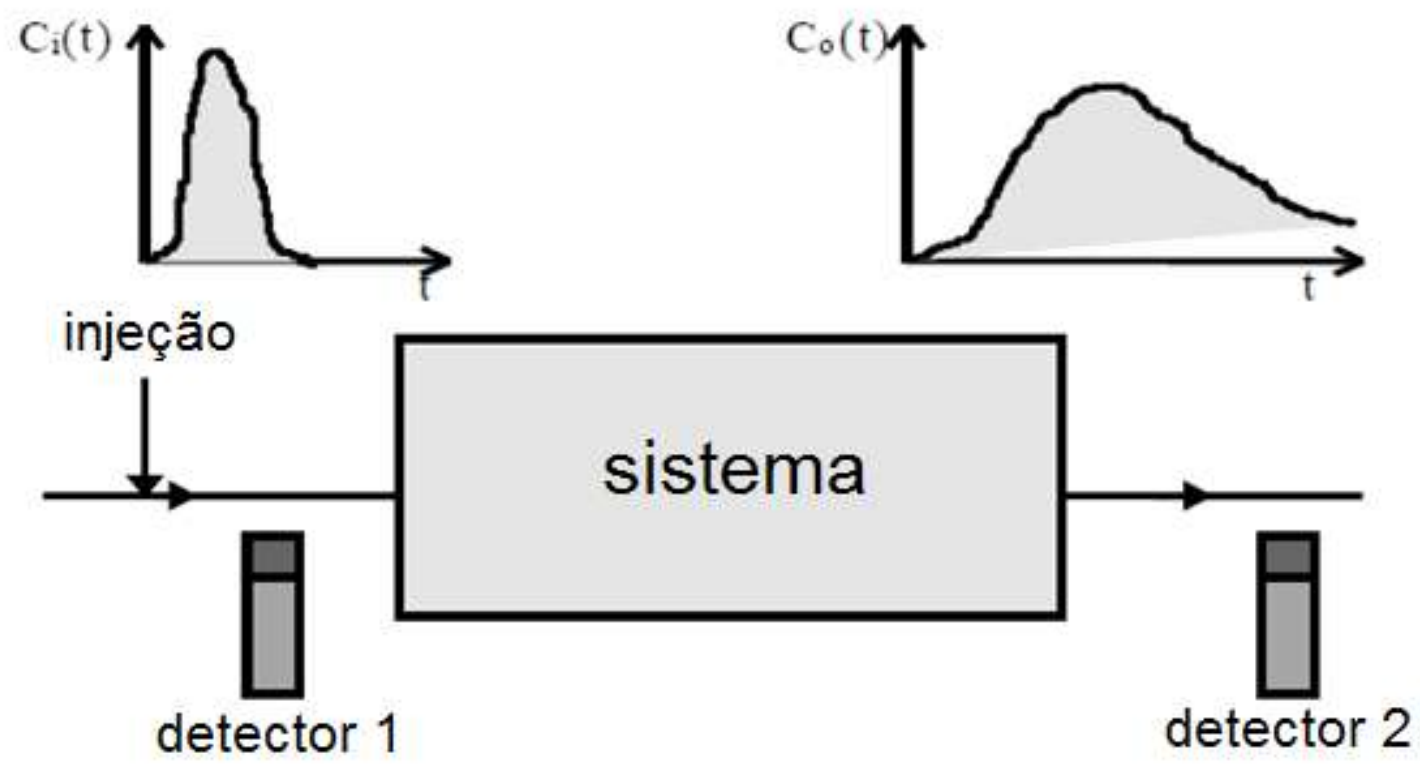

FIGURA 5 - Injeção e detecção de radiotraçador para determinação da distribuição do tempo de residência (DTR) [17]

Por meio dos radiotraçadores é possível o monitoramento qualitativo e quantitativo das conexões e poços de produção de petróleo, proporcionando uma melhor compreensão desses reservatórios e a recuperação do petróleo que eventualmente se perca. Tais informações não são possíveis de se obter utilizando-se outras técnicas convencionais [18].

\subsubsection{Argônio e criptônio}

Os elementos químicos argônio ( $\mathrm{Ar}$ ) e criptônio ( $\mathrm{Kr}$ ) cujas propriedades químicas estão descritas na TAB. 2 são gases nobres, ou seja, apresentam reatividade muito baixa. Os gases nobres são obtidos pela destilação fracionada do ar líquido (exceto hélio e radônio), compõem aproximadamente 1\% da atmosfera terrestre e encontram-se como gases monoatômicos, sendo o argônio o terceiro gás mais abundante depois do nitrogênio e do oxigênio (desconsiderando o vapor de água) [19]. 
TABELA 2 - Propriedades dos gases nobres argônio e criptônio

\begin{tabular}{cccccc}
\hline $\begin{array}{c}\text { Número } \\
\text { atômico } \\
\text { "Z" }\end{array}$ & Nome & Símbolo & $\begin{array}{c}\text { Massa } \\
\text { molar } \\
\left(\mathbf{g} \cdot \mathbf{m o l}^{-1}\right)\end{array}$ & $\begin{array}{c}\text { Ponto de } \\
\text { fusão (ㅇ) }\end{array}$ & $\begin{array}{c}\text { Ponto de } \\
\text { ebulição } \\
\text { (ㄷ) }\end{array}$ \\
\hline 18 & Argônio & $\mathrm{Ar}$ & 39,95 & -189 & -186 \\
36 & Criptônio & $\mathrm{Kr}$ & 83,80 & -157 & -153 \\
\hline
\end{tabular}

Fonte: ATKINS, 2001 [19].

O argônio possui três isótopos naturais estáveis (TAB. 3), é usado para gerar uma atmosfera inerte para soldas prevenindo que ocorra oxidação e para preencher alguns tipos de lâmpadas resfriando o filamento [19].

TABELA 3 - Isótopos naturais do argônio

\begin{tabular}{cc}
\hline Isótopo & Abundância natural (\%) \\
\hline${ }^{36} \mathrm{Ar}$ & 0,3336 \\
${ }^{38} \mathrm{Ar}$ & 0,0629 \\
${ }^{40} \mathrm{Ar}$ & 99,6035 \\
\hline
\end{tabular}

Fonte: NNDC, $2016[20]$.

Em relação ao criptônio, possui seis isótopos naturais (TAB. 4) sendo amplamente utilizado na iluminação de pistas de aeroportos por emitir uma intensa luz branca quando submetido a uma corrente elétrica $[19,20]$.

TABELA 4 - Isótopos naturais do criptônio

\begin{tabular}{cccc}
\hline Isótopo & $\begin{array}{c}\text { Abundância } \\
\text { natural (\%) }\end{array}$ & Isótopo & $\begin{array}{c}\text { Abundância } \\
\text { natural (\%) }\end{array}$ \\
\hline${ }^{78} \mathrm{Kr}^{\star}$ & 0,355 & ${ }^{83} \mathrm{Kr}$ & 11,500 \\
${ }^{80} \mathrm{Kr}$ & 2,286 & ${ }^{84} \mathrm{Kr}$ & 56,987 \\
${ }^{82} \mathrm{Kr}$ & 11,593 & ${ }^{85} \mathrm{Kr}$ & 17,279 \\
\hline
\end{tabular}

Fonte: NNDC, 2016 [20]

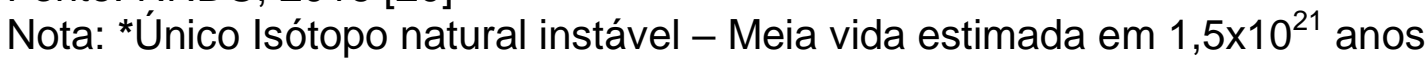

\subsubsection{Radiotraçadores ${ }^{41} \mathrm{Ar} \mathrm{e}{ }^{79} \mathrm{Kr}$}

Os radiotraçadores ${ }^{41} \mathrm{Ar}$ e ${ }^{79} \mathrm{Kr}$ são muito utilizados na inspeção de tubulações em refinarias de petróleo, por serem gases nobres (inertes). $\mathrm{O}{ }^{41} \mathrm{Ar}$ é um marcador clássico para a fase gasosa por ter uma energia de emissão 
elevada $(1,29 \mathrm{MeV})$, que facilita o seu rastreio, mas possui uma meia-vida relativamente curta (110 minutos), o que dificulta sua utilização em locais distantes dos centros de produção. Já o ${ }^{79} \mathrm{Kr}$ possui uma meia-vida superior (35 horas), mas sua energia de emissão é inferior (510 keV). Na TAB. 5 são apresentados os radioisótopos normalmente utilizados no diagnóstico de processos industriais e suas propriedades [3,5,7].

TABELA 5 - Radioisótopos utilizados no diagnóstico de processos industriais

\begin{tabular}{|c|c|c|c|c|}
\hline Isótopo & $\begin{array}{l}\text { Meia- } \\
\text { vida }\end{array}$ & $\begin{array}{c}\text { Radiação, energia } \\
\text { (MeV) e } \\
\text { abundância }\end{array}$ & Forma química & $\begin{array}{c}\text { Fase de } \\
\text { interesse ao } \\
\text { traçador }\end{array}$ \\
\hline${ }^{3} \mathrm{H}$ & $12,6 \mathrm{a}$ & $\beta: 0,018(100 \%)$ & Água tritiada & Aquosa \\
\hline${ }^{24} \mathrm{Na}$ & $15 \mathrm{~h}$ & $\begin{array}{c}\gamma: 1,37(100 \%) \\
2,75(100 \%)\end{array}$ & Carbonato de sódio & Aquosa \\
\hline${ }^{41} \mathrm{Ar}$ & $110 \min$ & $\gamma: 1,29(99 \%)$ & Argônio & Gasosa \\
\hline${ }^{46} \mathrm{Sc}$ & $84 d$ & $\begin{array}{c}\gamma: 0,89(100 \%), \\
1,84(100 \%)\end{array}$ & $\begin{array}{l}\text { Complexo de escândio } \\
\text { Óxido de escândio } \\
\text { (matriz vítrea) }\end{array}$ & $\begin{array}{l}\text { Aquosa } \\
\text { Sólida } \\
\text { (partículas) }\end{array}$ \\
\hline${ }^{79} \mathrm{Kr}$ & $35 \mathrm{~h}$ & $\gamma: 0,51(15 \%)$ & Criptônio & Gasosa \\
\hline${ }^{82} \mathrm{Br}$ & $36 \mathrm{~h}$ & $\begin{array}{c}\gamma: 0,55(70 \%), \\
1,32(27 \%)\end{array}$ & $\begin{array}{l}\text { Brometo de amônio } \\
\text { p-Dibromobenzeno } \\
\text { Dibromobifenil } \\
\text { Brometo de metila }\end{array}$ & $\begin{array}{c}\text { Aquosa } \\
\text { Orgânica } \\
\text { Orgânica } \\
\text { Gasosa }\end{array}$ \\
\hline${ }^{85} \mathrm{Kr}$ & $10,6 \mathrm{a}$ & $\gamma: 0,51(0.7 \%)$ & Criptônio & Gasosa \\
\hline${ }^{99 \mathrm{~m}} \mathrm{Tc}$ & $6 \mathrm{~h}$ & $\gamma: 0,14(90 \%)$ & Pertecnetato de sódio & Aquosa \\
\hline${ }^{131} \mid$ & $8,04 \mathrm{~d}$ & $\begin{array}{c}\gamma: 0,36(80 \%) \\
0,64(9 \%)\end{array}$ & $\begin{array}{l}\text { lodeto de } \mathrm{K} \text { ou } \mathrm{Na} \\
\text { lodobenzeno }\end{array}$ & $\begin{array}{l}\text { Aquosa } \\
\text { Orgânica }\end{array}$ \\
\hline${ }^{140} \mathrm{La}$ & $40 \mathrm{~h}$ & $\begin{array}{c}\gamma: 0,92(10 \%), \\
2,54(4 \%)\end{array}$ & Cloreto de lantânio & $\begin{array}{c}\text { Sólida } \\
\text { (adsorvida) }\end{array}$ \\
\hline${ }^{197} \mathrm{Hg}$ & $2,7 d$ & $\gamma: 0,077(19 \%)$ & Mercúrio metálico & Mercúrio \\
\hline${ }^{198} \mathrm{Au}$ & $2,7 d$ & $\gamma: 0,41(99 \%)$ & Ácido cloroáurico & $\begin{array}{c}\text { Sólida } \\
\text { (adsorvida) }\end{array}$ \\
\hline${ }^{203} \mathrm{Hg}$ & $46,6 \mathrm{~d}$ & $\gamma: 0,28(86 \%)$ & Mercúrio metálico & Mercúrio \\
\hline
\end{tabular}

Fonte: IAEA, 2009 [3]. 
Ambos os radioisótopos são produzidos por meio do bombardeamento de nêutrons térmicos em reatores nucleares tipo piscina e das reações nucleares descritas nas Equações 9 e 10, nas quais " $n$ " representa o nêutron térmico incidente. Os isótopos ${ }^{40} \mathrm{Ar}$ e ${ }^{78} \mathrm{Kr}$ possuem, respectivamente, seções de choque para captura de nêutrons térmicos de aproximadamente 0,66 barns e 4,732 barns $[9,21,22]$.

$$
\begin{gathered}
{ }^{40} \mathrm{Ar}+n \longrightarrow{ }^{41} \mathrm{Ar}+\gamma_{\text {pronto }} \\
{ }^{78} \mathrm{Kr}+n \longrightarrow{ }^{79} \mathrm{Kr}+\gamma_{\text {pronto }}
\end{gathered}
$$




\section{MATERIAL E MÉTODOS}

\subsection{Descrição do sistema}

Para o desenvolvimento do sistema de irradiação utilizou-se o Laboratório de Aplicações da Tecnologia de Radioisótopos no CTR e o reator nuclear de pesquisa IEA-R1, no Centro do Reator de Pesquisa (CRPq), ambos do IPEN/CNEN-SP, além dos seguintes equipamentos e materiais que compõem o sistema:

a) Cápsula de irradiação em alumínio, a ser posicionada no núcleo do Reator IEA-R1, composta por um cilindro de alumínio conectado a uma haste tubular rígida, que permite seu manuseio, inserção e remoção no núcleo do reator nuclear, além da carga e descarga do gás a ser irradiado, para produção do radiotraçador gasoso, conforme FIG. 6;

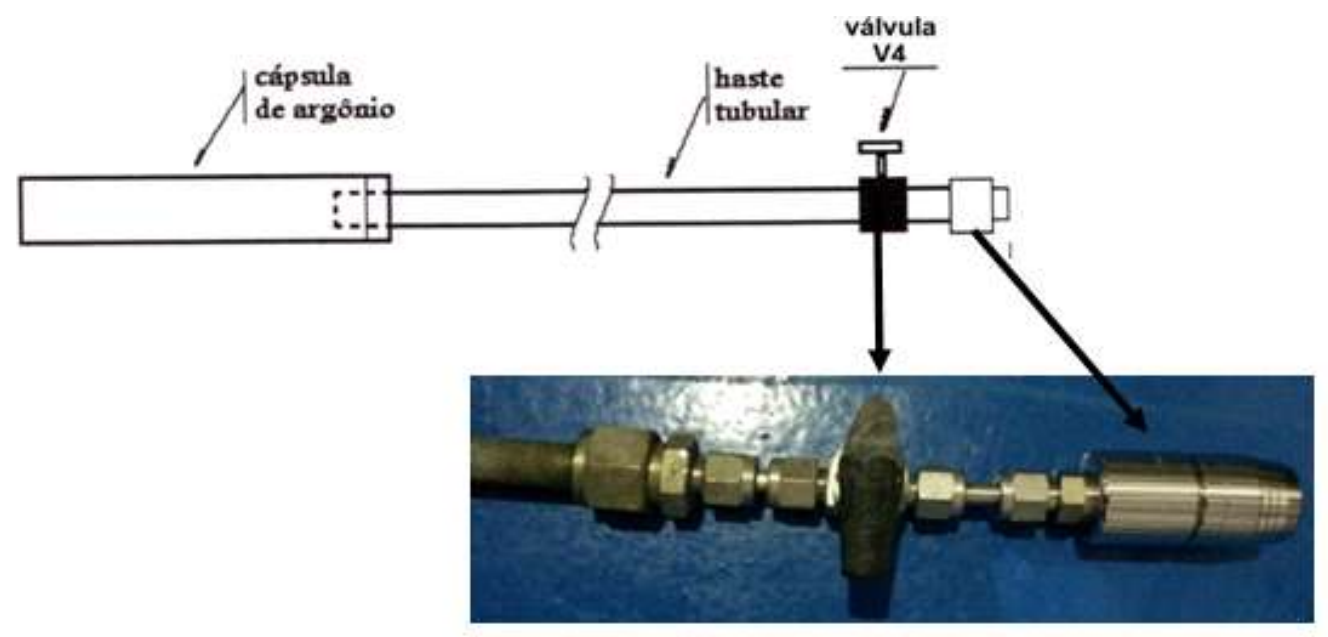

FIGURA 6 - Cápsula de irradiação para imersão na piscina do Reator IEA-R1

b) Carro de carga do tipo plataforma com roda maciça em borracha, para suportar a blindagem em chumbo de $240 \mathrm{~kg}$, aproximadamente, e toda linha de transferência;

c) Cilindro com gás argônio 5.0 (99,999\% de argônio) para se evitar a ativação de contaminantes indesejáveis; e 
d) Linha de transferência em aço inoxidável AISI 304, com diâmetro interno de 6,35 mm (1/4") na parte superior (FIG. 7) e 3,175 mm (1/8") na parte inferior (FIG. 8) do carro de carga. O diâmetro interno de 3,175 $\mathrm{mm}$ reduz o volume de gás radioativo residual em seu interior, quando da transferência ao CAT.

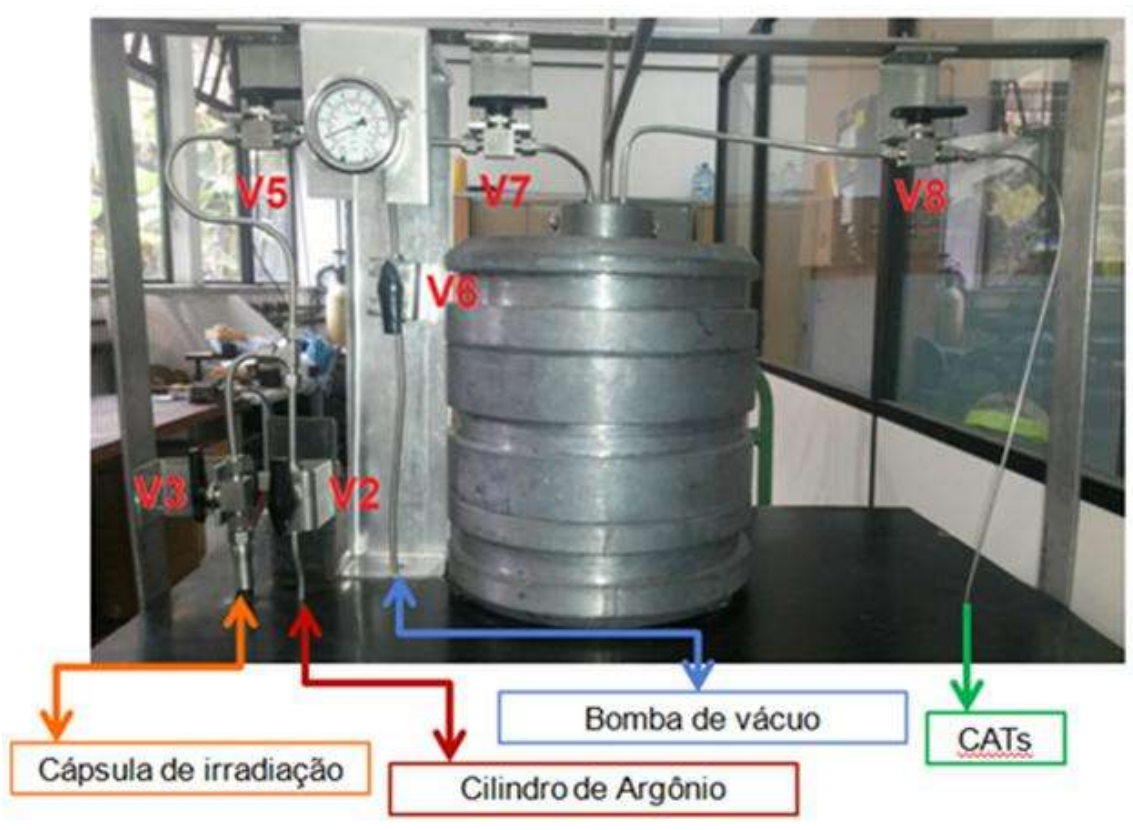

FIGURA 7 - Linha de transferência em aço inoxidável AISI 304 com diâmetro interno de 6,35 $\mathrm{mm}(1 / 4$ ") na parte superior

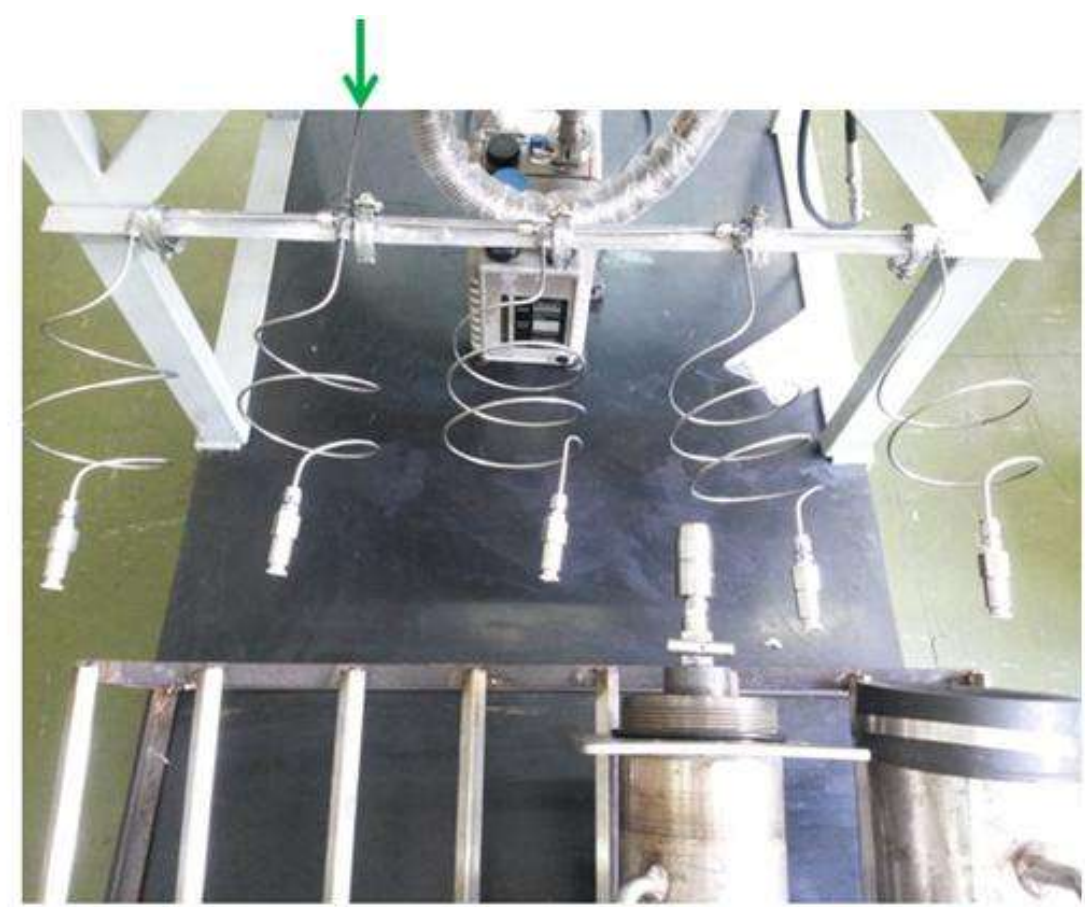

FIGURA 8 - Linha de transferência em aço inoxidável AISI 304 com diâmetro interno de 3,175 $\mathrm{mm}(1 / 8$ ") na parte inferior 
e) Válvulas agulhas, conexões anilhadas, conectores rápidos, manovacuômetro e tubulação em aço inoxidável AISI 304 para confecção da linha de transferência do gás radioativo (FIG. 9).
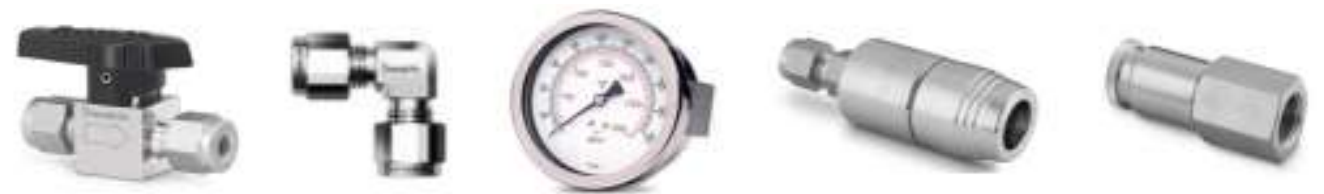

FIGURA 9 - Válvula agulha, conexão anilhada, manovacuômetro e engates rápidos presentes na linha de transferência do gás radioativo [23]

f) Sistema de resfriamento (dewar) para liquefação por meio de nitrogênio líquido (FIG. 10);

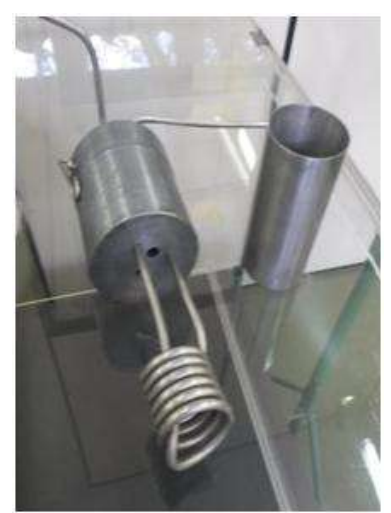

FIGURA 10 - Sistema de resfriamento para liquefação via nitrogênio líquido

g) Blindagem em chumbo com $11 \mathrm{~cm}$ de espessura de parede ao redor do dewar de liquefação (FIG. 11).

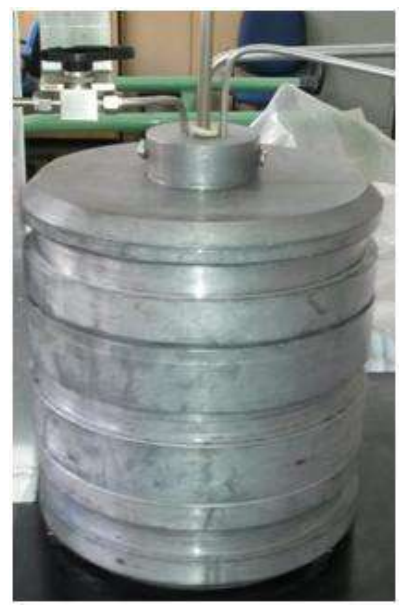

FIGURA 11 - Blindagem em chumbo ao redor do dewar de liquefação 
h) Caixa em acrílico para isolar a linha de transferência do ambiente com saída para sistema de exaustão do reator IEA-R1 (FIG. 12);

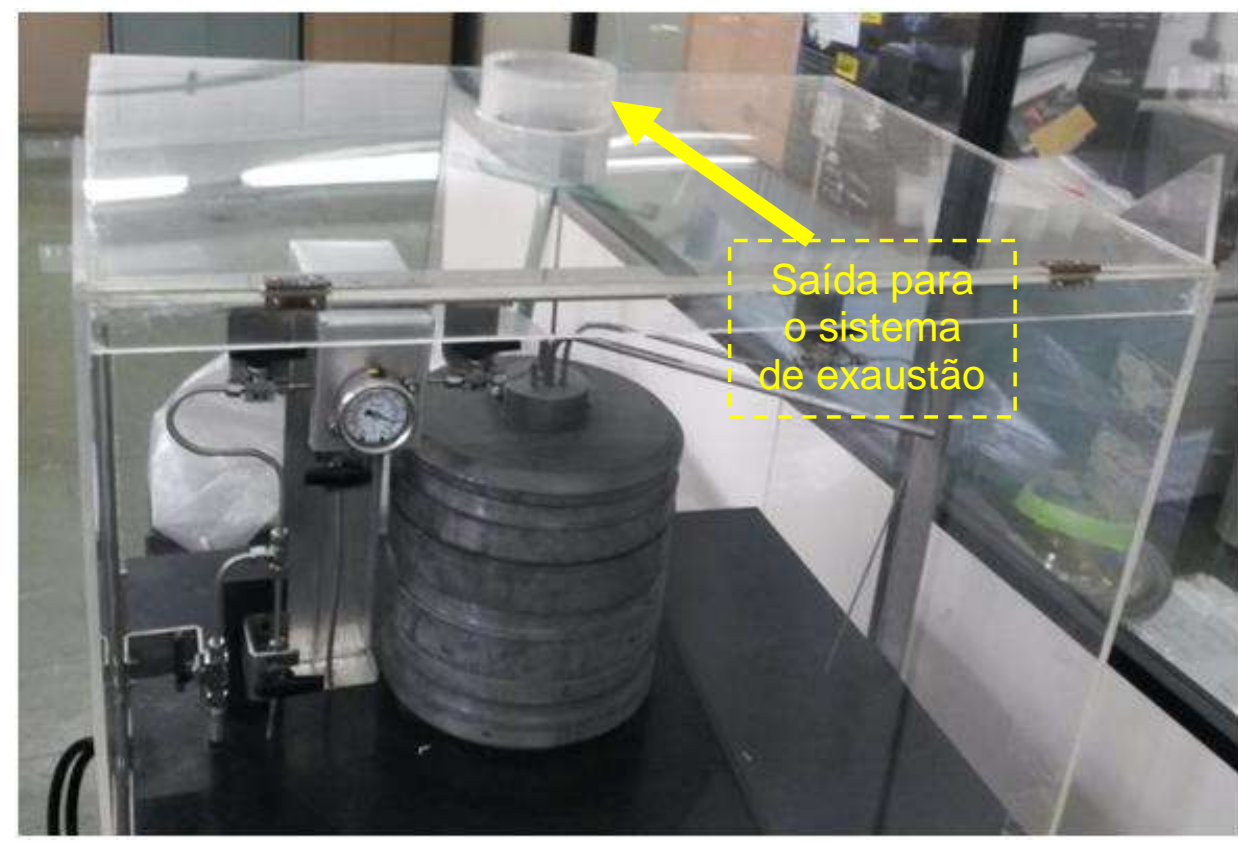

FIGURA 12 - Caixa em acrílico com saída para o sistema de exaustão do Reator IEA-R1

i) Sistema de vácuo com bomba mecânica EDWARDS - modelo E2M2; e

j) Cilindros de armazenamento e transporte do radiotraçador gasoso $\left({ }^{41} \mathrm{Ar}\right.$ ou ${ }^{79} \mathrm{Kr}$ ) em aço inoxidável AISI 304 revestidos com chumbo, acoplados às válvulas agulhas e conexões rápidas nas duas extremidades, com volume interno unitário de $20 \mathrm{~cm}^{3}$ (FIG. 13).

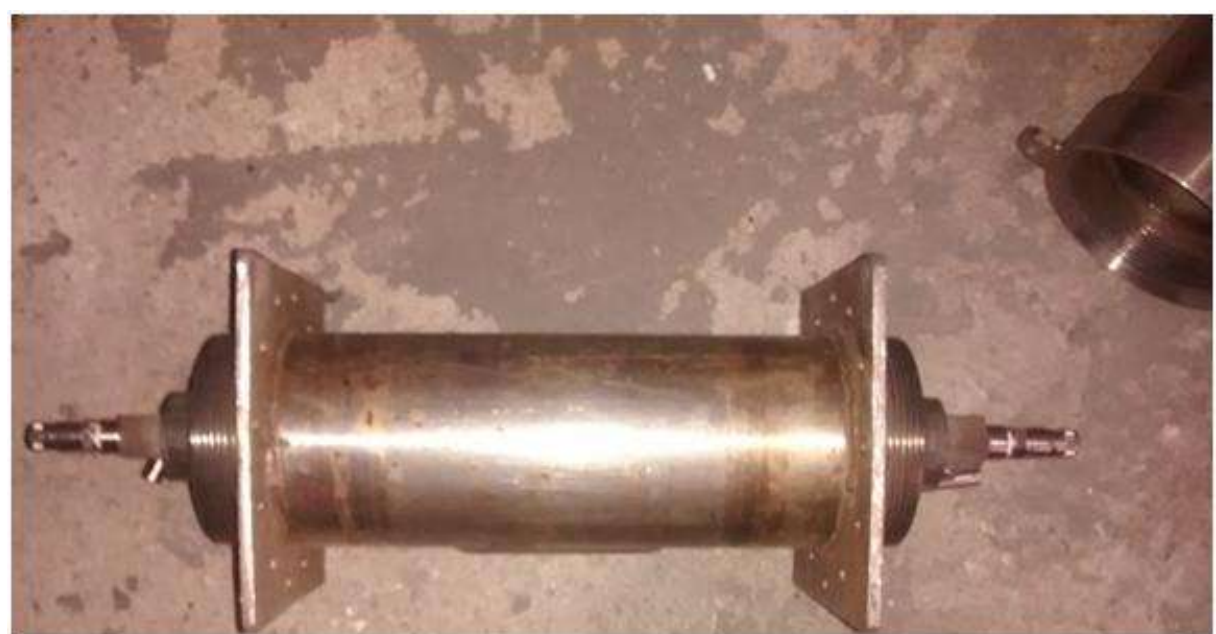

FIGURA 13 - Cilindro de armazenamento e transporte de gás radioativo 


\subsection{Metodologia}

O sistema de irradiação foi projetado e construído sobre o carro de carga tipo plataforma e, posteriormente, utilizaram-se técnicas de deteç̧ão de vazamento na cápsula de irradiação, conexões, engates rápidos e válvulas para assegurar a estanqueidade do sistema e consequentemente proteção radiológica para sua plena utilização.

E, para produção do radioisótopo gasoso utilizou-se o método de ativação por irradiação com nêutrons, por meio do reator nuclear de pesquisa IEA-R1.

\subsubsection{Técnicas para detecção de vazamento}

\subsubsection{Verificação de bolhas com solução formadora de espuma}

Neste método qualitativo, o objeto de ensaio é pressurizado e o local suspeito de apresentar vazamento é umedecido com uma solução formadora de espuma de pequena tensão superficial. No local onde há uma descontinuidade passante da qual escapa gás ocorre à formação de espuma proporcionando sua localização, conforme FIG. 14, cuja quantidade depende, dentre outros fatores, do tamanho da descontinuidade [24].

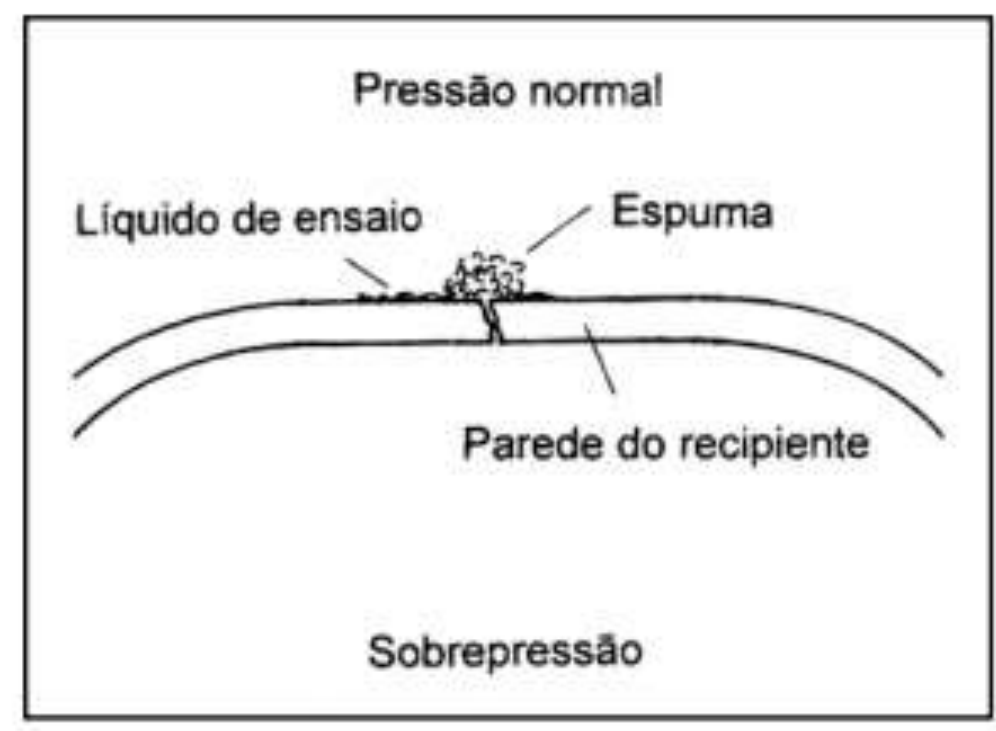

FIGURA 14 - Método da bolha com solução formadora de espuma [24] 


\subsubsection{Acompanhamento da variação de pressão}

As técnicas do método por variação de pressão têm, por finalidade, determinar qualitativamente a presença de vazamentos em objetos submetidos a um diferencial de pressão, por meio do acompanhamento de manovacuômetros que indicam um eventual vazamento na estrutura avaliada quando ela é pressurizada ou evacuada e verificam-se variações de pressão, após um período de estabilização, conforme FIG. 15, que apresenta curvas referentes às situações de ensaios, com e sem vazamento [25].

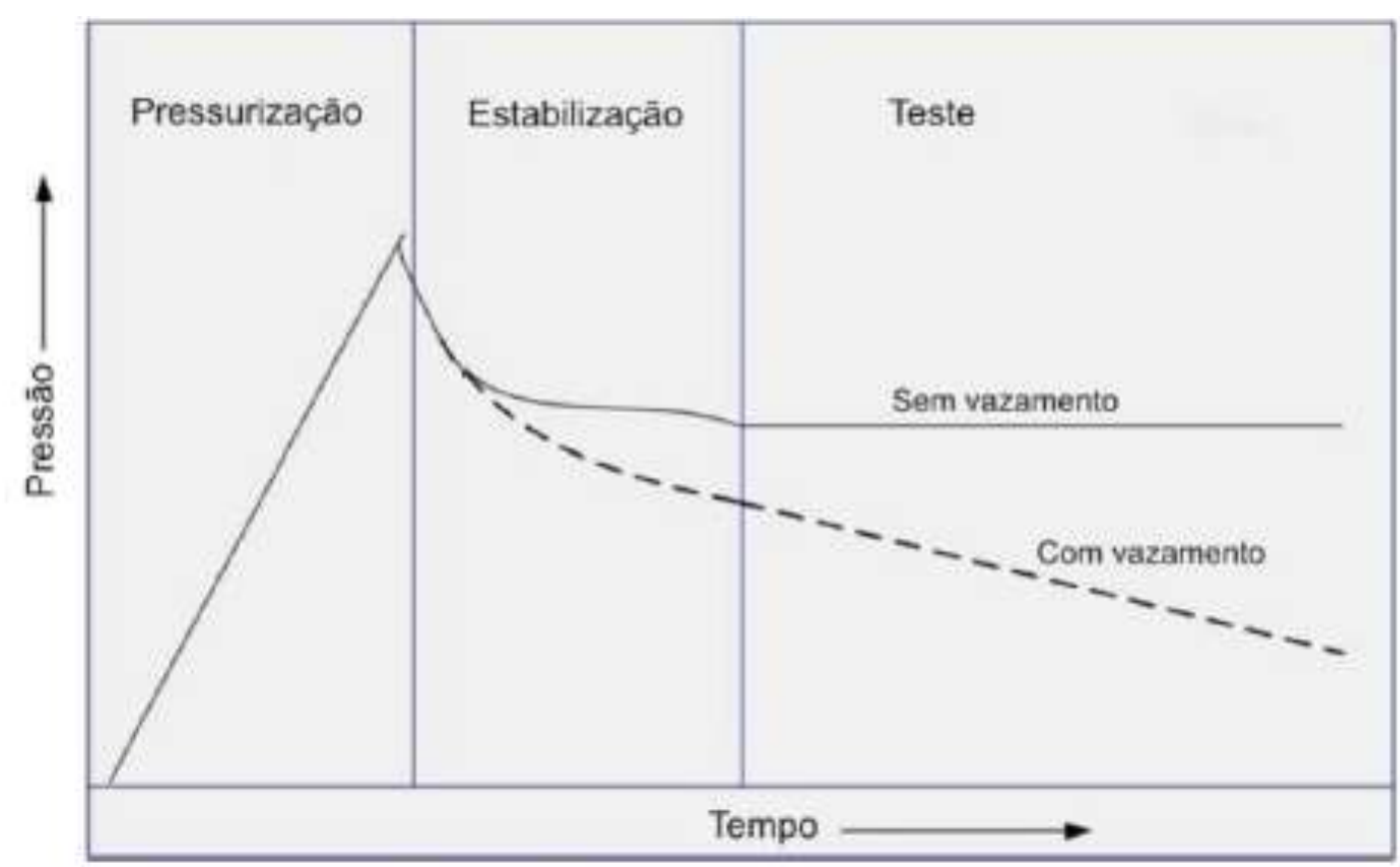

FIGURA 15 - Método de acompanhamento da variação de pressão [25]

\subsubsection{Detecção de vazamento com gás hélio (leak detector).}

O método para detecção de vazamento com gás hélio (por meio do equipamento leak detector) adotado neste trabalho proporciona uma medida direta da taxa de vazamento no objeto de estudo e, consequentemente, uma avaliação do nível de estanqueidade.

A utilização do gás hélio neste método pode ser justificada pelos seguintes fatores [26]:

- O átomo de hélio é o menor (depois do hidrogênio), permitindo assim sua passagem em descontinuidades mínimas; 
- Está presente na atmosfera em quantidades suficientemente baixas de forma a não interferir no ensaio;

- É inerte, de modo seguro para uso em testes, por não reagir com qualquer outro elemento que o componente for carregado posteriormente ao teste além de poder ser liberado na atmosfera sem efeitos ambientais adversos;

- Hélio tem um número de massa único (4) que permite a calibração em espectrômetros de massa na identificação apenas deste elemento; e

- O custo deste gás é relativamente baixo.

O equipamento, no método adotado, detecta automaticamente taxas de vazamento por meio de uma bomba turbomolecular, acoplada ao sistema, que evacua e, consequentemente, aspira qualquer gás presente, detectando a passagem de gás hélio, injetado nas conexões e válvulas que possam apresentar vazamentos, conforme FIG. 16 .

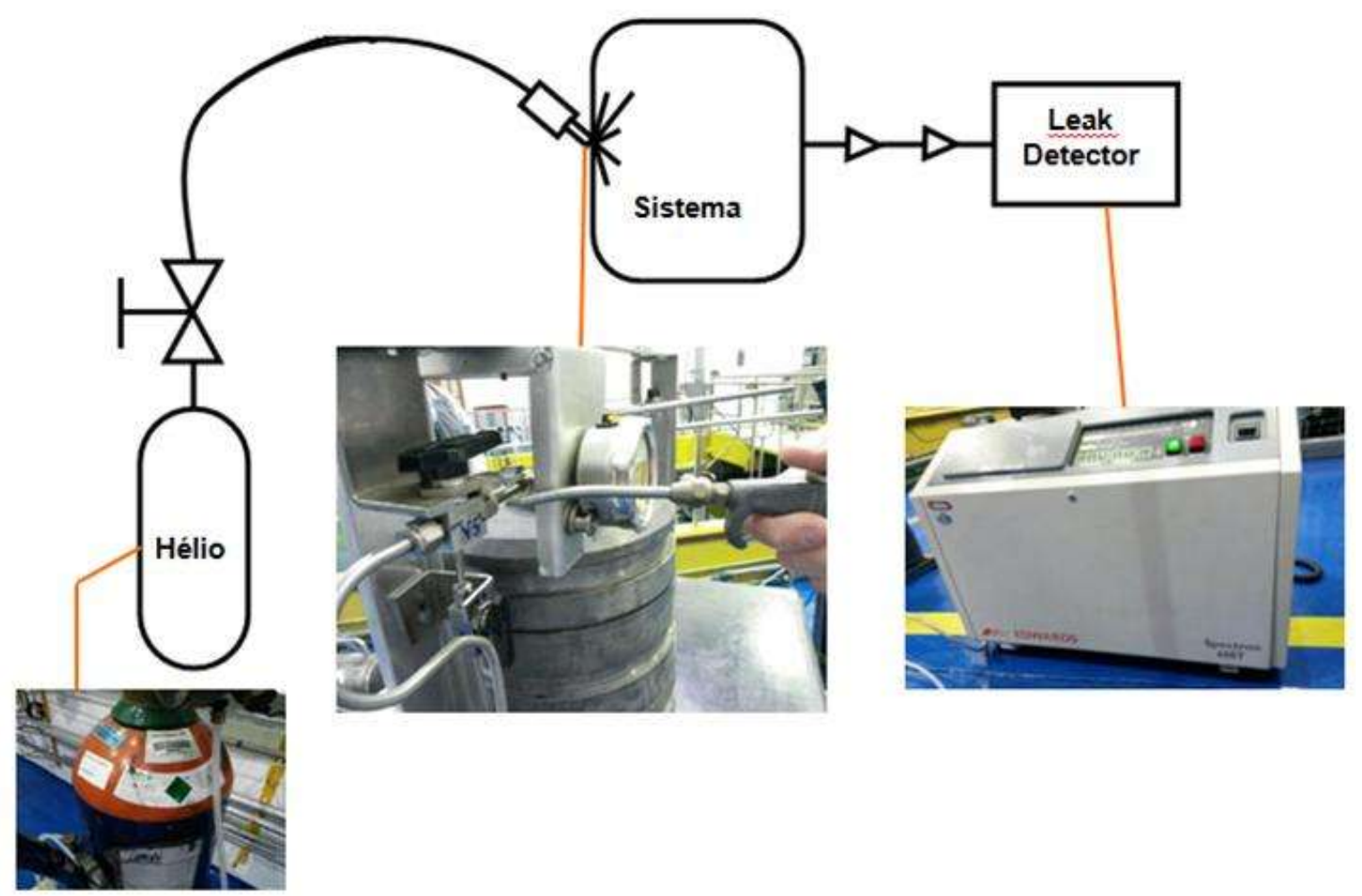

FIGURA 16 - Técnica utilizada para detecção de vazamento com equipamento leak detector 
O funcionamento do equipamento de leak detector é baseado em espectrômetros de massa, que ionizam e aceleram átomos de um gás por meio de um campo elétrico para que eles passem por um campo magnético e assim sofram a ação de uma força magnética que causa deflexões nas trajetórias diretamente proporcionais aos valores das cargas e de suas massas atômicas, proporcionando a seleção de elementos específicos. Os átomos selecionados são desviados para atingir um alvo, que detecta a corrente e proporciona a medida da taxa de vazamento, conforme esquema simplificado na FIG. 17. Esta técnica permite que quantidades extremamente pequenas de gás sejam detectadas e o limite de sensibilidade para um espectrômetro de massa de hélio pode ser de aproximadamente $1.10^{-10} \mathrm{mbar}$.L/s equivalente a $2.10^{-5}$ gramas por ano de vazamento $[27,28]$.

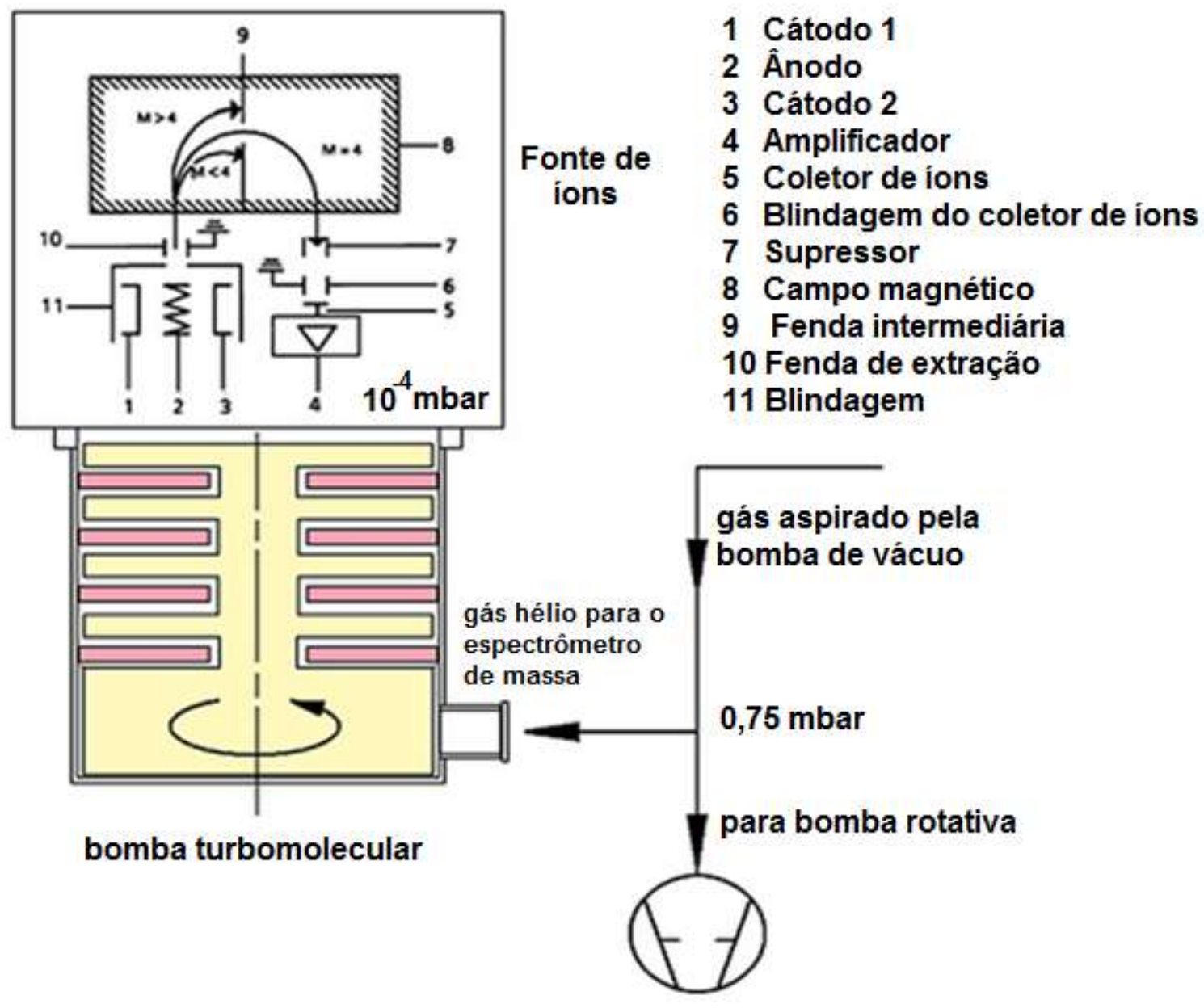

FIGURA 17 - Esquema de funcionamento de um espectrômetro de massa em um equipamento leak detector com gás hélio [27] 


\subsubsection{Método para produção do radioisótopo gasoso}

Para a produção do radioisótopo gasoso ${ }^{41} \mathrm{Ar}$ utilizou-se o método de irradiação com nêutrons, da cápsula de irradiação em alumínio (contendo o gás argônio natural) instalada em uma posição pré-estabelecida do Reator IEA-R1, com fluxo de nêutrons térmicos, conforme FIG. 18.

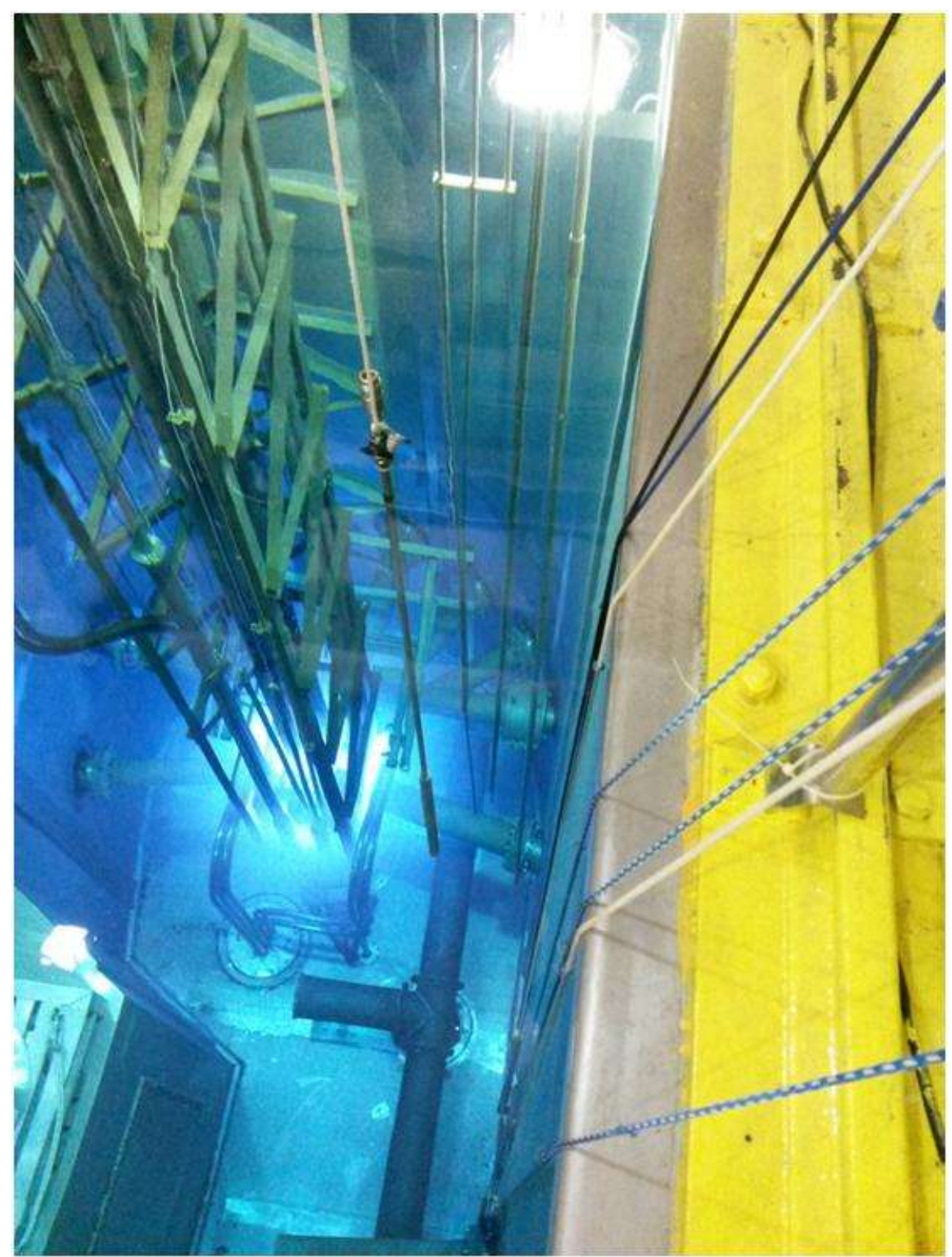

FIGURA 18 - Imersão da cápsula de irradiação na piscina do Reator IEA-R1 


\subsection{Procedimento Experimental}

O desenvolvimento do sistema de irradiação para produção de radioisótopos gasosos seguiu o procedimento experimental descrito no fluxograma mostrado na FIG. 19.

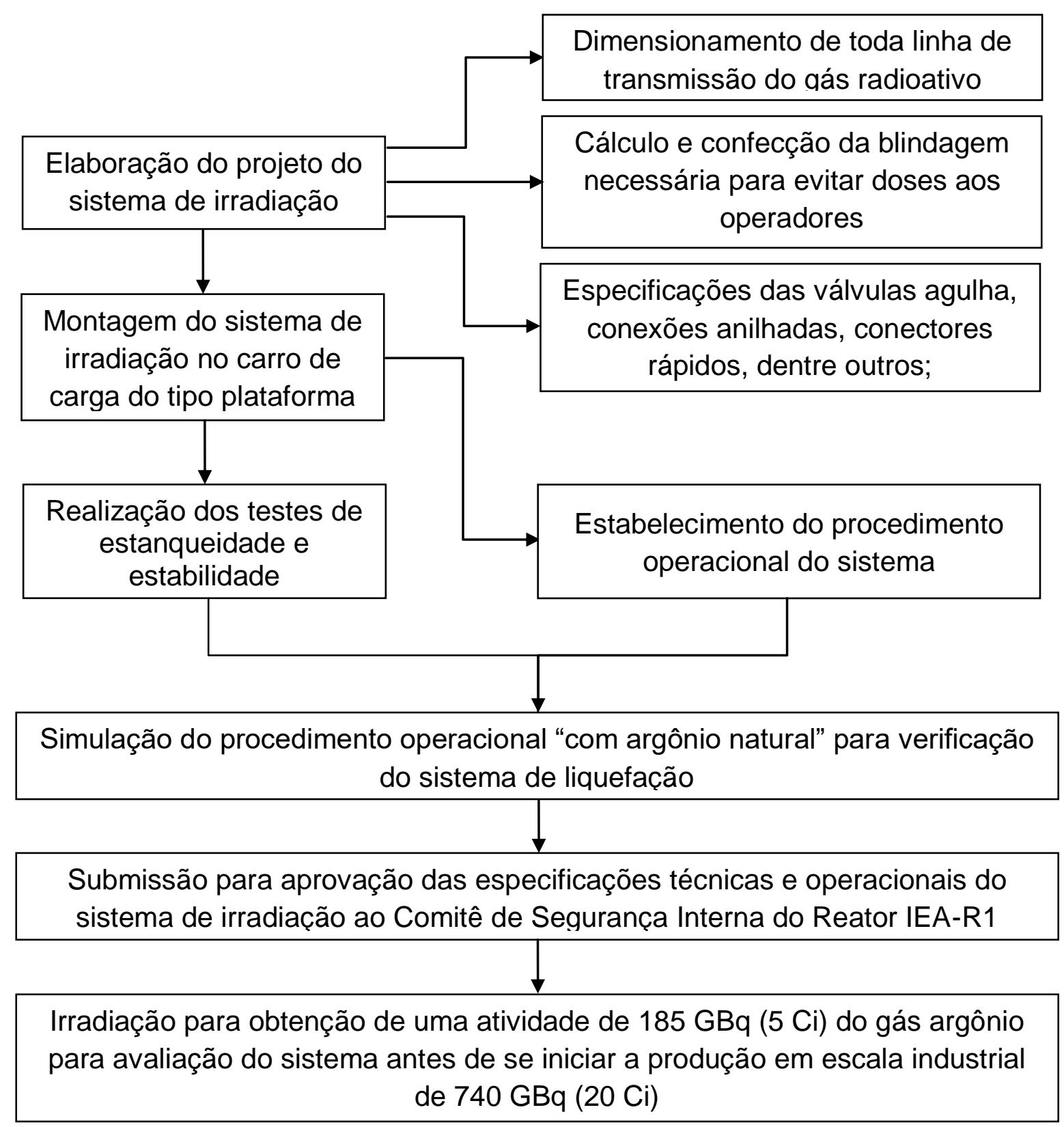

FIGURA 19 - Fluxograma do procedimento experimental 


\section{RESULTADOS E DISCUSSÃO}

Os resultados obtidos no desenvolvimento do sistema de irradiação, descritos a seguir, proporcionaram a publicação do trabalho completo "Development of an Irradiation System for Radioisotope Production Applied to Industrial Process Tomography", apresentado no ANEXO A. O trabalho será apresentado no "WCIPT8 - 8th World Congress on Industrial Process Tomography", Foz do Iguaçu/PR, no período de 26 a 29/09/2016, promovido pela "ISIPT - The International Society for Industrial Process Tomography".

\subsection{Projeto e construção do sistema de irradiação}

O sistema de irradiação foi projetado para proporcionar o preenchimento, irradiação com nêutrons e recolhimento do gás nobre de uma cápsula de irradiação $(\mathrm{Cl})$, a ser posicionada próximo ao núcleo do reator nuclear de pesquisa, para cilindros de armazenamento e transporte (CATs), passando por um sistema de liquefação com nitrogênio líquido (dewar). Considerando-se a possibilidade de locomoção para facilitar sua utilização no saguão da piscina do Reator IEA-R1, o sistema de irradiação foi montado em um carro de carga, contendo sistema de vácuo para transferência do gás por diferença de pressão, manovacuômetro, caixa em acrílico com saída para o sistema de exaustão do reator (isolar do ambiente parte da linha de transferência onde se concentra o gás radioativo para liquefação), assim como uma blindagem em chumbo para se evitar doses de radiação. Na FIG. 20 é mostrada a concepção do sistema de irradiação já acoplado aos cilindros de armazenamento e transporte (CATs) e ao cilindro de gás argônio 5.0. 


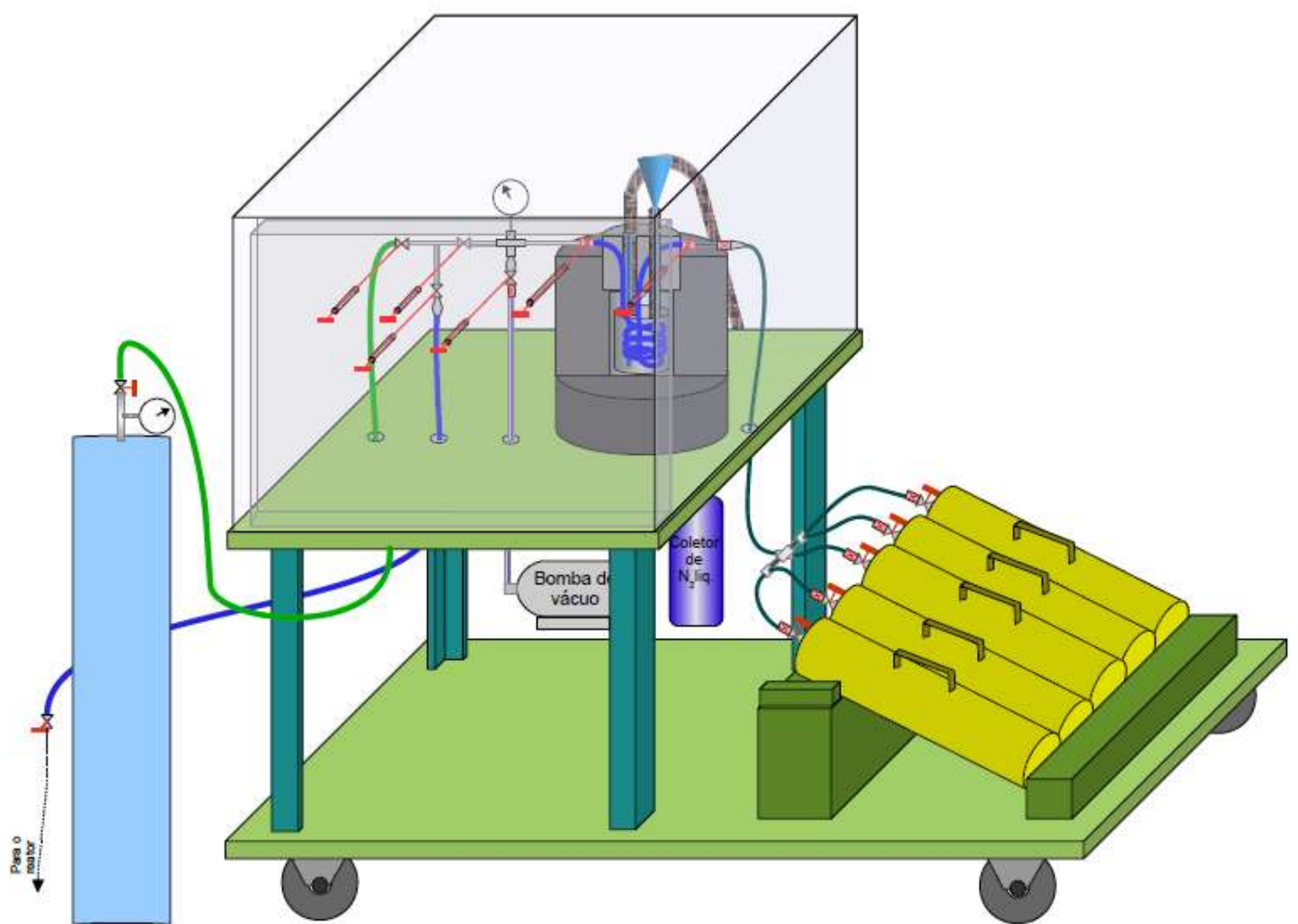

FIGURA 20 - Projeto do sistema de irradiação para produção de radioisótopos gasosos aplicados em processos industriais

De acordo com o projeto do sistema de irradiação (FIG. 20), elaborouse o esquema representado na FIG. 21, o qual representa todos os materiais utilizados, assim como toda linha de transferência e válvulas que permitem a passagem ou bloqueio do gás $\left({ }^{41} \mathrm{Ar}\right.$ ou $\left.{ }^{79} \mathrm{Kr}\right)$. 


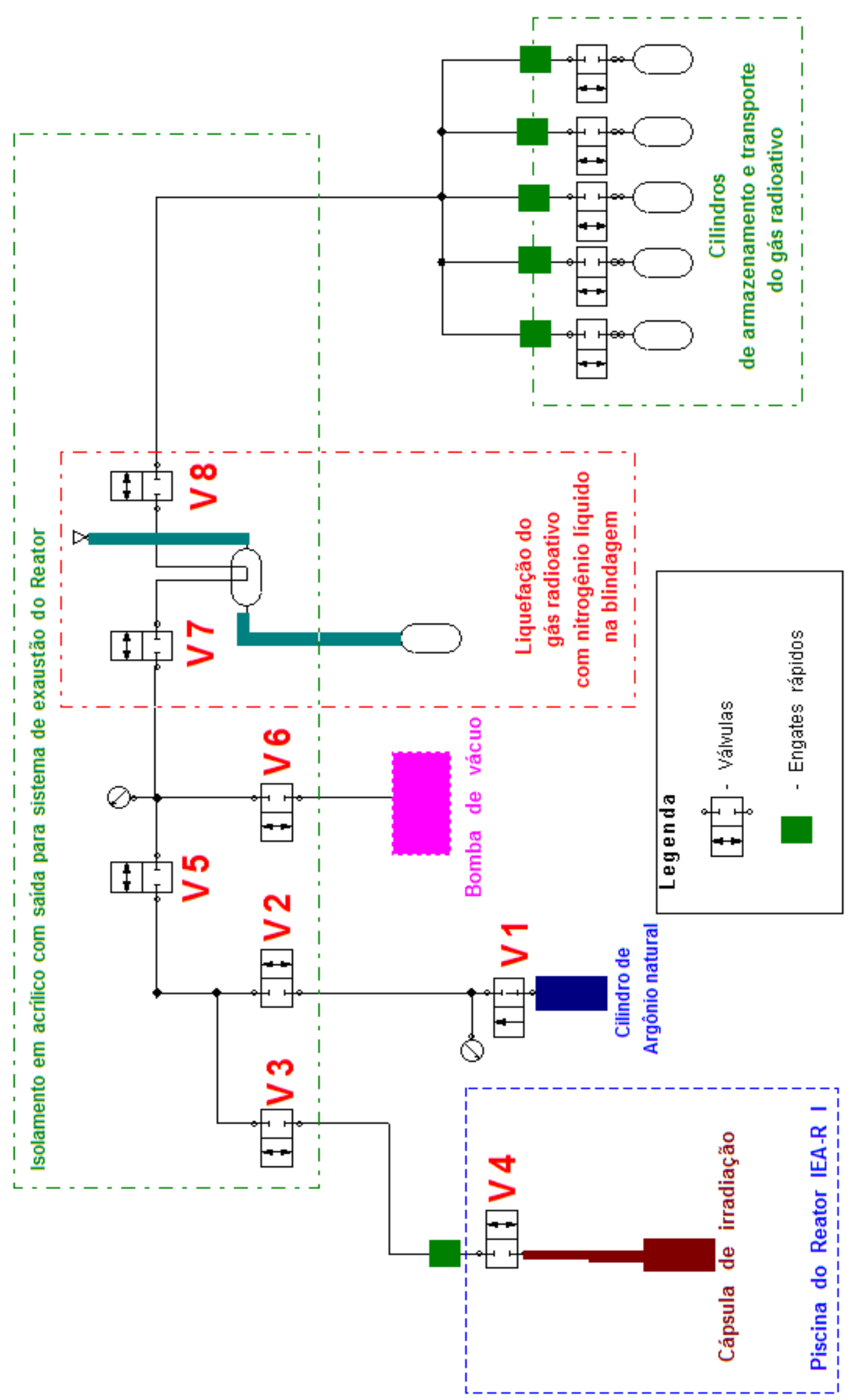

FIGURA 21 - Esquema geral do sistema de irradiação de radioisótopos gasosos aplicados em processos industriais 
A partir da aquisição de todos os materiais e equipamentos, confecção da caixa em acrílico e construção da blindagem em chumbo, o sistema de irradiação foi montado em um carro de carga, resultando no sistema completo, mostrado na FIG. 22.

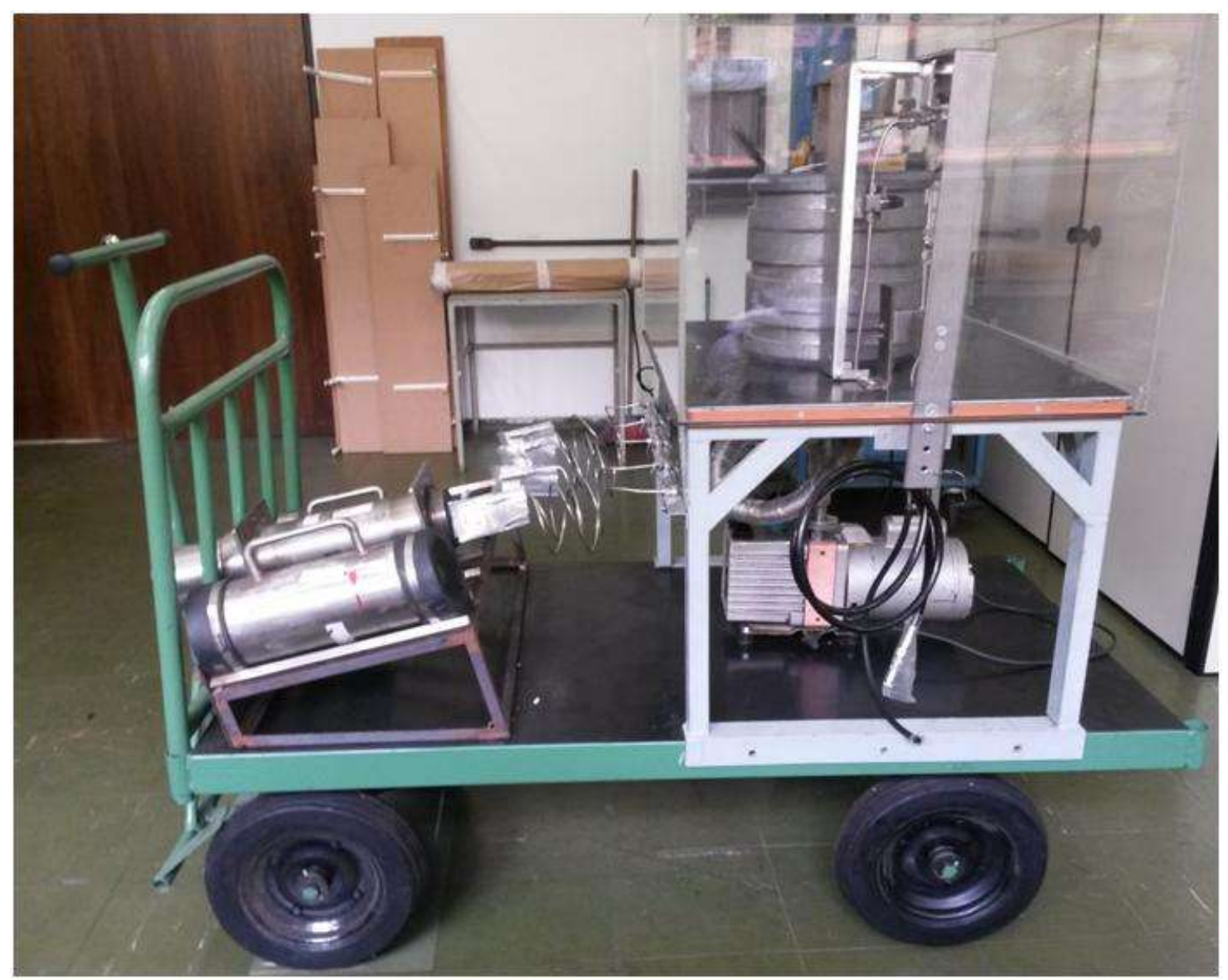

FIGURA 22 - Sistema de irradiação para produção de radioisótopos gasosos aplicados em processos industriais

\subsubsection{Cápsula de irradiação}

A cápsula de irradiação $(\mathrm{Cl})$ para instalação próxima ao núcleo, na piscina do Reator IEA-R1, possui um volume de $150 \mathrm{~cm}^{3}$, engate rápido e válvula (denominada V4) para transferência do gás ${ }^{41} \mathrm{Ar}$, conforme FIG. 23. 
(a)

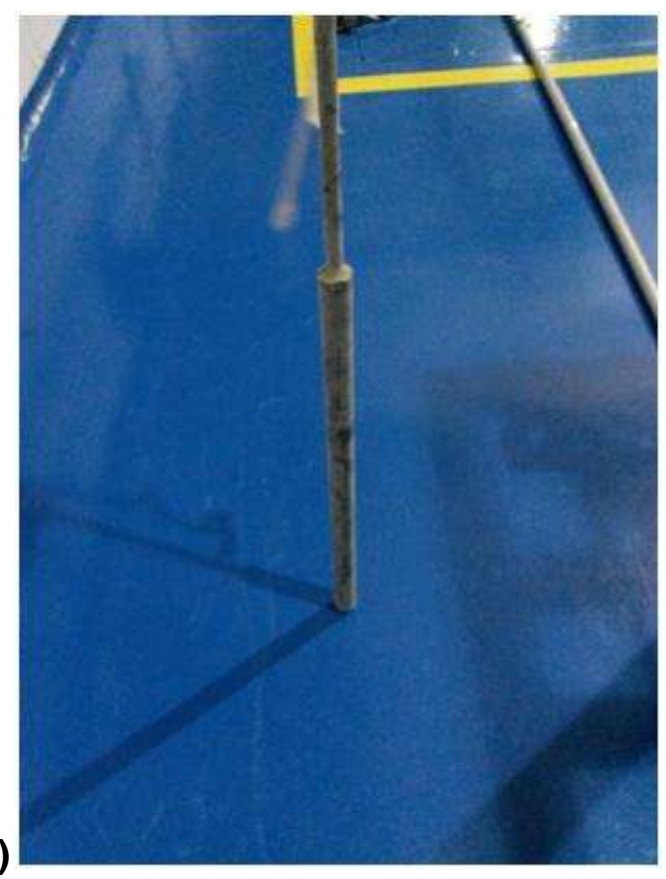

(b)

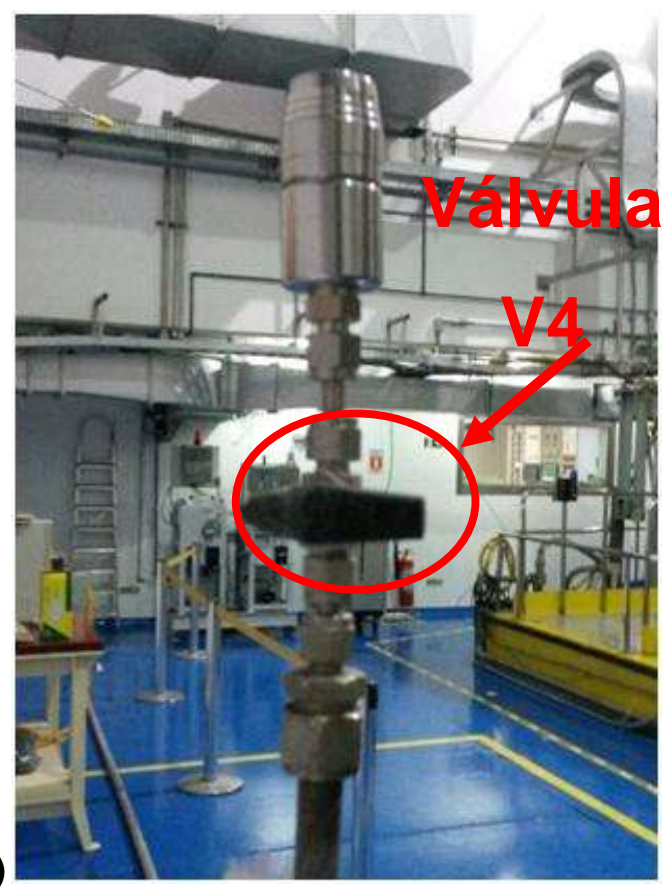

(b) da cápsula de irradiação

\subsubsection{Sistema de liquefação (dewar) e blindagem no sistema de irradiação}

A liquefação do radioisótopo gasoso no sistema de irradiação ocorre por meio da imersão em nitrogênio líquido (contido em um copo de alumínio, com diâmetro de $7 \mathrm{~cm}$ instalado dentro da blindagem em chumbo - dewar) de parte da linha de transferência (em forma de espiral), conforme FIG. 24.

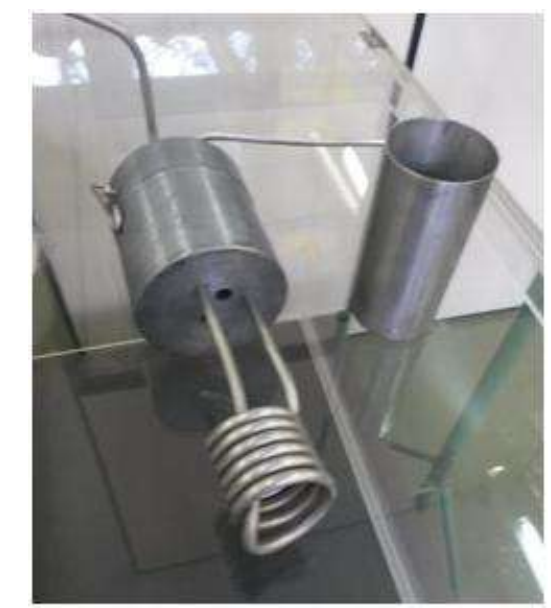

FIGURA 24 - Dewar de liquefação do gás ${ }^{41} \mathrm{Ar}$ ou ${ }^{79} \mathrm{Kr}$

O dewar do sistema de irradiação (que concentra o gás radioativo) foi instalado dentro de uma blindagem em chumbo com $29 \mathrm{~cm}$ de diâmetro e $11 \mathrm{~cm}$ 
de espessura de parede, conforme FIG. 25, assegurando uma elevada atenuação dos raios gama emitidos pelo gás ${ }^{41} \mathrm{Ar}$ ou ${ }^{79} \mathrm{Kr}$.

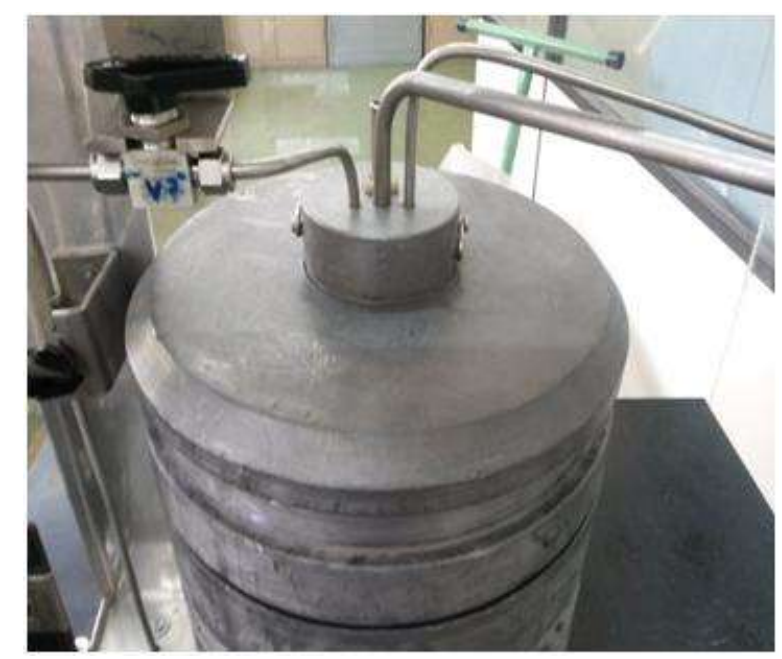

FIGURA 25 - Blindagem em chumbo na qual está instalado o dewar de liquefação do gás radioativo $\left({ }^{41} \mathrm{Ar}\right.$ ou $\left.{ }^{79} \mathrm{Kr}\right)$

A blindagem foi construída levando-se em consideração o coeficiente de atenuação de massa para energia de $1,25 \mathrm{MeV}\left(\mu / \rho=0,05876 \mathrm{~cm}^{2} / \mathrm{g}\right)$, densidade do chumbo $\left(\rho=11,4 \mathrm{~g} / \mathrm{cm}^{3}\right)$ e a lei de atenuação exponencial que proporciona uma aproximação, da intensidade "I" de saída de um feixe estreito de fótons monoenergéticos com uma intensidade incidente " $\mathrm{l}_{0}$ ", penetrando uma camada de material com espessura de massa " $x$ " e densidade " $\rho$ ", expressa na Equação 11, obtendo-se uma espessura mínima necessária de $10 \mathrm{~cm}$ para uma Intensidade de saída estimada em $0,1 \%$ em relação a intensidade incidente $\left(I_{0}\right)$ [29].

$$
I=I_{0} \cdot e^{-\mu \cdot x}
$$

\subsubsection{Cilindros de armazenamento e transporte (CATs)}

A empresa TRACERCO do Brasil cedeu um de seus cilindros de armazenamento e transporte de radioisótopos gasosos (CATs) para o desenvolvimento do sistema de irradiação. Cada cilindro consiste em um vaso de 
pressão blindado com aproximadamente $5 \mathrm{~cm}$ em chumbo, volume interno de 20 $\mathrm{cm}^{3}$, engates rápidos e válvulas em ambos os lados, conforme FIG. 26.

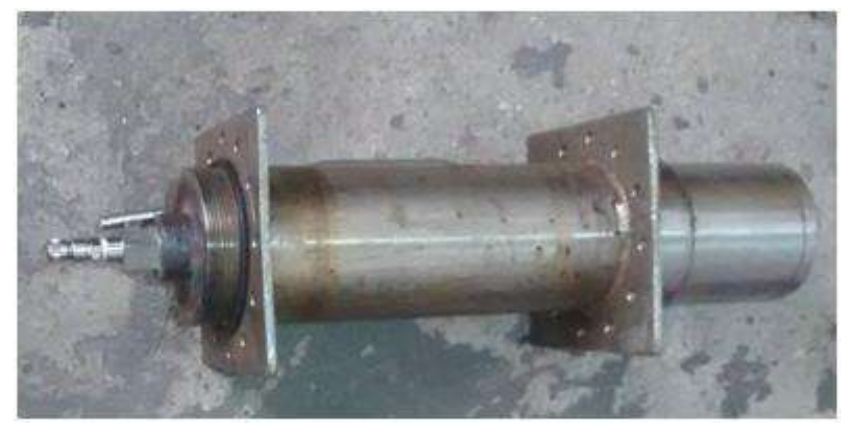

FIGURA 26 - Cilindro de armazenamento e transporte fornecido pela TRACERCO do Brasil

\subsubsection{Plataforma com a linha de transferência do gás}

A transferência do gás nobre $\left({ }^{40} \mathrm{Ar}\right.$ ou $\left.{ }^{78} \mathrm{Kr}\right)$ para a cápsula de irradiação (Cl), do gás radioativo $\left({ }^{41} \mathrm{Ar}\right.$ ou $\left.{ }^{79} \mathrm{Kr}\right)$ da cápsula para o dewar de liquefação e, posteriormente, para os cilindros de armazenamento e transporte se dá por meio de válvulas do tipo agulha instaladas ao longo da linha de transferência em aço inoxidável AISI 304, montada em uma plataforma no sistema de irradiação, conforme FIG. 27.

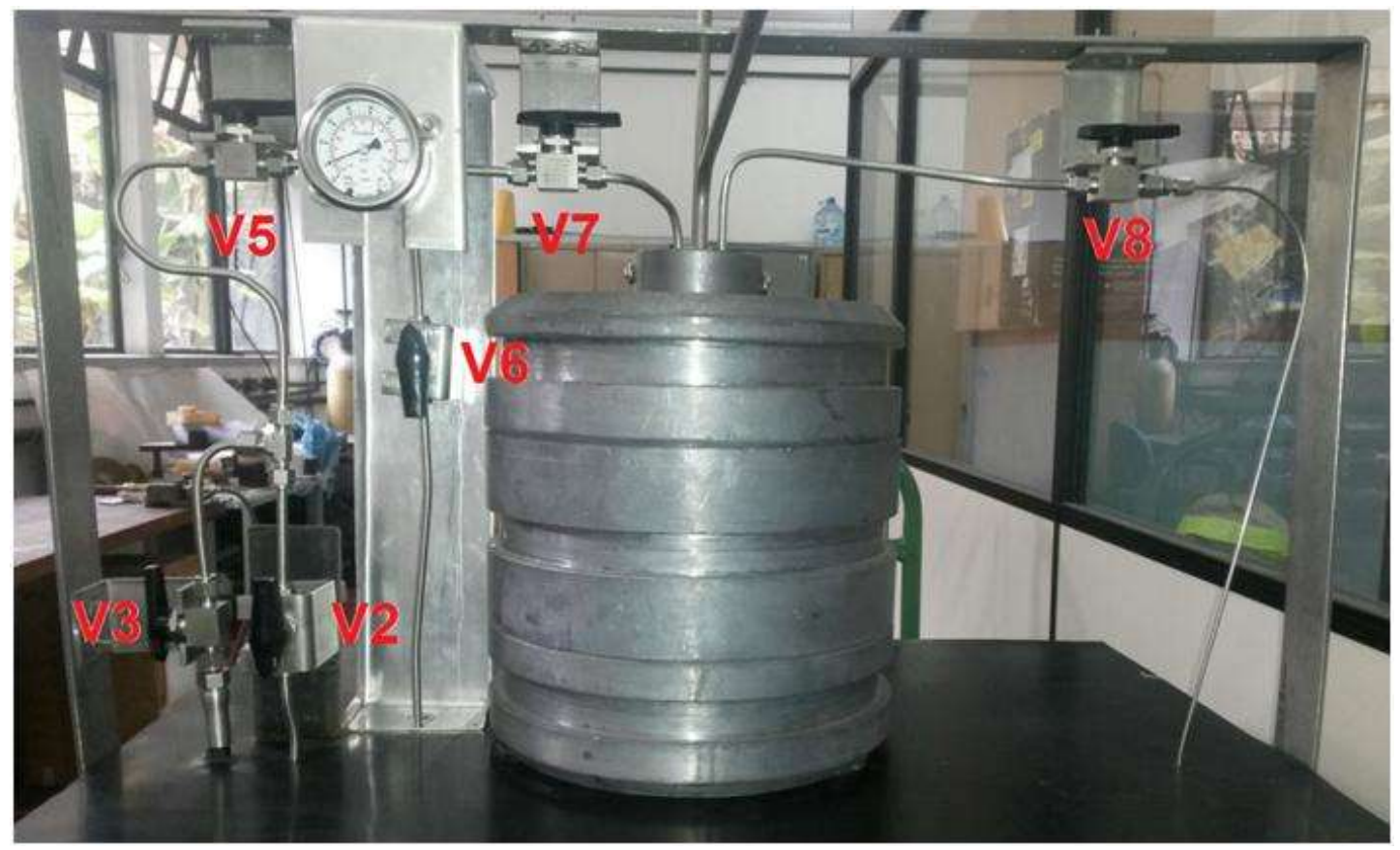

FIGURA 27 - Plataforma do sistema de Irradiação com as válvulas, manovacuômetro, e blindagem em chumbo 


\subsection{Procedimento operacional do sistema de irradiação}

Estabeleceu-se o procedimento operacional para produção do ${ }^{41} \mathrm{Ar}$, dividido em quatro etapas, conforme FIG. 28, a serem seguidas após a conexão de todos os componentes e do sistema de irradiação (SI) ao duto de ventilação/exaustão do Reator IEA-R1.

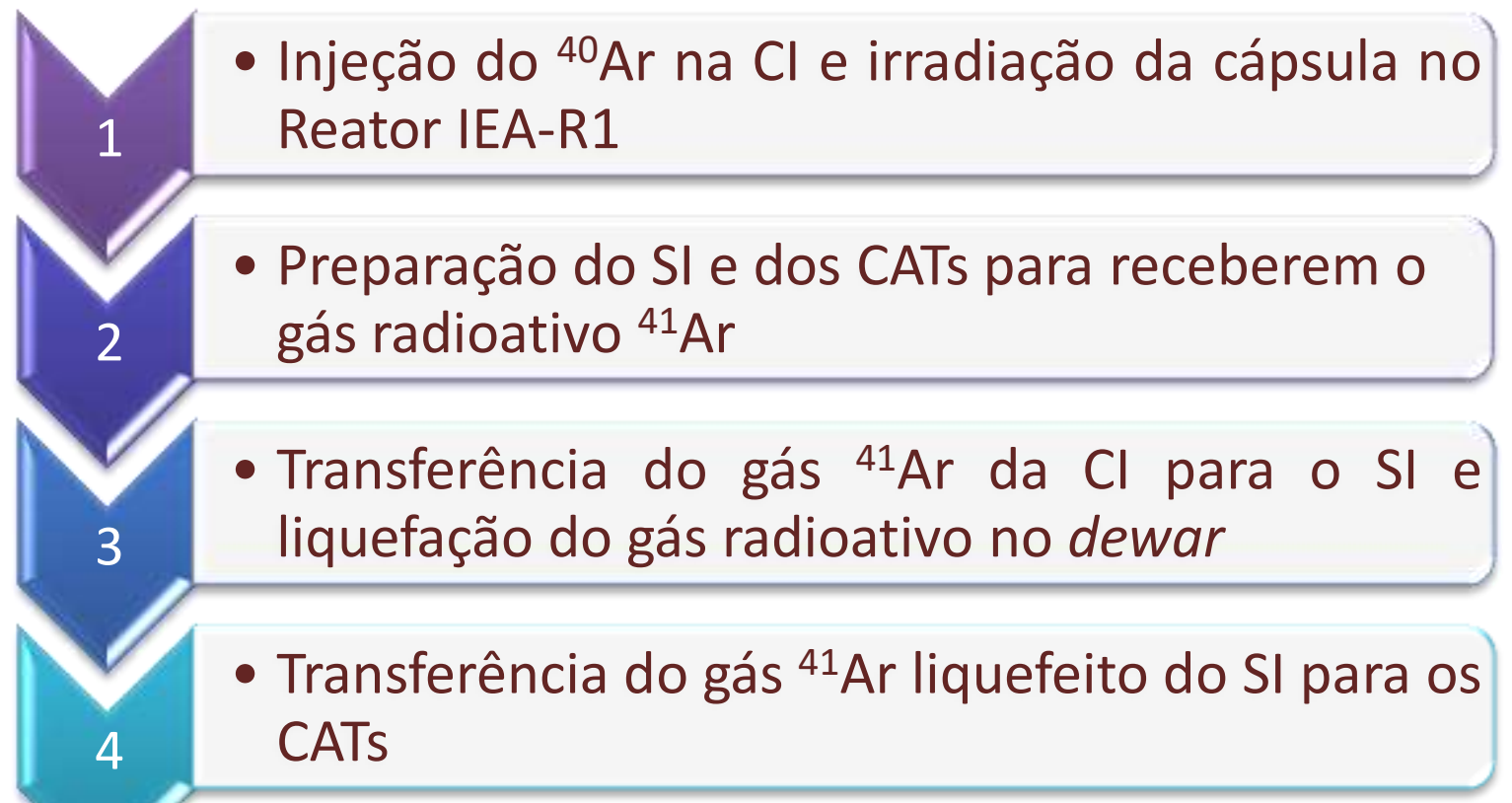

Figura 28 - Etapas do procedimento operacional para produção do ${ }^{41} \mathrm{Ar}$

\subsubsection{Etapa 1 - Injeção do argônio natural $\left({ }^{40} \mathrm{Ar}\right)$ na $\mathrm{Cl}$ e irradiação da cápsula no Reator IEA-R1}

A etapa 1 consiste na transferência do argônio $5.0\left({ }^{40} \mathrm{Ar}\right)$ do cilindro de gás à cápsula de irradiação $(\mathrm{Cl})$ e na colocação da cápsula na posição de irradiação do reator nuclear de pesquisa IEA-R1, esquematizada no fluxograma da FIG. 29. 


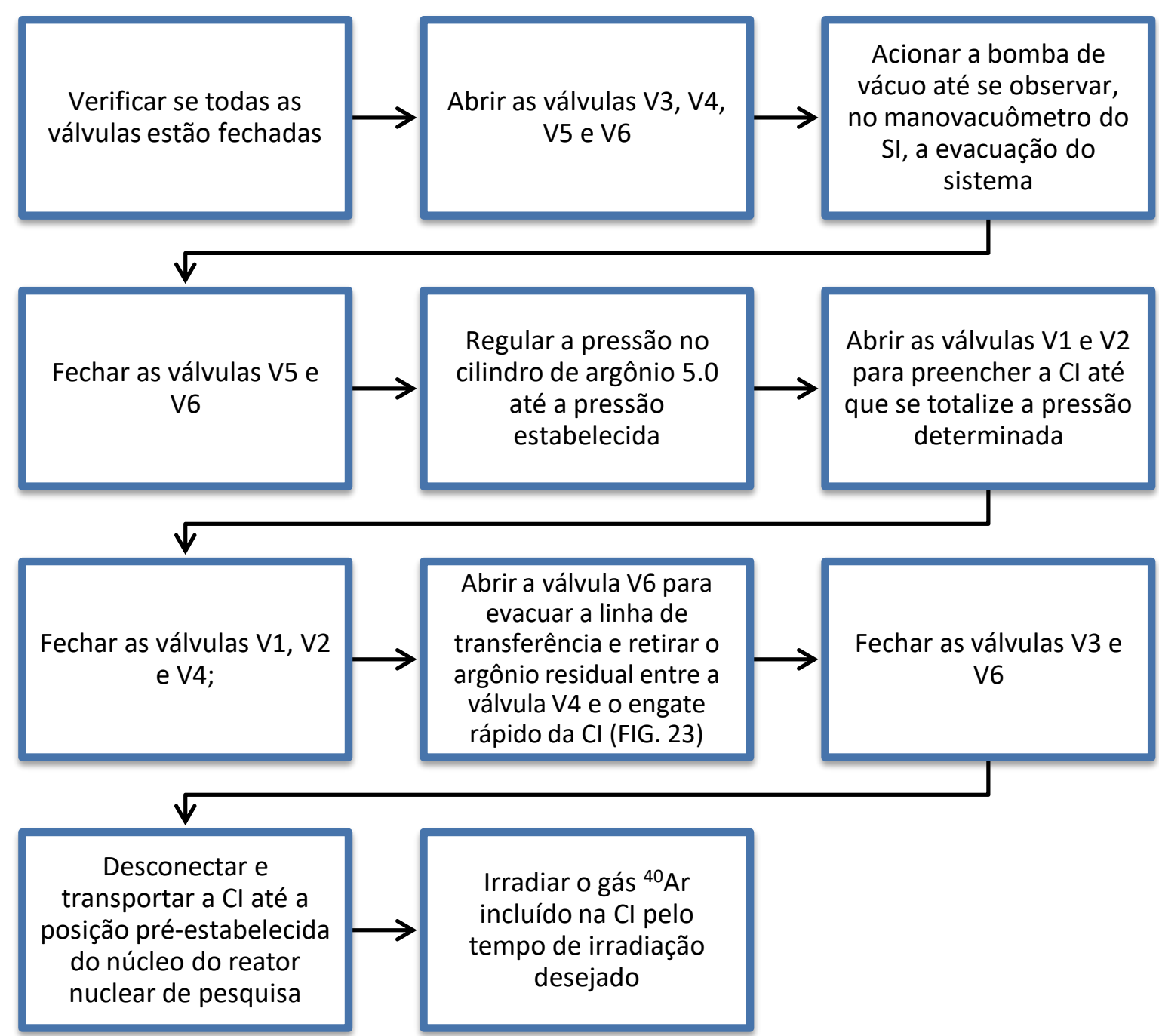

FIGURA 29 - Fluxograma da etapa 1 - Injeção do ${ }^{40} \mathrm{Ar}$ na $\mathrm{Cl}$ e irradiação da cápsula no Reator IEA-R1

\subsubsection{Etapa 2 - Preparação do SI e dos CATs para receberem o gás radioativo}

A etapa 2, esquematizada no fluxograma da FIG. 30, consiste na preparação do sistema de irradiação para receber o gás radioativo, a qual deve ser realizada 20 minutos antes do término da irradiação. 


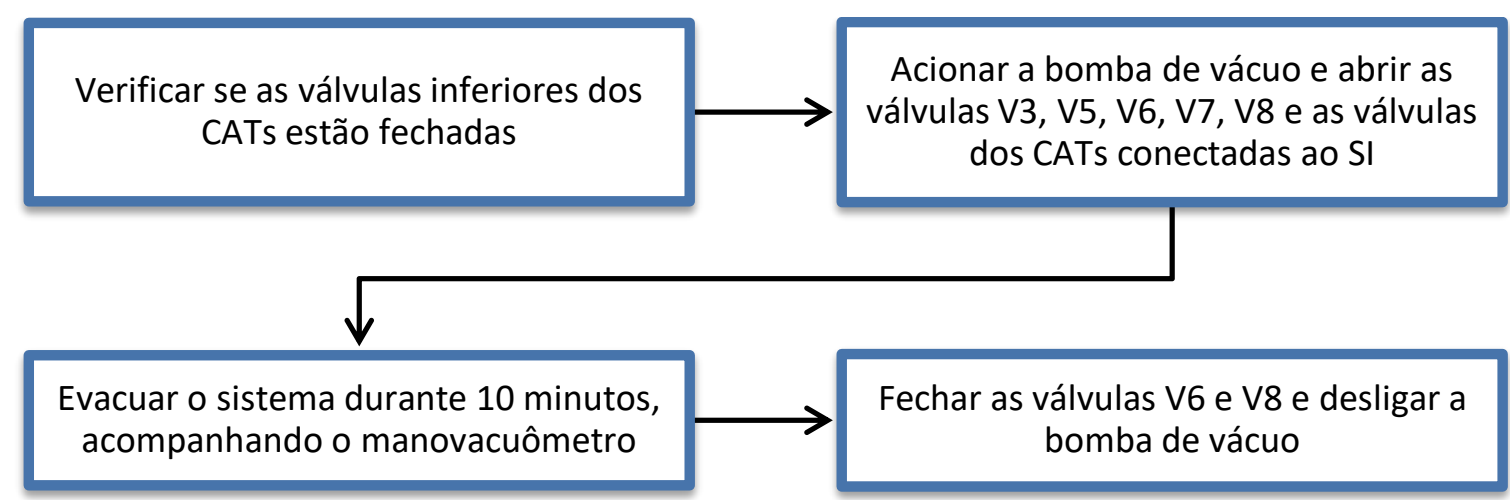

FIGURA 30 - Fluxograma da etapa 2 - Preparação do SI e dos CATs para receberem o gás radioativo

\subsubsection{Etapa 3 - Transferência do gás radioativo $\left({ }^{41} \mathrm{Ar}\right)$ da $\mathrm{Cl}$ para o $\mathrm{SI}$ e liquefação}

Com o sistema preparado na Etapa 2 e finalizada a irradiação da $\mathrm{Cl}$, deve-se iniciar a Etapa 3, esquematizada na FIG. 31, com acompanhamento da equipe de proteção radiológica do CRPq, no IPEN/CNEN-SP.

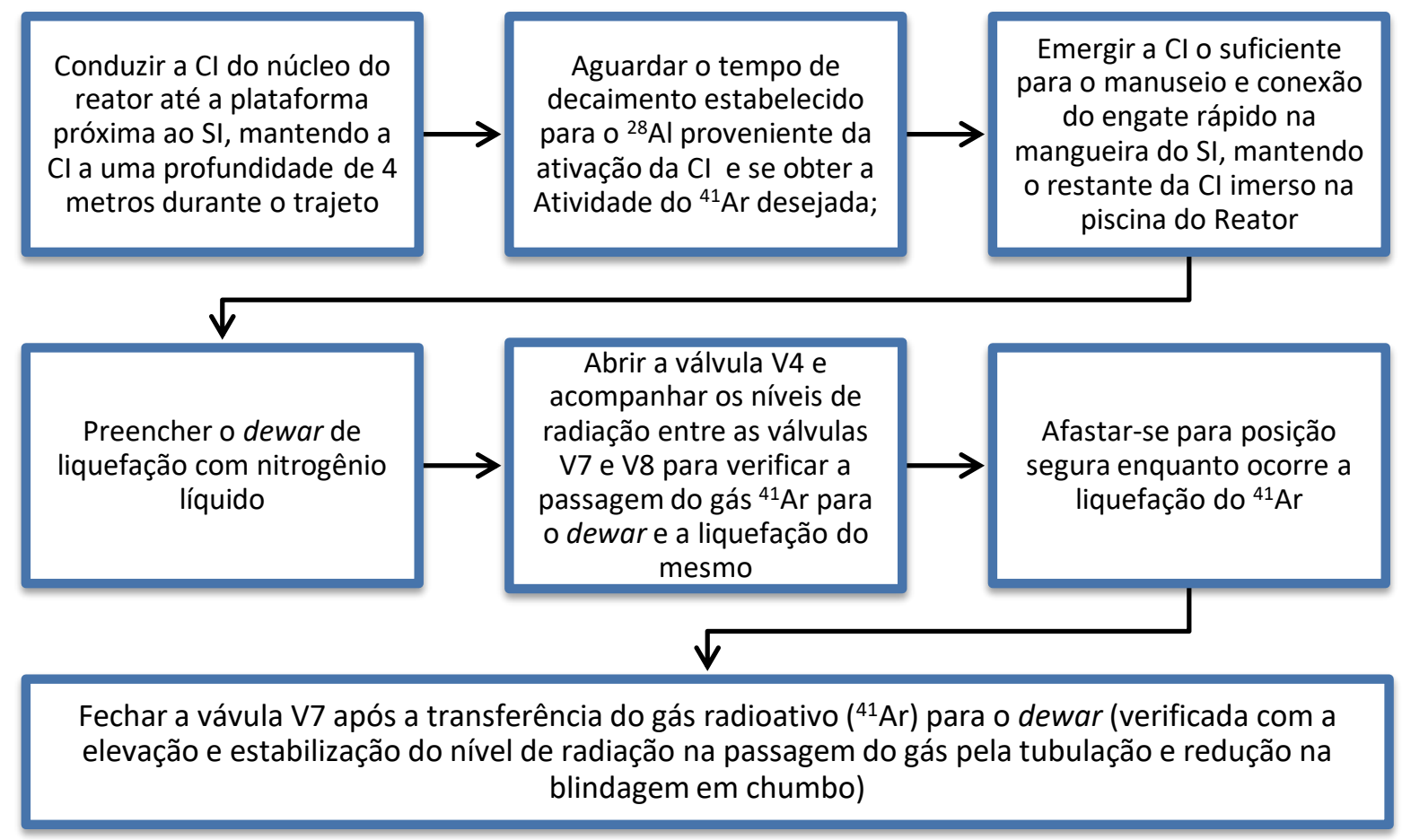

FIGURA 31 - Fluxograma da etapa 3 - Transferência do radioisótopo gasoso ao dewar 


\subsubsection{Etapa 4 - Transferência do gás radioativo para os CATs}

A etapa 4, evidenciada no fluxograma da FIG. 32, consiste na transferência do gás radioativo aos CATs, por meio da vaporização do gás liquefeito no dewar ao se injetar ar comprimido para remover o nitrogênio líquido e elevar novamente a temperatura.

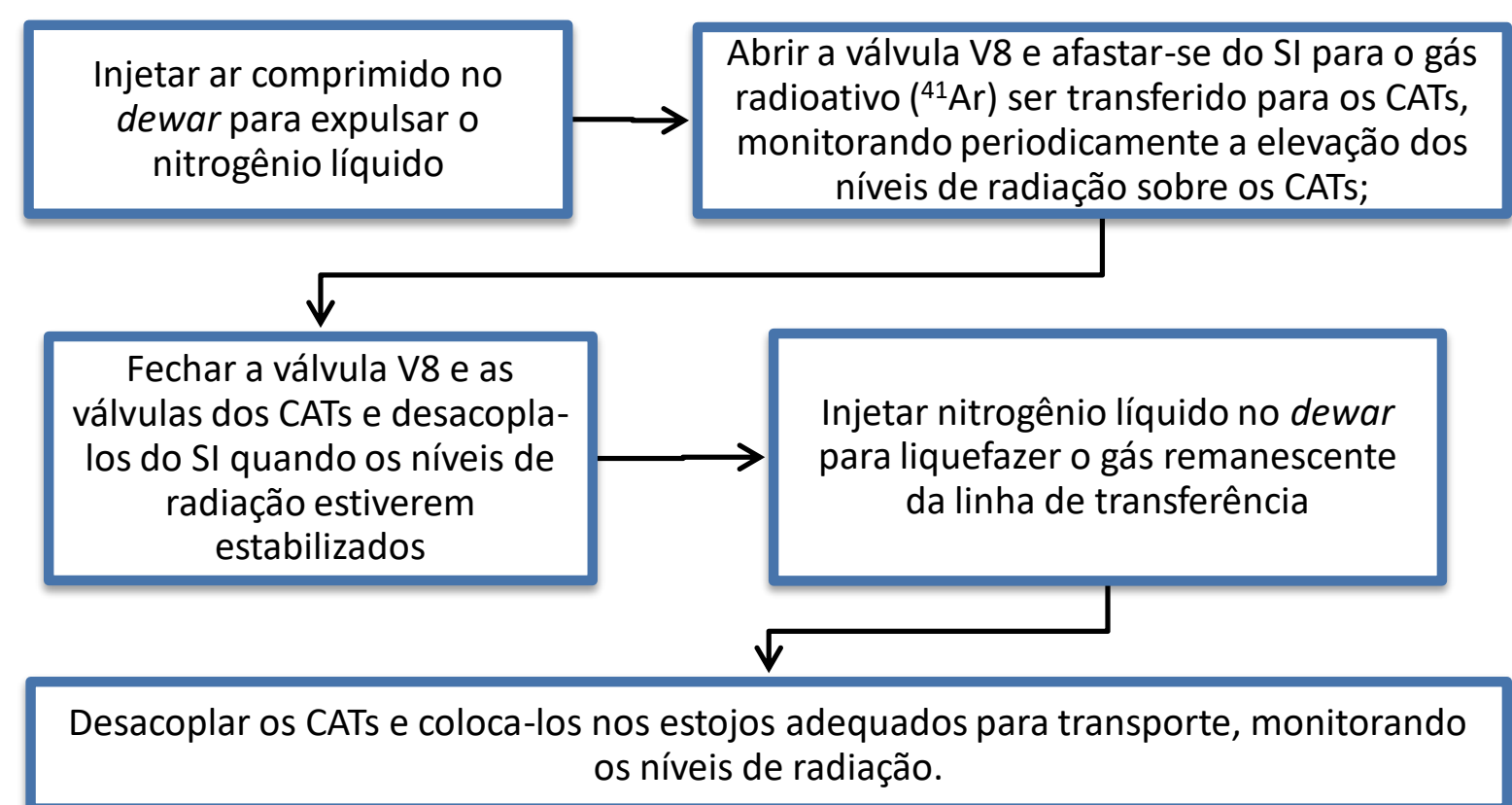

FIGURA 32 - Fluxograma da etapa 4 - Transferência do gás radioativo aos CATs

\subsection{Testes de estanqueidade e estabilidade}

De acordo com a metodologia adotada, foram utilizadas técnicas de detecção de vazamento para assegurar a estanqueidade e estabilidade do sistema de irradiação. Constatou-se que o sistema está em perfeitas condições de utilização por não ter apresentado vazamentos.

\subsubsection{Verificação de bolhas com solução formadora de espuma}

Inicialmente, por meio da pressurização com ar comprimido (7 bar), utilizou-se uma solução de água com detergente em todas as conexões e válvulas, para se verificar vazamentos por surgimento de bolhas. Resultou-se no encontro de conexões anilhadas que necessitavam ser apertadas e um engate 
rápido com vazamento, acarretando no envio para análise da empresa fabricante "Swagelok Brasil", que realizou a limpeza no sistema de vedação da peça, cessando o vazamento.

\subsubsection{Pressurização e evacuação do sistema}

A linha de transferência, assim como o cilindro de armazeamento e transporte foram evacuados e fechados por 24 horas. Posteriormente, pressurizados a 145 psi (10 bar) e fechados por 46 horas. Nas duas situações o manovacuômetro não sofreu alterações visíveis, conforme FIG. 33 e 34, respectivamente.
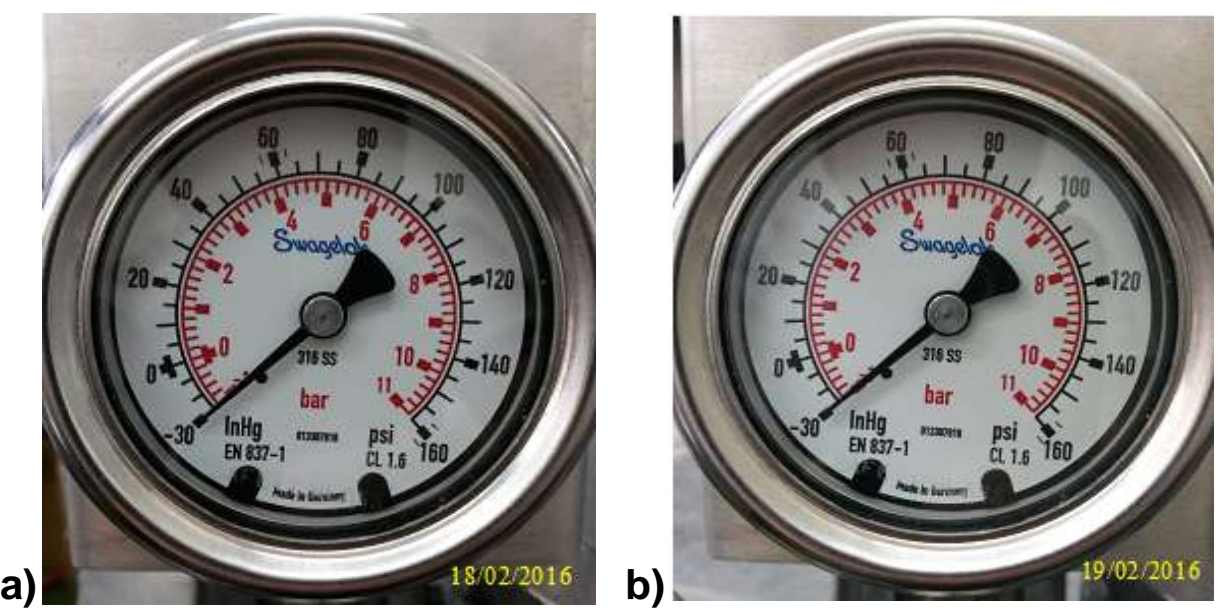

FIGURA 33 - Fotografias a) e b) do manovacuômetro instalado no sistema de irradiação (-1bar), obtidas às 10h00min dos dias 18 e 19/02/2016, respectivamente

a)

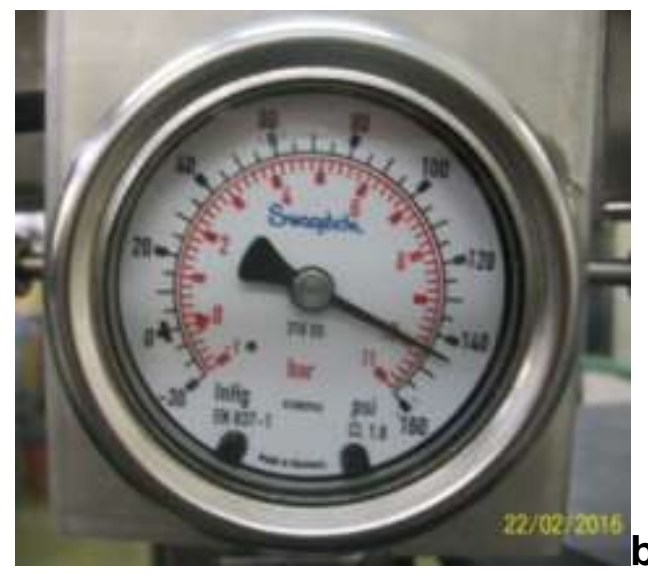

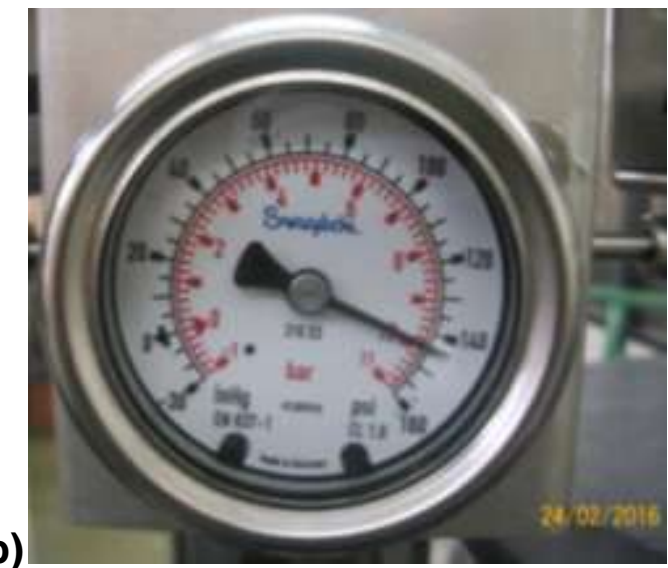

b)

FIGURA 34 - Fotografias a) e b) do manovacuômetro instalado no sistema de irradiação (10 bar), obtidas nos dias 22 às 16h47min e 24/02/2016 às 14h41min, respectivamente 
A cápsula de irradiação $(\mathrm{Cl})$, dispositivo a ser posicionado próximo ao núcleo do Reator IEA-R1 sofre elevação de temperatura nessa etapa. Avaliandose que o preenchimento inicial da cápsula com argônio $5.0\left({ }^{40} \mathrm{Ar}\right)$ ocorre com 8,5 bar para obtenção da atividade de $7,4 \times 10^{11} \mathrm{~Bq}(20 \mathrm{Ci})$, foram verificadas as possíveis elevações de pressão que a cápsula pode sofrer.

Considerando o argônio um gás ideal, a temperatura inicial de $20{ }^{\circ} \mathrm{C}$ $(293,15$ K) e a equação fundamental dos gases para transformações isovolumétricas (Equação 12) obteve-se que a pressão se eleva no máximo a 10,8 bar, se a cápsula atingir uma temperatura de $100 \stackrel{\circ}{\circ}(373,15 \mathrm{~K})$ [30].

$$
\frac{P_{1}}{T_{1}}=\frac{P_{2}}{T_{2}}
$$

Em decorrência dessa elevação de pressão realizou-se a pressurização isolada da $\mathrm{Cl}$ com uma pressão de 16 bar, aproximadamente. Mantendo-se a cápsula fechada durante 3 dias, verificou-se a inexistência de vazamentos, uma vez que o manômetro se manteve visualmente inalterado, conforme FIG. 35.

a)
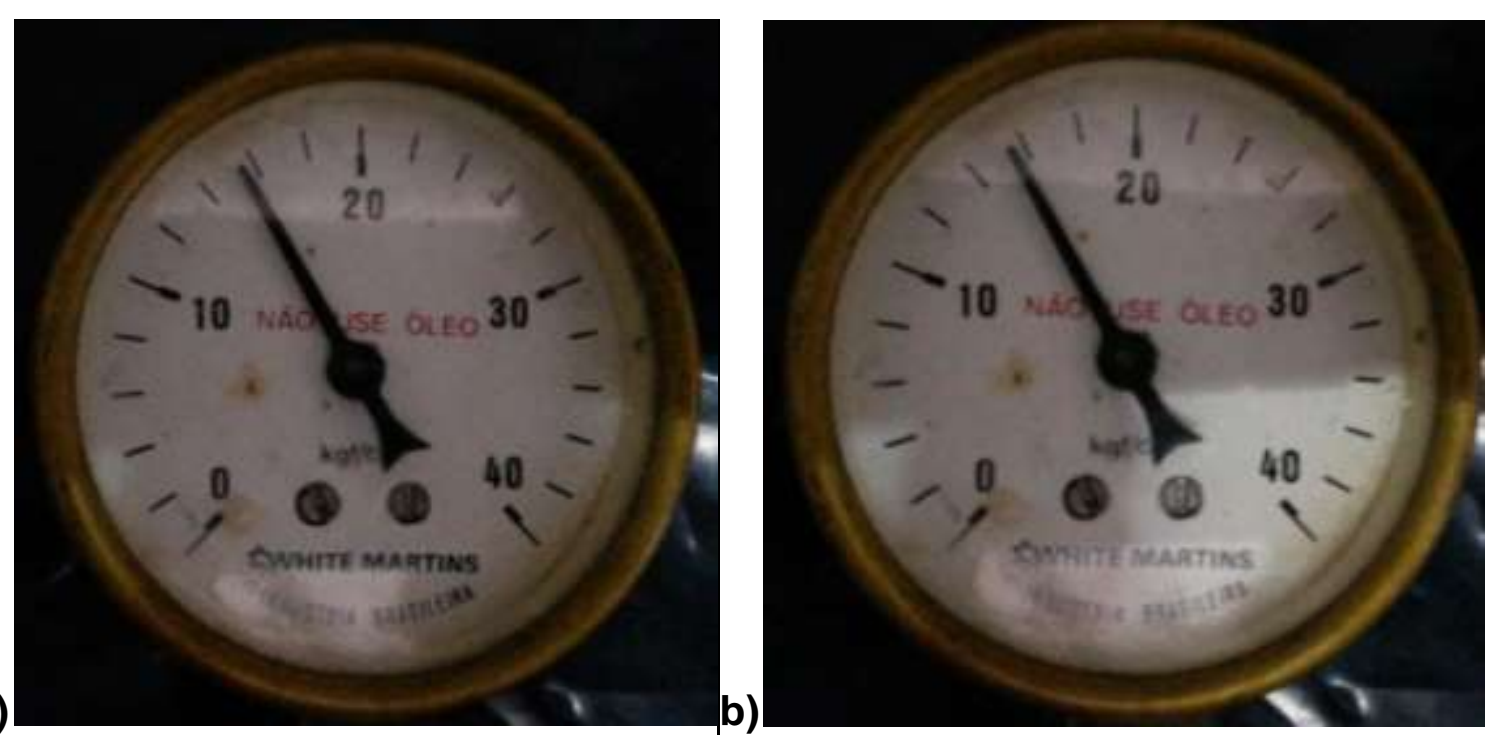

FIGURA 35 - Fotografias a) e b) do manômetro instalado na cápsula de irradiação (16 bar), obtidas às 13h00min dos dias 04 e 07/03/2016, respectivamente 


\subsubsection{Ensaio com detector de vazamento de hélio (leak detector)}

De acordo com a metodologia adotada o sistema de irradiação foi submetido ao ensaio com o equipamento leak detector SPECTRON $600 \mathrm{~T}$, o qual detecta automaticamente vazamentos por meio de uma bomba turbomolecular, acoplada ao sistema, que evacua e, consequentemente, aspira qualquer gás presente, detectando a passagem de gás hélio ao se tentar injeta-lo nas conexões e válvulas que possam apresentar vazamentos, conforme FIG. 36.

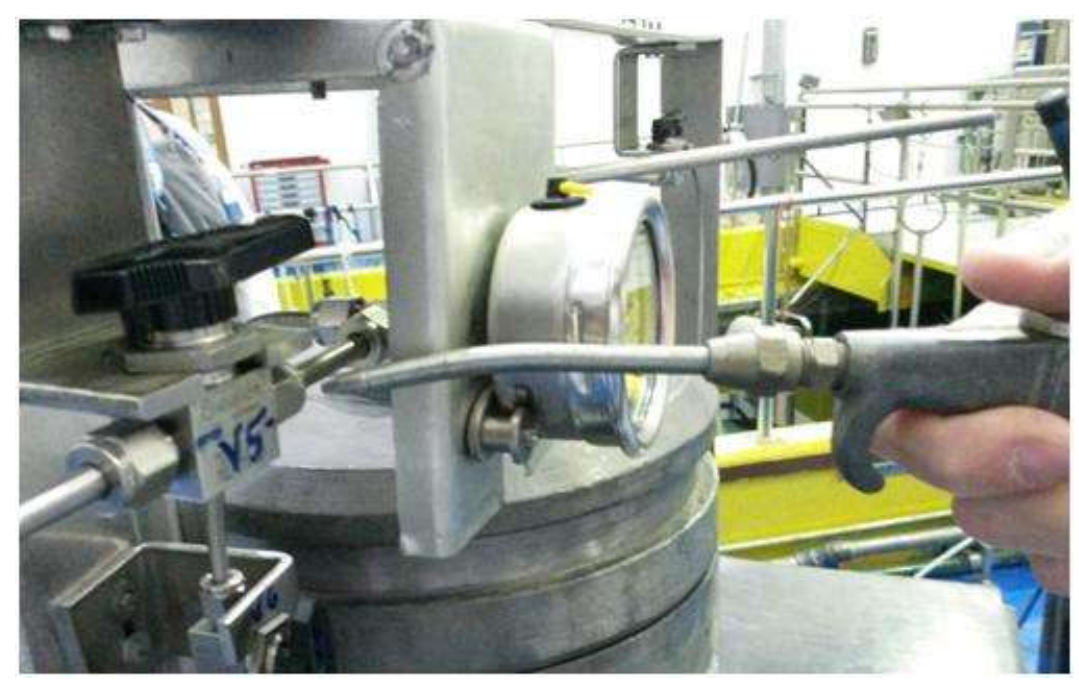

FIGURA 36 - Teste com leak detector e gás hélio injetado na válvula do SI

O ensaio foi realizado em duas etapas, inicialmente com o cilindro de armazenamento e cápsula de irradiação desacoplados do sistema, para se verificar as conexões, válvulas e engates rápidos presentes na linha de transferência. Posteriormente, realizou-se 0 teste com os dispositivos mencionados acoplados e em ambas as situações a taxa de vazamento detectada pelo SPECTRON $600 \mathrm{~T}$ variou de $1.10^{-9}$ a $5.10^{-9} \mathrm{mbar} . \mathrm{L} / \mathrm{s}\left(10^{-4}\right.$ $\mu \mathrm{Pa} . \mathrm{m}^{3} . \mathrm{s}^{-1}$ ), conforme FIG. 37, obtida durante o ensaio.

$\mathrm{Na}$ análise dos resultados obtidos, utilizou-se como parâmetro a norma ISO 9978 - Sealed radioactive sources - Leakage test methods (1992) que estabelece para fontes seladas de conteúdo lixiviável ou gasoso, o valor limite para a taxa de vazamento de hélio de $10^{-2} \mu \mathrm{Pa} \cdot \mathrm{m}^{3} \cdot \mathrm{s}^{-1}$ 


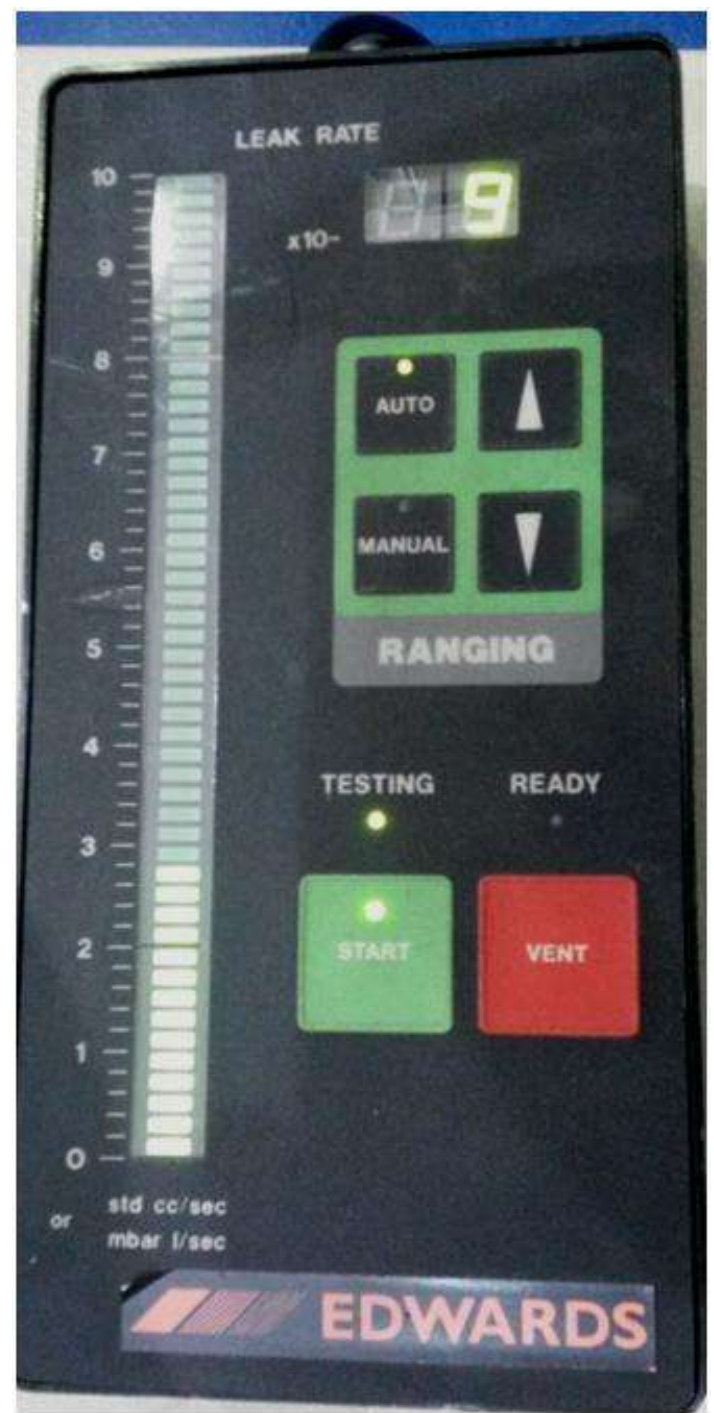

FIGURA 37 - Taxa de vazamento detectada no ensaio com equipamento leak detector SPECTRON 600 T $\left(10^{-9}\right.$ mbar.L/s)

\subsection{Teste do sistema sem material radioativo}

Após a conclusão dos testes de estanqueidade e aprovação do procedimento operacional pelo Comitê de Segurança Interno (CSI) do Reator IEAR1, o sistema de irradiação foi testado, seguindo o procedimento operacional estabelecido sem a irradiação da cápsula de alumínio com nêutrons, para se averiguar a transferência e liquefação do gás.

$\mathrm{Na}$ realização deste teste com gás argônio 5.0 e por meio do acompanhamento do manovacuômetro, constatou-se que o sistema não conseguia liquefazer o gás na transferência da $\mathrm{Cl}$ para o dewar, em decorrência da elevada troca de calor entre a blindagem em chumbo e o dewar, que evaporava rapidamente o nitrogênio líquido. 
Como solução ao problema, o revestimento do dewar (FIG. 38) foi substituído por politetrafluoretileno (PTFE), em virtude da baixa condutividade térmica desse material, evitando-se a evaporação do nitrogênio líquido.

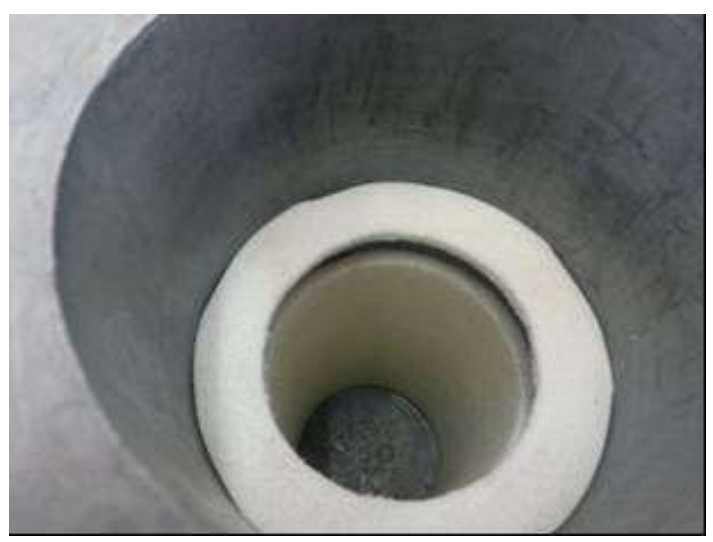

FIGURA 38 - Revestimento do dewar em PTFE, no interior da blindagem

\subsection{Irradiação para teste do sistema}

Uma irradiação para teste do sistema foi realizada com argônio natural $\left({ }^{40} \mathrm{Ar}\right)$ e obtenção do radioisótopo gasoso ${ }^{41} \mathrm{Ar}$, por meio da irradiação com nêutrons no Reator IEA-R1. A cápsula de irradiação foi posicionada na posição 34 $A$, sendo assim submetida ao fluxo de nêutrons térmicos médio de $4,71 \times 10^{13}$ $\mathrm{ncm}^{-2} \mathrm{~s}^{-1}$, obtido por meio dos diferentes fluxos ao longo das prateleiras da posição, conforme TAB. 6.

TABELA 6 - Variação do fluxo de nêutrons térmicos ao longo da posição 34 A do Reator IEA-R1

\begin{tabular}{cc}
\hline Prateleira & $\begin{array}{c}\text { Fluxo térmico } \\
\left(\mathbf{1 0 ^ { 1 3 }} \mathbf{n} \cdot \mathbf{c m}^{-2} \cdot \mathbf{s}^{-1}\right)\end{array}$ \\
\hline $\mathbf{1}$ & 1,16 \\
$\mathbf{2}$ & 2,57 \\
$\mathbf{3}$ & 3,99 \\
$\mathbf{4}$ & 5,40 \\
$\mathbf{5}$ & 6,81 \\
$\mathbf{6}$ & 6,69 \\
$\mathbf{7}$ & 6,69 \\
$\mathbf{8}$ & 4,37 \\
\hline
\end{tabular}

Fonte: Centro do Reator de Pesquisas (CRPq) e Reator IEA-R1 
Essa irradiação teve como objetivo a obtenção de $1,0 \times 10^{11} \mathrm{~Bq}(2,9 \mathrm{Ci})$ em atividade, aproximadamente, estimada por meio das Equações 2, 4 e 7 e equação fundamental dos gases (Equação 13), na qual "P" corresponde a pressão, "V" ao volume, "R" a constante universal dos gases (0,082 atm.L/mol.K) e "T" a temperatura absoluta do gás. Os dados referentes a irradiação são apresentados na TAB. 7 [30].

$$
P V=\frac{m}{M} R T
$$

TABELA 7 - Dados para estimativa da atividade de ${ }^{41} \mathrm{Ar}$ na primeira irradiação com o sistema de irradiação

\begin{tabular}{cc}
\hline Isótopo utilizado & ${ }^{40} \mathrm{Ar}$ \\
\hline Pressão na Cl & $1,5 \mathrm{bar}$ \\
Massa estimada & $0,37 \mathrm{~g}$ \\
\hline Tempo de irradiação & $4,0 \mathrm{~h}$ \\
\hline Tempo de decaimento & $0,6 \mathrm{~h}(36 \mathrm{~min})$ \\
\hline Posição de irradiação & $34 \mathrm{~A}$ \\
\hline Fluxo térmico médio & $4,71 \times 10^{13} \mathrm{n} \mathrm{cm}^{-2} \mathrm{~s}^{-1}$ \\
\hline Atividade estimada & $1,07 \times 10^{11} \mathrm{~Bq}(2,9 \mathrm{Ci})$ \\
\hline
\end{tabular}

O gás obtido após a irradiação com nêutrons $\left({ }^{41} \mathrm{Ar}\right)$ foi armazenado em apenas um CAT. Verificou-se o comportamento do sistema de irradiação na operação e as doses absorvidas nos dosímetros de alanina dispostos ao longo do sistema. As taxas de exposição na parede da blindagem ao concentrar o gás radioativo liquefeito e no CAT, após a transferência do ${ }^{41} \mathrm{Ar}$, foram determinadas por meio medidor de radiação portátil Teletector Probe 6150 AD-t/H.

Ao todo, dez dosímetros de alanina (FIG. 39) foram dispostos ao longo do sistema de irradiação, conforme FIG. 40, para se constatar a distribuição de dose em diversos pontos do sistema, após a realização do procedimento operacional. 


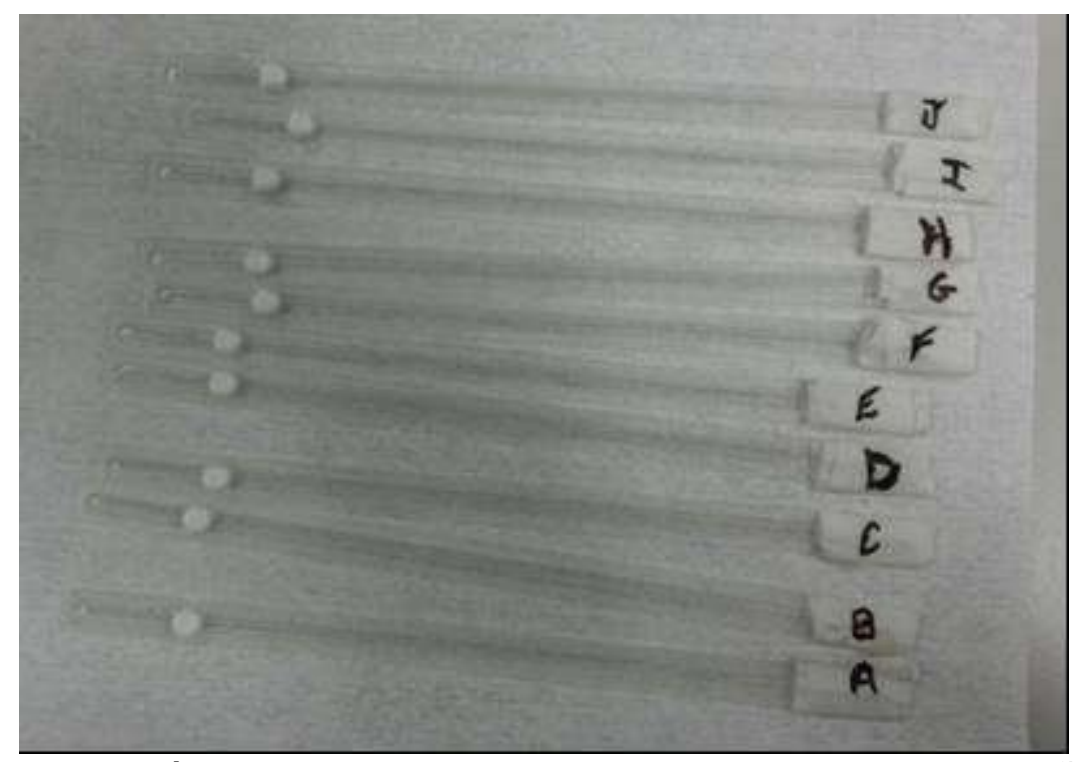

FIGURA 39 - Dosímetros de alanina utilizados na primeira obtenção do ${ }^{41} \mathrm{Ar}$

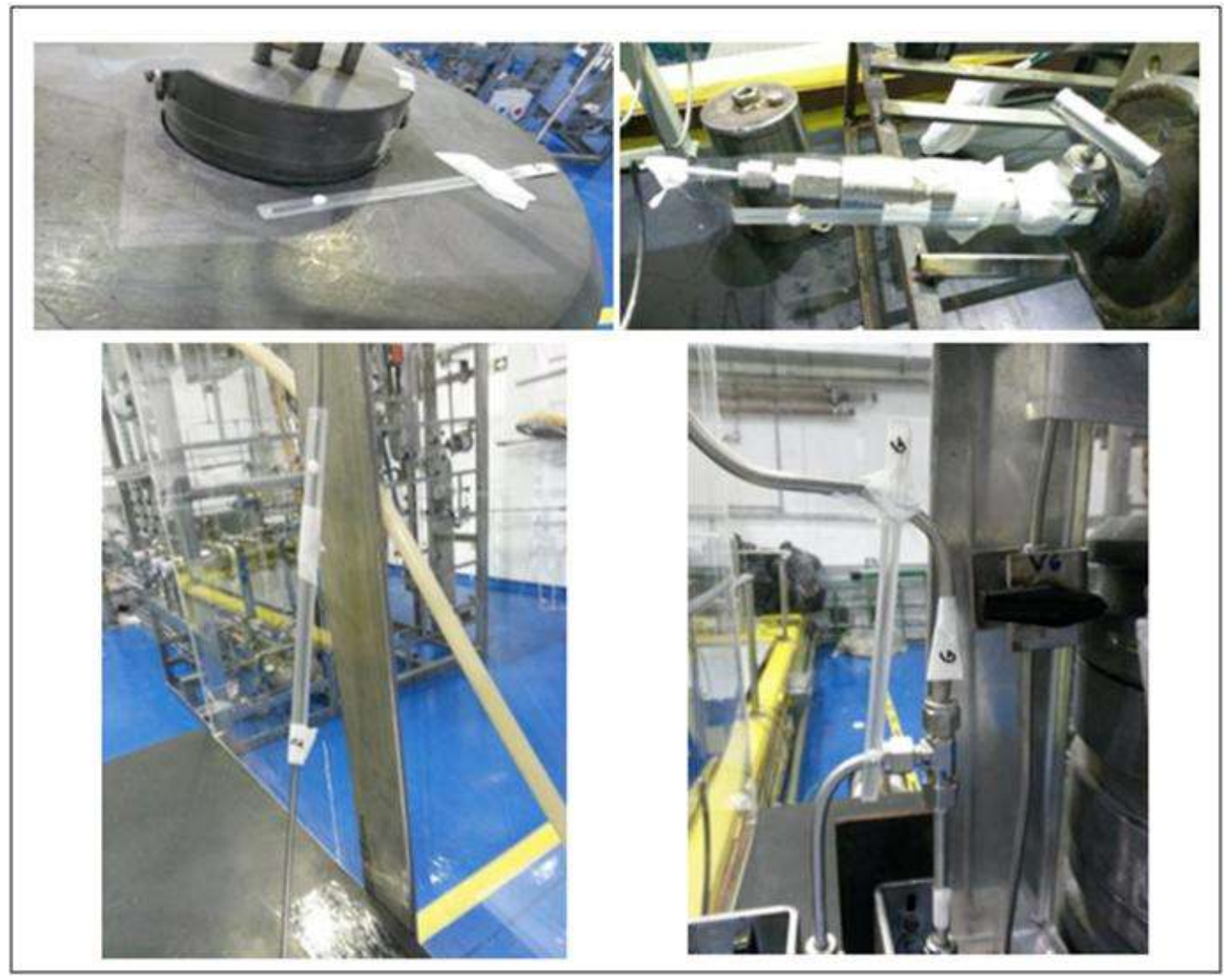

FIGURA 40 - Dosímetros distribuídos ao longo da linha de transferência do SI

Por meio de uma curva de calibração para a energia de emissão gama do ${ }^{41} \operatorname{Ar}(1,29 \mathrm{MeV})$ realizou-se a análise dos dosímetros de alanina, na qual nove deles não atingiram o limite de detecção (5 Gy). Apenas um, localizado entre os tubos capilares que abastecem os CATs (FIG. 41), indicou uma dose absorvida 
indesejada de 5 Gy, em decorrência da concentração do gás radioativo $\left({ }^{41} \mathrm{Ar}\right)$ na linha de transferência ao CAT.

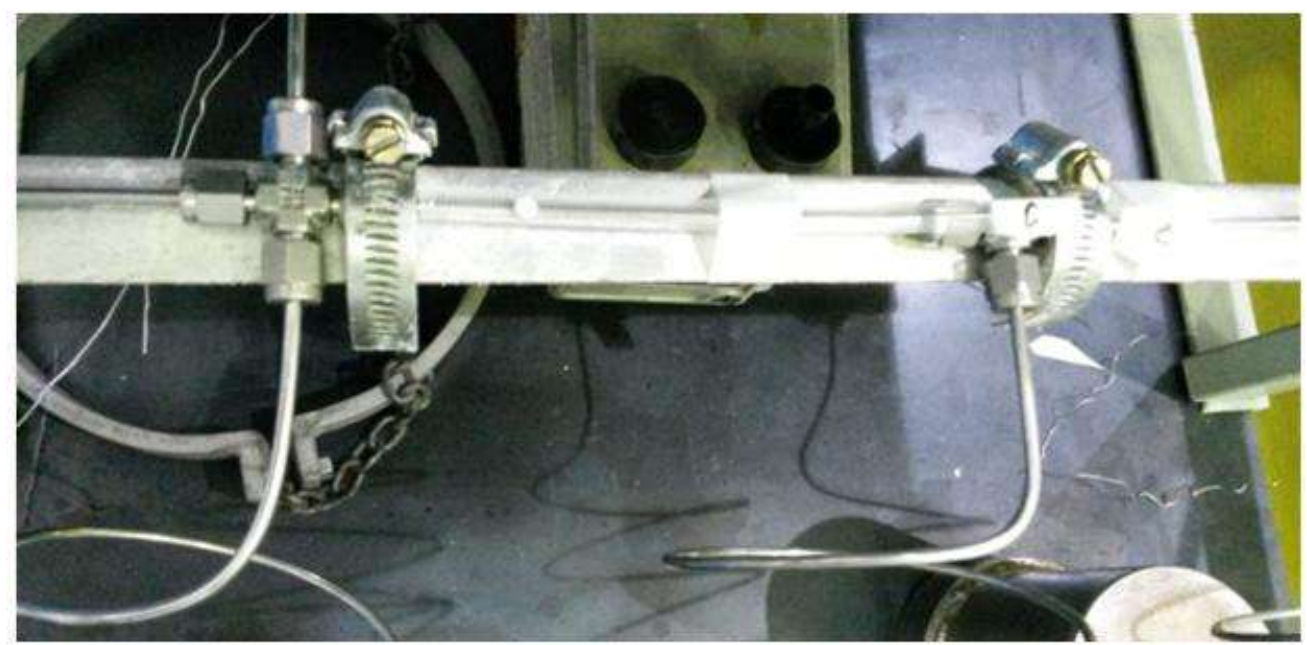

FIGURA 41 - Dosímetro de alanina na linha de transferência ao CAT, no qual se registrou a maior dose absorvida (5 Gy), na obtenção do ${ }^{41} \mathrm{Ar}$ no SI

$\mathrm{E}$, em relação às taxas de exposição obtiveram-se $10 \mathrm{mSv} / \mathrm{h}$ na parede da blindagem do dewar ao concentrar o gás radioativo liquefeito e $25 \mathrm{mSv} / \mathrm{h}$ na parede do CAT, após a transferência do ${ }^{41} \mathrm{Ar}$.

\subsection{Estimativa para obtenção de atividades superiores}

Da mesma maneira que a irradiação realizada para teste do $\mathrm{SI}$, estimaram-se os valores para obtenção da atividade máxima desejada de $7,4 \times 10^{11} \mathrm{~Bq}(20 \mathrm{Ci})$, apresentados na TAB. 8, utilizando-se cinco CATs.

TABELA 8 - Valores estimados para obtenção da atividade máxima desejada no SI

\begin{tabular}{cc}
\hline Isótopo utilizado & ${ }^{40} \mathrm{Ar}$ \\
\hline Pressão na Cl & $8,5 \mathrm{bar}$ \\
\hline Massa estimada & $2,09 \mathrm{~g}$ \\
\hline Tempo de irradiação & $7,0 \mathrm{~h}$ \\
\hline Tempo de decaimento & $0,6 \mathrm{~h}(36 \mathrm{~min})$ \\
\hline Posição de irradiação & $34 \mathrm{~A}$ \\
\hline Fluxo térmico médio & $4,71 \times 10^{13} \mathrm{n} \mathrm{cm}^{-2} \mathrm{~s}^{-1}$ \\
\hline Atividade estimada & $7,25 \times 10^{11} \mathrm{~Bq}(19,59 \mathrm{Ci})$ \\
\hline
\end{tabular}




\section{CONCLUSÃo}

O objetivo de desenvolver o sistema de irradiação de acordo com o projeto apresentado foi alcançado com êxito.

Em relação ao procedimento operacional, estanqueidade e estabilidade do sistema de irradiação (SI), conclui-se que:

- O SI está apto para ser utilizado de acordo com o procedimento operacional proposto, pois na verificação de estanqueidade $\mathrm{e}$ estabilidade (testes de formação de bolhas, pressurização, evacuação e com leak detector) nenhum componente apresentou problema de funcionamento;

- O SI encontra-se estanque, pois a taxa de vazamento obtida no teste com equipamento leak detector $\left(10^{-4} \mu \mathrm{Pa} . \mathrm{m}^{3} . \mathrm{s}^{-1}\right)$ é 100 vezes inferior ao limite estipulado pela norma ISO 9978 - Sealed radioactive sources Leakage test methods (1992). A ISO 9978 estabelece para fontes seladas de conteúdo lixiviável ou gasoso o valor limite para a taxa de vazamento de hélio de $10^{-2} \mu \mathrm{Pa} \cdot \mathrm{m}^{3} \cdot \mathrm{s}^{-1}$, ao se considerar o sistema de irradiação preenchido com gás radioativo $\left({ }^{41} \mathrm{Ar}\right)$, uma fonte selada [31,32]; e

- A estanqueidade do SI foi comprovada na primeira obtenção de ${ }^{41} \mathrm{Ar}$, uma vez que não houve detecção de gás radioativo pelos sensores dispostos na tubulação de exaustão do Reator IEA-R1. 
Com a primeira irradiação realizada na obtenção de ${ }^{41} \mathrm{Ar}$ no SI, concluise que:

- Houve retenção de ${ }^{41} \mathrm{Ar}$ na linha de transferência (entre a blindagem e o CAT), pois o dosímetro de alanina posicionado nesta região registrou a maior dose absorvida (5 Gy), tornando necessária uma modificação no procedimento operacional; e

- Em termos de proteção radiológica, como as taxas de exposição obtidas na parede da blindagem ao concentrar o gás radioativo liquefeito e na parede do CAT foram respectivamente, 10 e $25 \mathrm{mSv} / \mathrm{h}$, torna-se necessário que os acionamentos das válvulas realizadas pelo operador sejam rápidas e que seja mantida distância sempre que possível na transferência do ${ }^{41} \mathrm{Ar}$ no SI.

\subsection{Sugestões para melhoria do Sistema de Irradiação}

De acordo com os resultados e conclusões deste trabalho, sugere-se:

- Substituição da válvula presente na cápsula de irradiação em alumínio "V4" (FIG. 23) por dispositivo ou válvula de acionamento à distância, para minimizar a dose ao operador;

- Modificação do procedimento operacional - realização de arraste do gás radioativo remanescente na linha de transferência com gás hélio (por ser um gás inerte e ter massa atômica menor);

- Fixação de tijolos de chumbo ao lado da linha de transferência da parte inferior do carro de carga (FIG. 8), para minimizar a dose ao operador.

- Solicitar ao consumidor final do gás radioativo CATs com blindagens mais espessas para permitir a produção, manuseio e transporte após a transferência. 


\title{
ANEXO A - Trabalho completo publicado no WCIPT8 - 8th World Congress On Industrial Process Tomography
}

WCIPT $8-8^{\text {th }}$ WORLD CONGRESS ON INDUSTRIAL PROCESS TOMOGRAPHY Iguassu Falls, PR, Brazil, September 26 to 29, 2016 ISIPT - The International Society for Industrial Process Tomography

\section{DEVELOPMENT OF AN IRRADIATION SYSTEM FOR RADIOISOTOPE PRODUCTION APPLIED TO INDUSTRIAL PROCESS TOMOGRAPHY}

\author{
Nelson X. Cardozo*, Nelson M. Omi, Jose J. Ambiel, Anselmo Feher, Celia M. \\ Napolitano, Samir L. Somessari, Wilson A. Parejo Calvo \\ Nuclear and Energy Research Institute (IPEN-CNEN/SP) \\ National Nuclear Energy Commission \\ Radiation Technology Centre
}

Av. Prof. Lineu Prestes, 2242 - 05508-000 - São Paulo, SP, Brazil

*nxcardozo@ipen.br; wapcalvo@ipen.br

\begin{abstract}
Among the various applications of radioisotopes, the use of radiotracers is considered the most important in diagnosing operation and troubleshooting of industrial process plants in chemical and petrochemical companies. The radiotracers are used in analytical procedures to obtain qualitative and quantitative data systems, in physical and physicochemical studies transfers. In the production of gaseous radioisotopes used as tracers in industrial process measurements, argon-41 $\left({ }^{41} \mathrm{Ar}\right)$ and krypton-79 $\left({ }^{79} \mathrm{Kr}\right)$ have low reactivity with other chemical elements. ${ }^{41} \mathrm{Ar}$ is a transmitter range with high-energy $(1.29 \mathrm{MeV})$ and a high percentage of this energy transformation $(99.1 \%)$, resulting in relatively small quantities required in relation to the other, for an efficient detection, even in large thicknesses components. Nowadays, the production of gaseous radioisotopes in nuclear research reactors is performed in small quantities (batches), through quartz ampoules containing natural gas ${ }^{40} \mathrm{Ar}$ or ${ }^{78} \mathrm{Kr}$. In this sense, the aim of this study is to develop an irradiation system for gaseous radioisotope production in continuous scale, applied in industrial applications of emission tomography and flow measurement. The irradiation system may produce ${ }^{41} \mathrm{Ar}$ with activity of $7.4 \times 10^{11} \mathrm{~Bq}$ (20Ci) per irradiation cycle, through the Reactor IEA-R1 with $4.5 \mathrm{MW}$ and average thermal neutron flux of $4.71 \times 10^{13} \mathrm{ncm}^{-2} \mathrm{~s}^{-1}$ to meet an existing demand in NDT and inspections companies, and even needed by the Radiation Technology Centre, at IPEN/CNEN-SP. The irradiation system consists of an aluminium irradiation capsule, transfer lines, needle valves, stripy connections, quick connectors, manometer, vacuum system, dewar, lead shielding, storage and transport cylinders, among other components. The irradiation system was approved in the leakage and stability tests (bubble test, pressurization, evacuation and with leak detector equipment SPECTRON 600 T). In the experimental production, alanine dosimeters were distributed into various components of the irradiation system, obtaining $1.07 \times 10^{11} \mathrm{~Bq}(2.9 \mathrm{Ci})$ of ${ }^{41} \mathrm{Ar}$. In addition, exposure rates were determined in the lead shielding wall, in which the liquefied radioactive gas was concentrated, and in the storage and transport cylinders after ${ }^{41} \mathrm{Ar}$ was transferred, by the portable radiation meter Teletector ${ }^{\circledR}$ Probe 6150 $A D-t / H$.
\end{abstract}

Keywords : Industrial process measurement, emission tomography, radioisotope production, argon-41, irradiation system. 


\section{INTRODUCTION}

Among the various industrial applications of radioisotopes, such as the use of fixed or incorporated sources of ionizing radiation on gammagraphy, level gauges for liquids and density or thickness measurements, the use of radionuclides as tracers (radiotracers) is considered one of the most important applications. A tracer consists of an injected material in a system to determine the actual conditions of the system in relation to the passage and location of fluid, by detecting this material at different points. There are also non isotopic chemical tracers. Fluorescent dyes and radiotracers are widely used for petrochemical industries, possessing properties associated with the emission of radiation that facilitate the analysis of complex systems, difficult to access, common in such industries (Bradford, 1953; IAEA, 1990; IAEA, 2009).

Argon-41 $\left({ }^{41} \mathrm{Ar}\right)$ and kripton-79 $\left({ }^{79} \mathrm{Kr}\right)$ stand out in the production of gaseous radioisotopes used as industrial process tracers, having very low reactivity with other elements. The ${ }^{41} \mathrm{Ar}$ is a high energy gamma source (1.2MeV), with half-life of 110 minutes and high yield in the highest energy photon. These properties allow the use of relatively small portions, compared to other radioisotopes, to detect its presence in high width walls $\left(5\right.$ to $6 \mathrm{~cm}$ ) setups. On the other hand, ${ }^{79} \mathrm{Kr}_{\mathrm{r}}$, with lower energy gamma $(0.51 \mathrm{MeV})$ but with a half-life of 35 hours, is affordable to be used in locals that are far from the isotope production center (IAEA, 2009; Chariton, 1986; Okuno and Yoshimura, 2010).

\subsection{Background}

The production of small quantities of gaseous radioisotopes in nuclear research reactors is carried out by quartz ampoules. Fig. 1 shows the sequential steps of India's first production neutron activation, in 2006 , of ${ }^{41} \mathrm{Ar}$ and ${ }^{79} \mathrm{Kr}$, intending to normalize the production and the delivery of radioisotopes for industrial use (Yelgaonkar et al, 2007; Quang et al, 2007).

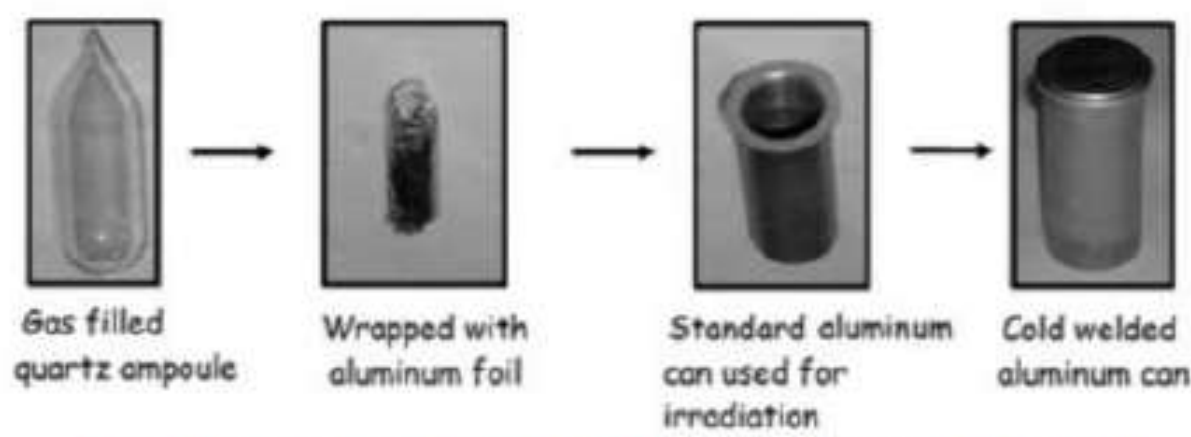

Figure 1. Gaseous radioisotope production in quartz ampoules (Yelgaonkar et al, 2007).

For higher quantity productions, irradiation setups consisting of sample cylinders, valves and transfer lines to lead shielded storage cylinders, which are taken to the radiotracer use site after the radioactive gas loading.

This second way of production was adopted for few times in the IEA-R1 nuclear research reactor, located in IPEN-CNEN/SP, by argon-40 ( $\left.{ }^{40} \mathrm{Ar}\right)$ irradiation, transfer and transport. The setup was made in the reactor's water pool room always when the operation was done to produce the ${ }^{41} \mathrm{Ar}$ radiotracer to attend the enterprises increasing demand of non destructive tests and inspections. Due to leakage issues and high exposition to the operators, this type of production was interrupted. Thus, the development of the gaseous radioisotope production irradiation system originated the topic of this work. 


\subsection{Objectives}

a) To develop an irradiation system with the capacity of a permanent production of gaseous radioisotopes to be used as radiotracers, in batches up to $7.4 \times 10^{11} \mathrm{~Bq}(20 \mathrm{Ci})$ using a water pool type nuclear research reactor (Material Testing Reactor - MTR), like the IEA-R1 nuclear reactor, to meet the demand for NDT and inspections for enterprises and the Radioisotope Technology Application group of the Radiation Technology Centre (CTR), at IPEN-CNEN/SP;

b) To produce ${ }^{41} \mathrm{Ar}$ or ${ }^{79} \mathrm{Kr}$ with a lower activity, to evaluate the radioprotection and production of the developed system; and

c) To allow the gaseous radiotracer production system for partner enterprises of NDT and to follow the equipment use and its performance in chemical and petrochemical industries.

\section{MATERIAL AND METHODS}

\subsection{System components}

The following material and equipment are used to develop and construct the irradiation system at the CTR and Research Reactor Centre (CRPq), both in IPEN-CNEN/SP:

a) Aluminum irradiation capsule, with $150 \mathrm{~cm}^{3}$ internal volume to be positioned in the IEA-R1 nuclear reactor core, connected to a long tube. The rigid tube allows the capsule handling, inserting and removing it from the reactor core. The process of loading and unloading the gas to be irradiated to produce the gaseous radiotracer, shown in Fig. 2;

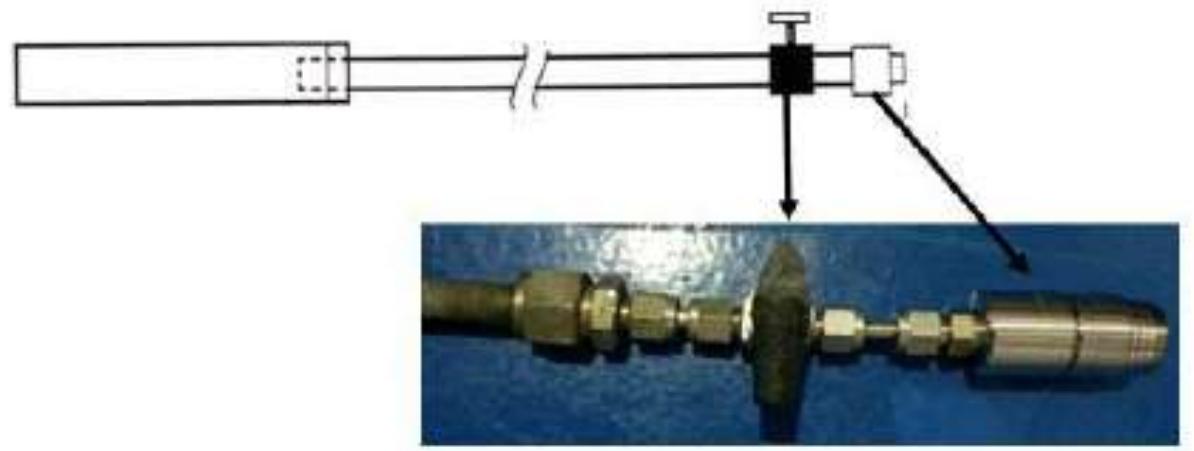

Figure 2 - Irradiation capsule with long tube (schematic) and gas load/unload control valve (in detail).

b) Solid rubber wheel platform type car;

c) Argon gas cylinder $5.0(99,999 \%)$;

d) AISI 304 stainless steel transfer line with $6.35 \mathrm{~mm}\left(1 / 4^{n}\right)$ diameter on the superior level (Fig. 3 ) and $3.175 \mathrm{~mm}\left(1 / 8^{*}\right)$ on the inferior level (Fig. 4); 


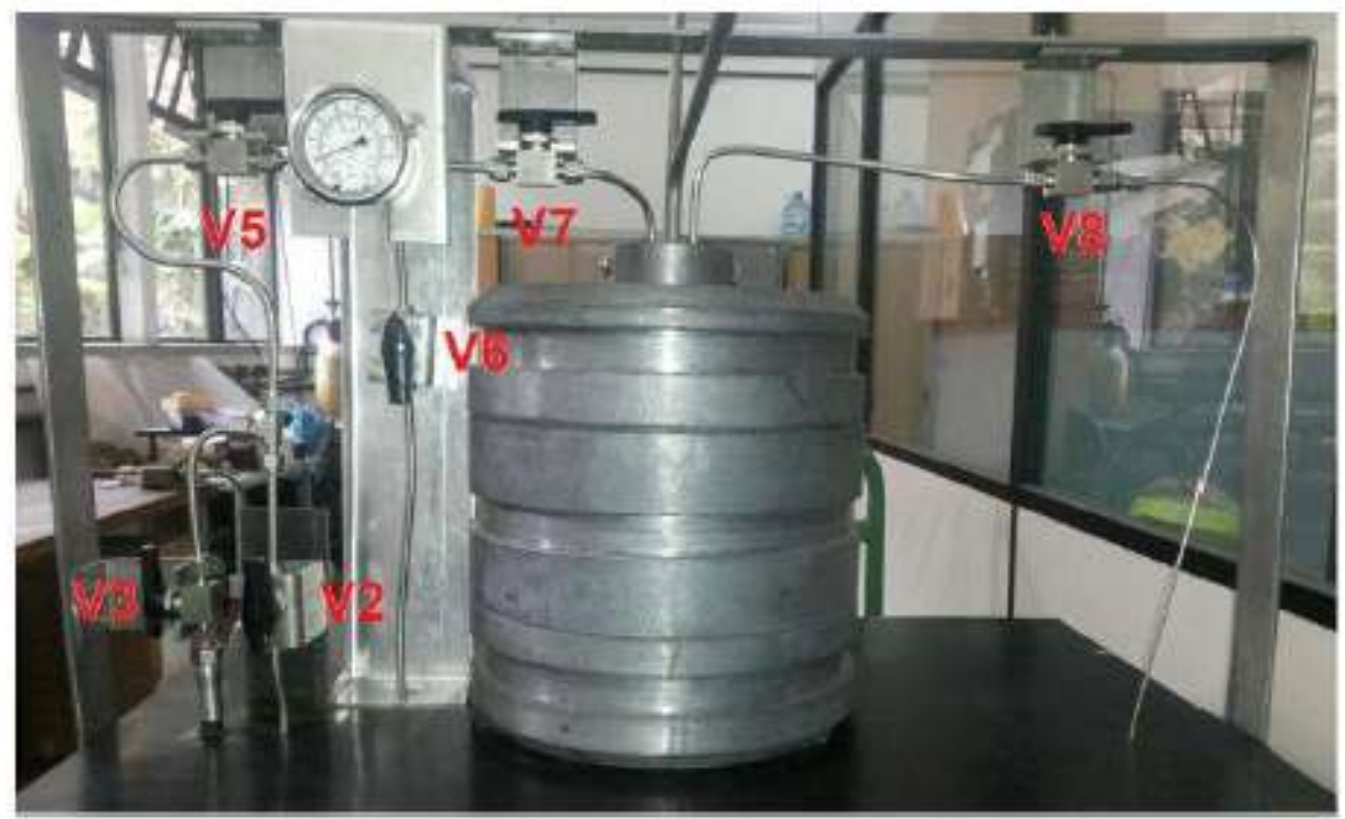

Figure 3. AISI 304 stainless steel tubing with $6.35 \mathrm{~mm}\left(1 / 4^{\prime \prime}\right)$ inner diameter (superior level) and needle valves (V2-V8).

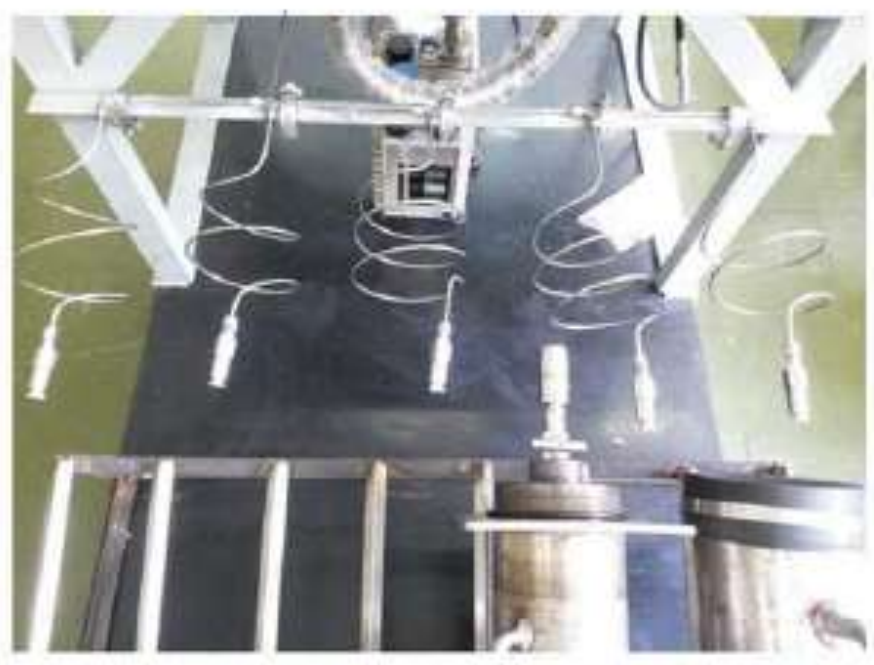

Figure 4. AlSI 304 stainless steel tubing with $3.175 \mathrm{~mm}\left(1 / 8^{-}\right)$inner diameter (inferior level).

e) Needle valves, ringed connection, fast lock connectors, manovacuometer and AISI 304 stainless steel tubing for the radioactive gas transfer line setup (Fig. 5);
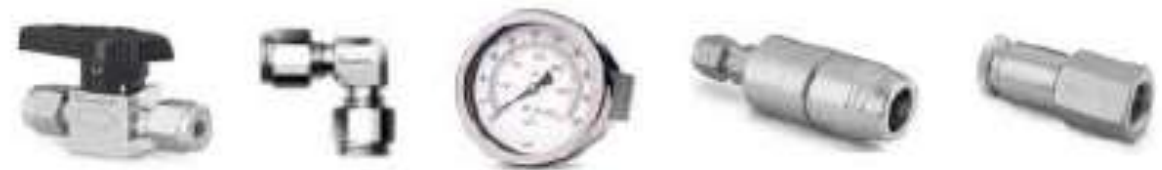

Figure 5. Needle valves, ringed connection, fast lock connectors, manovacuometer and AISI 304 stainless steel tubing for the radioactive gas transfer line setup.

f) Liquid nitrogen based freezing system (dewar) for gas liquefaction (Fig. 6); 


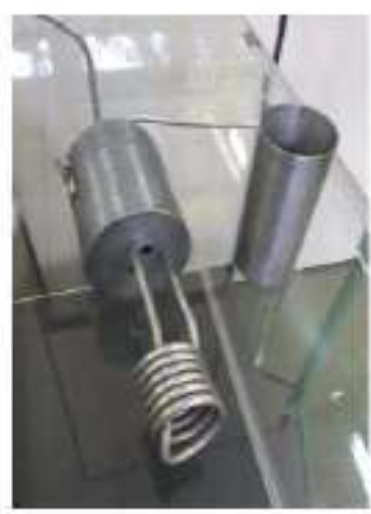

Figure 6. Liquid nitrogen based freezing system for gas liquefaction

g) Dewar with $11 \mathrm{~cm}$ thick walls lead shielding for the liquefaction (Fig. 7) (National Institute of Standards and Technology, 2016);

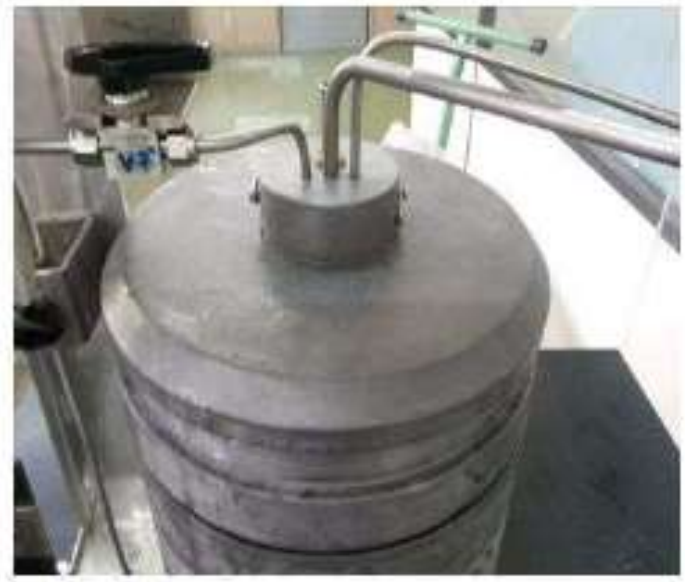

Figure 7. Lead shielding for the liquefaction dewar.

h) Acrylic box to isolate the transfer lines with air exit to be connected with the IEA-R1 nuclear reactor exhaust system (Fig. 8);

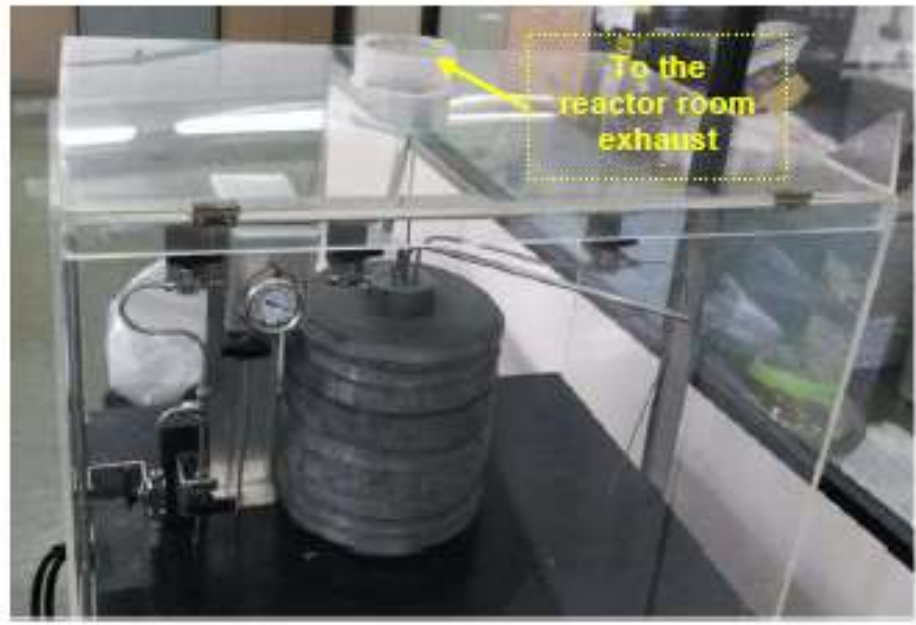

Figure 8. Acrylic box with inner air exit to the IEA-R1 nuclear reactor exhaust system. 
i) Vacuum system with the mechanical vacuum pump; and

j) Cylinder for storage and transport of the gaseous radiotracers $\left({ }^{41} \mathrm{Ar}\right.$ or ${ }^{79} \mathrm{Kr}$ ) in AISI 304 stainless steel, with $5 \mathrm{~cm}$ thick lead jackets coupled to needle valves and fast lock connections on both sides, and with $20 \mathrm{~cm}^{3}$ of inner volume (Fig. 9).

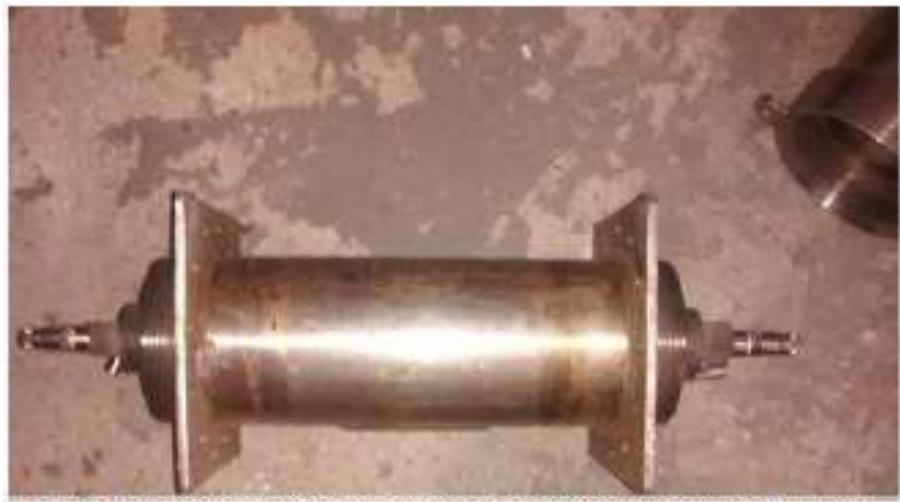

Figure 9. Cylinder for storage and transport of the gaseous radiotracers.

\subsection{Methodology}

The irradiation system was designed and mounted in the platform type cargo car.

To assure the tightness of the system against radioactive gas leakage, and improve the overall radioprotection, three leak test proceedings were performed:

a) Foam former solution bubble testing:

b) Pressure tracking on the pressurized and evacuated system; and

c) Helium leak detection procedure.

For the gaseous radioisotope production, the neutron activation technique was used, placing the irradiation ampoule inside the IEA-R1 reactor water pool (Fig. 10). The ampoule is placed on a known thermal neutron flux. The nuclear reaction described in Equation 1 occurs with a neutron capture and a prompt gamma is released, then, a radioisotope is formed (Kaplan, 1966).

$$
{ }_{Z} X^{A}+{ }_{0} n^{1} \longrightarrow\left[{ }_{2} X^{A+1}\right] \longrightarrow\left({ }_{Z} X^{A+1}\right) *+\gamma_{p r o m p t}
$$




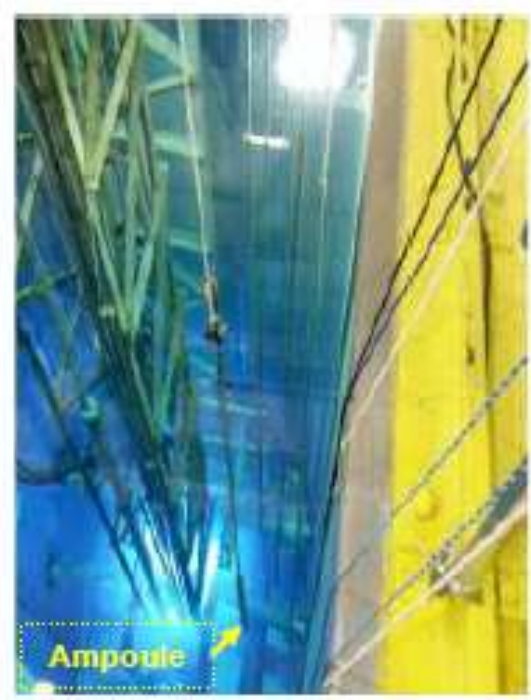

Figure 10. IEA-R1 nuclear reactor water pool and the ampoule inserted.

\subsection{Experimental sequence}

The development of the gaseous radioisotope irradiation system used the following steps:

a) Irradiation system design with gas transport system dimensioning, calculations of the necessary radiation shielding and system parts specifications;

b) System parts production and device mounting on the platform type cargo car;

c) Operational proceedings determination;

d) Performance, stability and tightness tests;

e) Irradiation system technical and operational specifications is submitted to the Internal Safety Committee of the IEA-R1 nuclear reactor; and

f) Thermal Neutron flux exposure to get a $1.0 \times 10^{11} \mathrm{~Bq}(2.9 \mathrm{Ci})$ of ${ }^{40} \mathrm{Ar}$ gas to check the system performance before starting the production of batches with up to $740 \mathrm{GBq}(20 \mathrm{Ci})$ in industrial scale.

\section{RESULTS}

\subsection{Irradiation system design and construction}

The irradiation system was designed to allow the loading, neutron flux exposition, unloading of the gas on an irradiation capsule (IC) located near the nuclear reactor core and transferring it to storage and transport cylinders (STC). It uses the liquid nitrogen frozen gas liquefaction, vaporization with heating to normal room temperature and valves dealing to conduct the gas to the STCs.

Considering movement in the IEA-R1 reactor's water pool room, most of the system is mounted in the cargo car with the parts described. There is, also, an acrylic box intended to isolate eventual gas leaks from the room and take the air inside the box to the reactor's exhaust system.

Fig. 11 shows the conception design of the outside pool part, already coupled to the STCs and the argon gas cylinder $5.0(99,999 \%)$. 


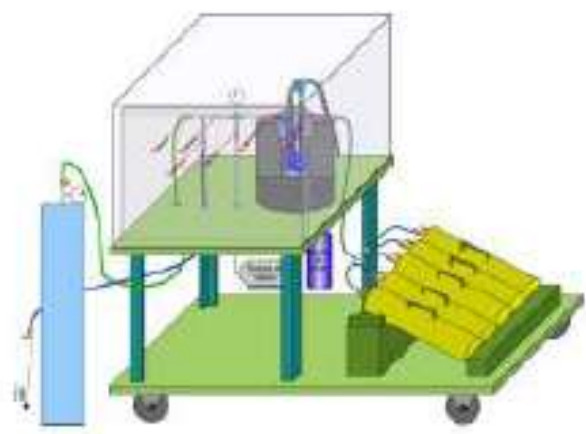

Figure 11 - Industrial processes applied to gaseous radioisotope production irradiation system.

Since the material and parts acquisition, the acrylic box mounting and the manufacturing of the lead shielding, the system was mounted in the cargo car. The complete system is shown in Fig. 12.

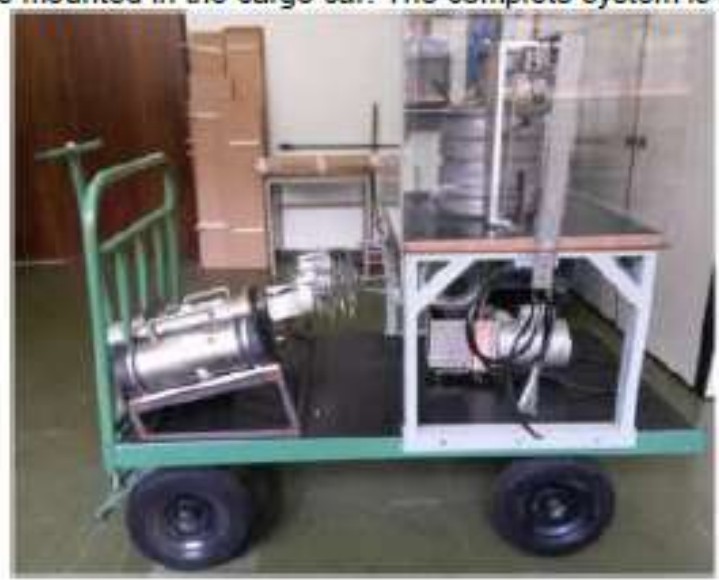

Figure 12 - System to load and unload the irradiation capsule placed inside the IEA-R1's water pool.

\subsection{Operational routine}

The ${ }^{41}$ Ar producing operational proceeding was established and it was divided in four steps, as seen in Fig. 13. The proceedings took place after all the connections had been made, including the rigid long tube to place the irradiation ampoule and the STCs, and the exhaust duct was connected on the top of the acrylic box.

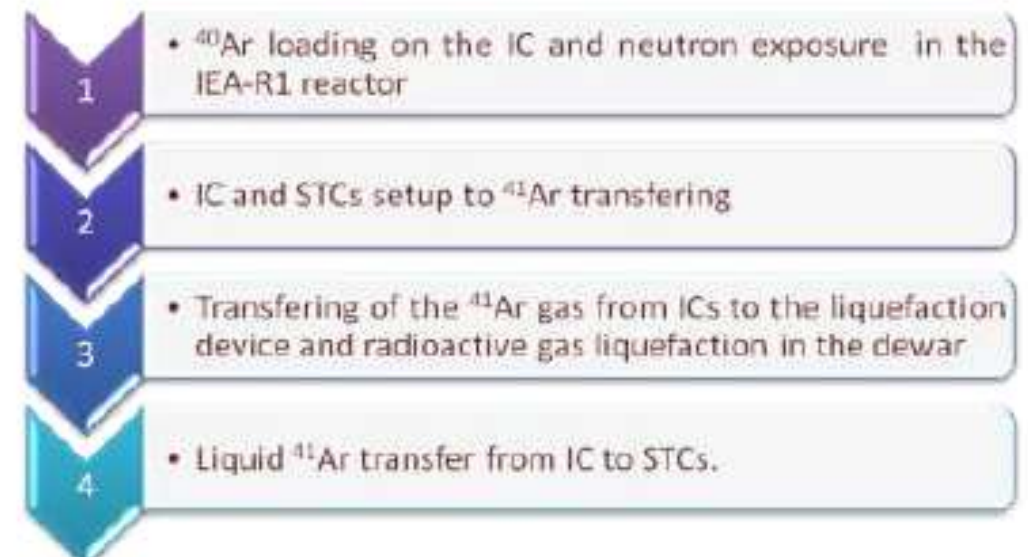

Figure 13 - "Ar production proceeding steps. 


\subsection{Testing tightness and stability FROM HERE}

The three techniques of leak detection described in 2.2 session were performed and it was concluded that there is no leak in the irradiation system. The tests showed that the detected leak rates ranged from $1 \times 10^{-9}$ to $5 \times 10^{-9} \mathrm{mbar} \cdot \mathrm{L} / \mathrm{s}\left(10^{-4} \mu \mathrm{Pa} \cdot \mathrm{m}^{3} \cdot \mathrm{s}^{-1}\right)$.

\subsection{Irradiation for system testing}

An irradiation test for the system was performed in the ${ }^{40} \mathrm{Ar}$ to obtain ${ }^{41} \mathrm{Ar}$ by neutron irradiation. The iradiation capsule was positioned in a $4.71 \times 10^{13} \mathrm{ncm}^{-2} \mathrm{~s}^{-1}$ average thermal neutron flux site inside the IEA-R1 nuclear reactor. This exposure intended to get about $1.0 \times 10^{11} \mathrm{~Bq}(2.9 \mathrm{Ci})$ of ${ }^{41} \mathrm{Ar}$ activity.

The irradiation data are shown in Table 1.

\begin{tabular}{cc} 
Table 1 - ${ }^{-1}$ Ar testing production with the irradiation system. \\
\hline Isotope & $1.5 \mathrm{bar}$ \\
Pressure inside the ampoule & $0.37 \mathrm{~g}$ \\
Estimated mass & $4 \mathrm{~h}$ \\
Irradiation time & $0.6 \mathrm{~h}(36 \mathrm{~min})$ \\
Decay time & $34 \mathrm{~A}$ \\
Irradiation site & $4.71 \times 10^{13} \mathrm{ncm}^{-2} \mathrm{~s}^{-1}$ \\
Mean thermal flux & $1.07 \times 10^{11} \mathrm{~Bq}(2.9 \mathrm{Ci})$ \\
\hline
\end{tabular}

The ${ }^{41} \mathrm{Ar}$ produced in this test was stored in only one STC. The irradiation system was observed, 10 alanine dosimeters were used to evaluate the radiation exposure through the system and the dose rate outside the shielding was measured when the liquefied radioactive gas was concentrated in it.

The alanine dosimeters were evaluated with the ${ }^{41} \mathrm{Ar}(1.29 \mathrm{MeV})$ energy calibration curve. Nine dosimeters showed that the doses were below detection limit (5Gy). The tenth one, located between the STCs transfer tubes (Fig. 14) showed a 5 Gy absorbed dose.

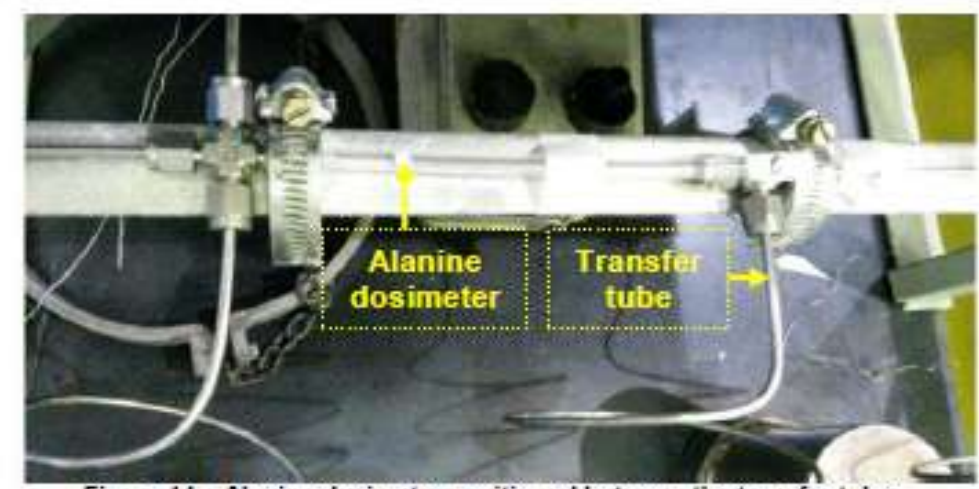

Figure 14 - Alanine dosimeter positioned between the transfer tubes.

The measured dose rates were $10 \mathrm{mSv} / \mathrm{h}$ on the shielding surface when the radioactive liquefied gas was concentrated in it and $25 \mathrm{mSv} / \mathrm{h}$ on the STC surface, after $41 \mathrm{Ar}$ transfer to it.

\section{DISCUSSION AND CONCLUSIONS}

To develop the irradiation system according to the design, the first objective was successfully achieved. 
WCIPTB $-8^{\text {th }}$ WORLD CONGRESS ON INDUSTRIAL PROCESS TOMOGRAPHY Iguassu Falls, PR, Brazil, September 26 to 29, 2016 ISPT - The International Society for Industrial Process Tomography

Related to the operational proceedings, tightness and stability of the irradiation system, the conclusions are:

- The irradiation system is ready to be used according to the proceedings, since the tightness and stability tests showed that no component presented performance issues;

- The system is tight because the leak detector equipment showed $10^{-4} \mu \mathrm{Pa} . \mathrm{m}^{3} . \mathrm{s}^{-1}$, which is 100 times lower than the determined limit in the ISO 9978 - Sealed radioactive sources - Leakage test methods (1992); and

- The system tightness was, also, proved because no radioactive gas was detected by the sensors in the IEA-R1 nuclear reactor exhaust system, during the test performance.

Performing the test irradiation to obtain the ${ }^{41} \mathrm{Ar}$ with the irradiation system, the assumptions are:

- The alanine dosimeter placed between the STCs transfer lines showed the highest absorbed dose (5Gy). The lines inner volume, although very small, may retain some radioactive gas;

- The highest exposure rates obtained in the dewar shielding $(10 \mathrm{mSv} / \mathrm{h})$ and STC surface $(25 \mathrm{mSv} / \mathrm{h})$. To limit the operators dose, the valves handling should be very fast, keeping distance and/or replacing the valves with electromagnetic ones; and

The irradiation system developed produces gaseous radioisotopes $\left({ }^{40} \mathrm{Ar}\right.$ and ${ }^{78} \mathrm{Kr}$ ) in continuous scale, which can be applied in industrial applications of emission tomography and flow measurement (Johansen and Jackson, 2004).

\section{REFERENCES}

BRADFORD, J.R., (1953), Radioisotopes in industry. Reinhold; Chapman \& Hall: New York, 1953.

CHARLTON J.S., (1986), Radioisotope techniques for problem-solving in industrial process plants, Le onard Hill. ISBN-13: 978-94-010-8306-5.

INTERNATIONAL ATOMIC ENERGY AGENCY, (1990), Guidebook on Radioisotope Tracers in Indust ry, Technical Reports Series, 316. ISBN 92-0-165090-6.

INTERNATIONAL ATOMIC ENERGY AGENCY, (2009), Leak Detection in Heat Exchangers and Underground Pipelines Using Radiotracers.

INTERNATIONAL ORGANIZATION FOR STANDARDIZATION, (1992), Radiological protection Sealed radioactive sources - Leak test methods. ISO 9978-1992.

JOHANSEN G.A.; JACKSON P., (2004), Radioisotope Gauges for Industrial Process Measurements, John Wiley \& Sons, Ltd. ISBN 0-471-48999-9.

KAPLAN, I., (1963), Nuclear Physics. 2. ed. Massachusetts: Addison-Wesley Publishing Company Inc.

NATIONAL INSTITUTE OF STANDARDS AND TECHNOLOGY, (2016), X-Ray Mass Attenuation Coefficients. Available in: http://physics.nist.gov/PhysRefData/XrayMassCoef/chap2.html. Access in: 03 Feb. 2016.

OKUNO, E.; YOSHIMURA, E.M., (2010), Radiation Physics. 1 ed. Sao Paulo: Oficina de textos.

QUANG, N.H.; TRI, B.Q.; NGAN, H.T.K.; DUY, D.N.; HAI, T.T.; HA, P.H.C.; COUNG, T.B.; KHOA, P.T., (2007), Establishment of Tracer Technologies in Gas Phase, In: The Annual Report. Nuclear Research Institute, VAEC, Vietnam.

V.N. YELGAONKAR; K.C. JAGADEESAN; V. SHIVARUDRAPPA; V.K. SHARMA; S. CHITRA, (2007), Production of ${ }^{41} \mathrm{Ar}$ and ${ }^{79} \mathrm{Kr}$ gaseous radiotracers for industrial applications. Journal of Radiationalytical and Nuclear Chemistry, 274, 2, pp. 277-280. 


\section{REFERÊNCIAS BIBLIOGRÁFICAS}

[1] BRADFORD, J. R. Radioisotopes in industry. Reinhold; Chapman \& Hall: New York, 1953.

[2] INTERNATIONAL ATOMIC ENERGY AGENCY. Technical Reports Series No. 316: Guidebook on Radioisotope Tracers in Industry. Vienna, 1990.

[3] INTERNATIONAL ATOMIC ENERGY AGENCY. Leak Detection in Heat Exchangers and Underground Pipelines Using Radiotracers. Viena, 2009.

[4] CHARLTON, J. S.; WEBB, M. Radioisotope techniques for problemsolving in industrial process plants. HOUSTON: GULF PUBLISHING COMPANY, 1986.

[5] OKUNO, E.; YOSHIMURA, E. M.; Física das Radiações. 1 ed. São Paulo: Oficina de textos, 2010.

[6] V. N. Yelgaonkar, K. C. Jagadeesan, V. Shivarudrappa, V. K. Sharma, S. Chitra. Production of ${ }^{41} \mathrm{Ar}$ and ${ }^{79} \mathrm{Kr}$ gaseous radiotracers for industrial applications. Journal of radiationalytical and Nuclear Chemistry, Vol. 274, ํㅡ 2 (2007) 277-280.

[7] QUANG, N. H.; TRI, B. Q.; NGAN, H. T. K.; DUY, D. N.; HAI, T. T.; HA, P. H. C.;COUNG, T. B.; KHOA, P. T. Establishment Of Tracer Technologies In Gas Phase: The Annual Report. Nuclear Research Institute, VAEC, Vietnam, 2007.

[8] INSTITUTO DE PESQUISAS ENERGÉTICAS E NUCLEARES. Irradiação e transferência do gás argônio no reator IEA-R1. Procedimento experimental PE-CRO-0901-00, 2006.

[9] KAPLAN, I. Nuclear Physics. 2. ed. Massachusetts: Addison-Wesley Publishing Company Inc, 1963.

[10] KNOLL, G. F. Radiation Detection and Measurement. 3. ed. Hoboken, N.J.: John Wiley \& Sons, 1999. 
[11] INTERNATIONAL ATOMIC ENERGY AGENCY. Research Reactors: Purpose and Future. Viena, 2010.

[12] MESQUITA, A. Z.; LAMEIRAS, F. S.; VASCONCELOS, V.; COSTA, A. C. L. da.; SOUZA, R. M. G. Proposta de utilização do reator nuclear de pesquisa triga IPRR1 do Centro de Desenvolvimento da Tecnologia Nuclear (CDTN) em pesquisa e treinamento. In: IV CONGRESSO NACIONAL DE ENGENHARIA MECÂNICA, agosto, 18-21, 2010. Campina Grande, PB. Disponível em: <http://biblioteca.cdtn.br/cdtn/arpel/adobe/Art 11_Amir_ZMesquita.pdf>. Acesso em 07 jul. 2016.

[13] INSTITUTO DE PESQUISAS ENERGÉTICAS E NUCLEARES. Reator IEAR1: Utilização do Reator. Disponível em:

<https://www.ipen.br/portal_por/portal/interna.php?secao_id=729>. Acesso em: 07 jul. 2016.

[14] COMISSÃO NACIONAL DE ENERGIA NUCLEAR. Aplicações da Energia Nuclear. Disponível em:

$<$ http://www.cnen.gov.br/images/cnen/documentos/educativo/aplicacoes-da energia-nuclear.pdf>. Acesso em: 02 jan. 2016.

[15] RAMOS, V. S. Uso das técnicas de radiotraçadores e de contagem total em medidas de vazão de sistemas abertos. 2006. Dissertação (Mestrado) - Universidade Federal do Rio de Janeiro, Rio de Janeiro. Disponível em: $<$ http://antigo.nuclear.ufrj.br/MSc\%20Dissertacoes/Vitor/Vitor(tese).pdf>. Acesso em 02 dez. 2015.

[16] COMISSÃO NACIONAL DE ENERGIA NUCLEAR. DIRETRIZES BÁSICAS DE PROTEÇÃO RADIOLÓGICA. Mar, 2014 (CNEN NN 3.01 Resolução 164/14).

[17] INTERNATIONAL ATOMIC ENERGY AGENCY. Radiotracer technology as applied to industry: Final report of a co-ordinated research project 1997-2000. Viena, 2001

[18] INTERNATIONAL ATOMIC ENERGY AGENCY. Application of Radiotracer Techniques for Interwell Studies. Viena, 2012.

[19] ATIKINS, P; JONES, L. Príncipios de Química: Questionando a vida moderna e o meio ambiente. Porto Alegre: Bookman, 2001.

[20] NATIONAL NUCLEAR DATA CENTER. Chart of Nuclides. Disponível em: $<\mathrm{http}: / /$ www.nndc.bnl.gov/chart/reCenter.jsp? $\mathrm{z}=18 \& \mathrm{n}=22>$. Acesso em $07 \mathrm{jul}$. 2016 
[21] JAPAN ATOMIC ENERGY AGENCY. 18-ar-40. Disponível em: <http://wwwndc.jaea.go.jp/cgi-bin/Tab80WWW.cgi?/data/JENDL/JENDL-4prc/intern/Ar040.intern>. Acesso em: 07 jul. 2016.

[22] JAPAN ATOMIC ENERGY AGENCY. 36-Kr-78. Disponível em: <http://wwwndc.jaea.go.jp/cgi-bin/Tab80WWW.cgi?/data/JENDL/JENDL-4prc/intern/Kr078.intern>. Acesso em: 07 jul. 2016.

[23] SWAGELOK BRASIL. Engates rápidos. São Paulo, 2007. (Catálogo comercial)

[24] Companhia Siderúrgica de Tubarão. Técnicas preditivas ligadas à inspeção. Disponível em: <http://www.abraman.org.br/arquivos/50/50.pdf>. Acesso em: 07 jul. 2016.

[25] MARCIÓ, B. S. Avaliação de estanqueidade em vasos de pressão de pequeno porte. 2014. Dissertação (mestrado) - Universidade Federal de Santa Catarina, Florianópolis. 113 p. Disponível em: $<$ https://repositorio.ufsc.br/xmlui/bitstream/handle/123456789/128943/33228 6.pdf?sequence=1\&isAllowed=y>. Acesso em: 07 jul. 2016.

[26] VACUUM ENGINEERING SERVICES. Leak Testing Information.

Disponível em: <http://www.vac-eng.com/leak-test-info/> Acesso em: 07 jul. 2016.

[27] VACUUM ENGINEERING SERVICES. Vacuum engineering leak testing machines for evaporators and condensers. Disponível em: $<$ http://www.vac-eng.com/leak-test-info/leak-testing-evaporatorscondensers/>. Acesso em: 07 jul. 2016.

[28] NUSSENZVEIG, H. M. Curso de física básica: eletromagnetismo. 2. Ed. São Paulo: Edgard Bluecher, 2015.

[29] NATIONAL INSTITUTE OF STANDARDS AND TECHNOLOGY. $\boldsymbol{X}$-Ray Mass Attenuation Coefficients. Disponível em: <http://physics.nist.gov/PhysRefData/XrayMassCoef/chap2.html>. Acesso em 03 fev. 2016.

[30] HALLIDAY, D.; RESNICK, R.; WALKER, J. Fundamentos de Física 2: Gravitação, Ondas e Termodinâmica. 4 ed. Rio de Janeiro: LTC, 1996.

[31] ISO - INTERNATIONAL ORGANIZATION FOR STANDARDIZATION. Radiological protection - Sealed radioactive sources - Leak test methods. Feb. 15, 1992. (ISO 9978-1992) 
[32] COSTA, O. L. Estudo e desenvolvimento de uma nova metodologia de produção de iodo-125 a partir do xenônio-124 pelo método de ativação neutrônica. 2015. Tese (Doutorado) - Instituto de Pesquisas Energéticas e Nucleares, São Paulo. 